\title{
SERVICEABILITY RATINGS OF HIGHWAY PAVEMENTS
}

\section{FEB. 1962 NO. 6}
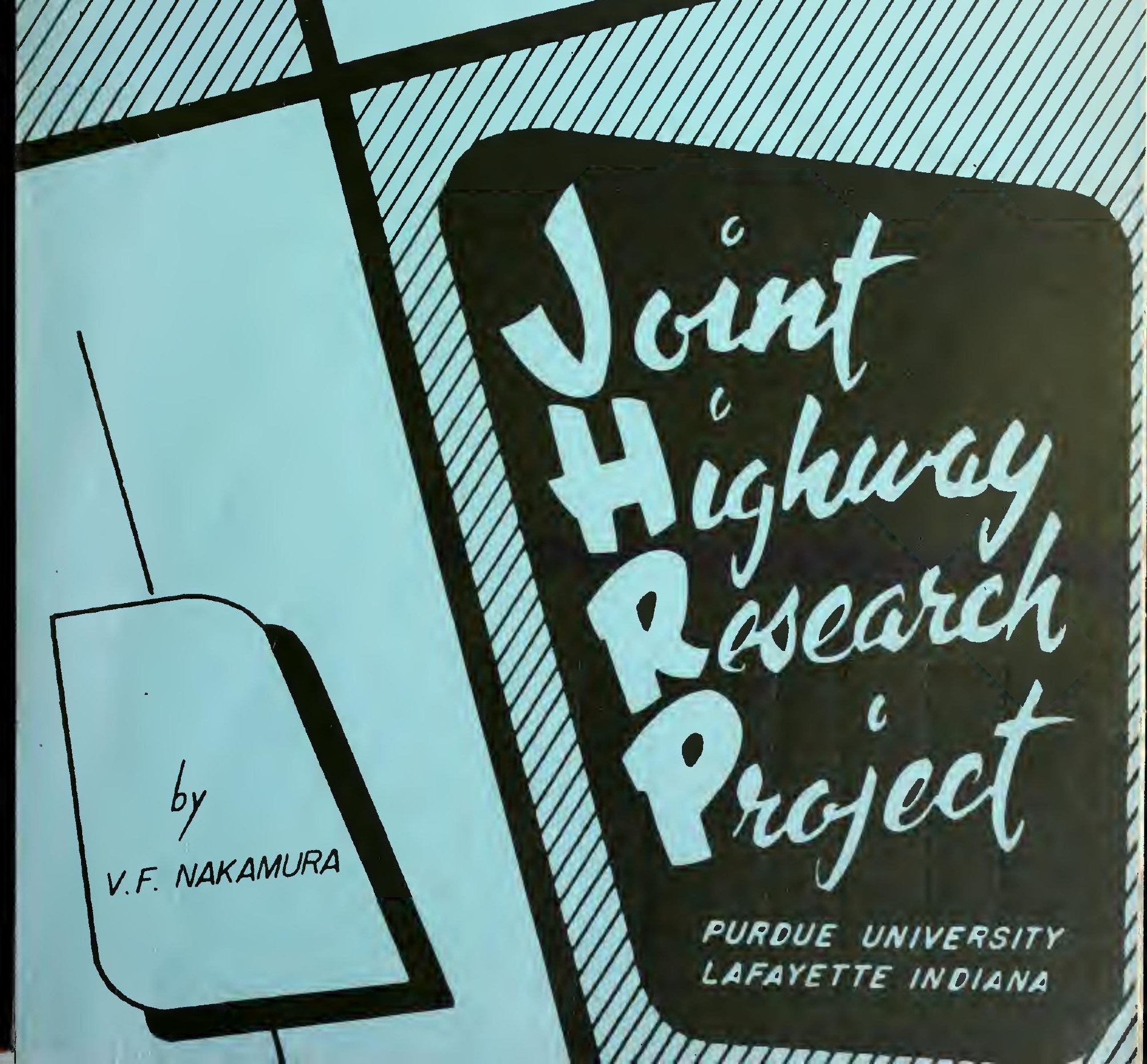
TO:

K. B. Woods, Director Joint Highinay Research Project

FROM: H. Lo Michsel, Assoclate Director Joint Highwey Research Project
Feorvary 14,1962

F11e: $3-3-28$

Project: $\quad-36-54 B B$

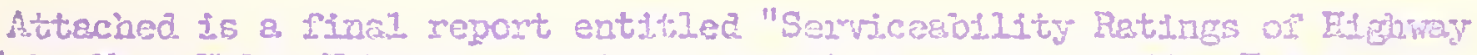

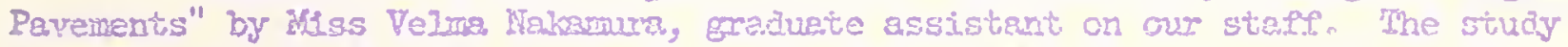
was also used by Hiss Hohamura es her thesis for part of tine returirements for the MSce degree, The stuay was performed urder the nitrection of Proiessor $\mathrm{H}$. Is

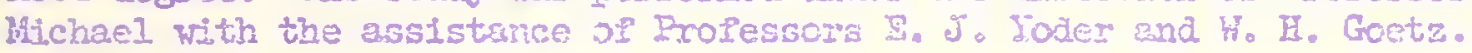

The parnel rating jethod for pavement serviceability wes found to be practical. The three panels used geve resul's which vere very siritiar, even thougl one of the psnels was corsposed of muthers wo were not trained in highway cngineerIng. Roughness masurements mede by the Hfghway Department's rovghometer

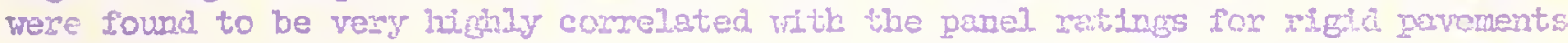
but poorly correlated for: overlay end rlexible pevanents. Adationel ressarch is conterplated on finding puvement charteteristics winch car be messured end which will be better cor'elated with panel retings for overlay and rlexíbis paraments.

The Project Elincerely appreciates the cooperation of the menwers or the staff of the School of Civil Engineering wo ratea the sections and the cooperation of the Indiana Statio Highasy Comolssion for providing the nembers of one penel and the equipment and manpors to rake the roughness messurements. The eflonts, edvice and assistance of Mr. Fred fiskbancher in ihs study is perticulariy acknowledged.

The report is presented for the record。

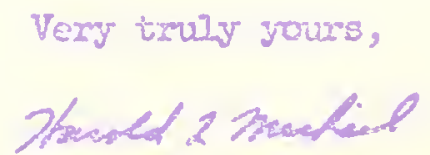

Harold Io Haschel, Secretary

HII: $\mathrm{kmc}$

Attachment

Conjes:

F. I. Ashbaucher

J.R. Cooper

W. L. Iolch

W. H. Coetz

F. F. Havey

F. S. HiII

G. A. Leonards
J. F. Helaghlin

R. D, MLIes

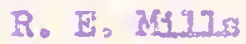

I. B. Scoti

J. V. Surythe

J. L. Whing

E. J. Yoder 
Digitized by the Internet Archive in 2011 with funding from

LYRASIS members and Sloan Foundation; Indiana Department of Transportation 
FINAL REPORT

SERVICEABILITY RATINGS OF HIGHWAY PAVEMENTS

\author{
by \\ Velma Fumfko Nakamura \\ Graduate Assistant
}

Joint Highway Research Project

File No: 3-3-28

Project No: C-36-54BB

Purdue University

Lafayette, Indiana

February 14, 1962 


\section{ACKNOWLEDGMEANTS}

To Professor Harold L. Michael, Associate Director, Joint Highway Research Project, under whose direction this research was performed; for his patience and invaluable assistance in all phases of the study and in the preparation of the manuscript; to Professor K. B. Woods, Head of the School of Civil Engineering and Director of the Joint Highway Research Project at Purdue, for the sponsorshtp of this investigation by the Joint Highway Research Project; to Mrs. Betty J. Havlicak, Department of Statistics, for her advice on the statistical design of the study; to the Indiana State Highway Commission for their cooperation and interest in the study; and especially to Dr. Theodore S. Donaldson for his encouragement -Mahalo Nui Loa. 
TABLE OF CONTENTS

Page

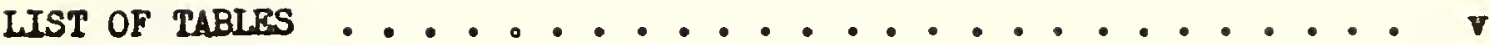

LIST OF FIGURES . . . . . . . . . . . . . . . . . . vil

ABSTRACT ............................ . ix

INTRODUCTION . . . . . . . . . . . . . . . . . . . I

Prevlous InvestIgations . . . . . . . . . . . . . . 3

Evaluation by Sufficiency Ratings . . . . . . . . . . . . 4

Evaluation by Roughness Indicators . . . . . . . . . . . . 4

Evaluation by Riding Quality Indicators and Subjective

Serviceability Ratings . . . . . . . . . . . . 5

PURPOSE . . . . . . . . . . . . . . . . . . 12

SCOPE ............................ 13

PROCEDURE ........................... 15

Selection of Pavement Sections . . . . . . . . . . . 15

Karking of the Parement Sect1ons . . . . . . . . . . . 16

Select1on of the Panels of Raters . . . . . . . . . . . 18

Rating Instructions . . . . . . . . . . . . . . . . . 20

Road Roughness Measurement ..... . . . . . . . . . . 24

RESULTS - SERVICEABILITY RATINGS . . . . . . . . . . . 27

Analys1s of Variance . . . . . . . . . . . . . . . . 27

Individual Serviceability Rating Variability ....... . . 31

Number of Raters Required to Estimate "Truen Rat1ng . . . . . . . 42

Evaluation of the Rating Panel Kethod . . . . . . . . . . 43

Acceptability Rat1os ..................... . 48

Rater Characterist1cs . . . . . . . . . . . . . 54

RESULIS - CORRELATION OF SERVICBABILITY RATINGS AND

ROUGHNESS INDICES ............. 59

Linear Analjsis . . . . . . . . . . . . . . . . 59

Linear Regression Equations . . . . . . . . . . . . 64

Curvilinear Analysis . . . . . . . . . . . . . . . 64

Regression Equations .................. 69 
TABLE OF CONTENTS (continued)

Page

DISCUSSION OF RESULTS .................. 73

CONCLUSIONS . . . . . . . . . . . . . . 78

BIBLIOGRAPHI ..................... 80

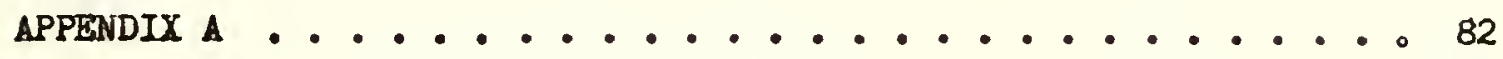

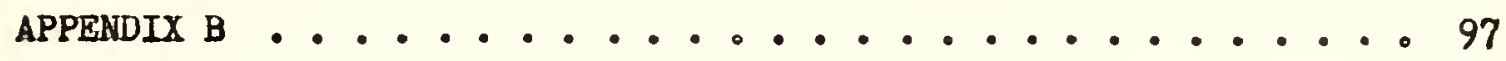


LIST OF TABLES

Table

1. Summary of Analysis of Variance - Serviceability

Ratings . . . . . . . . . . . . . . . . . . 29

2. Summary of Data - Rigid Pavement Sections . . . . . . . 32

3. Summary of Data - Overlay Pavement Sections . . . . . . . 33

4. Summary of Data - Flexible Pavement Sections . . . . . . 34

5. One-hundred Per Cent and Ninety Per Cent Overall and Panel Ranges - Rigld Pavement Sections . . . . . . . . 35

6. One-hundred Per Cent and Ninety Per Cent Overall and Panel Ranges - Overlay Pavement Sections . . . . . . . . 36

7. One-hundred Per Cent and Ninety Per Cent Overall and Panel Rangea - Flexible Pavement Sections . . . . . . . 37

8. Comparison of Individual Priority Rankings and Serviceability Ratings of Three Raters - Rigld Pavement Sections . - 39

9. Comparison of Individual Priority Rankings and Serviceability Ratings of Three Raters - Overlay Pavement Sections - 40

10. Comparison of Individual Priority Rankings and Serviceability Ratings of Three Raters - Flexible Pavement Sections. 41

11. Number of Raters Required to Estimate the "True" Rating Rating Panel Evaluation Method . . . . . . . . . 43

12. Comparison of Serviceability Ratings and Priority Rankings of Thirty, Ten, and Three-Member Rating Panels and Individuals - Rigid Pavement Sections . . . . . . . . 45

13. Comparioon of Serviceability Ratings and Priority Rankingo of Thirty, Ten, and Three-Member Rating Panels and Individuale - Overlay Pavement Sections . . . . . . . . 46

14. Comparison of Serviceability Ratings and Priority Rankings of Thirty, Ten, and Three-Member Rating Panels and Individuals - Flexible Pavement Sections . . . . . . . . 
LIST OF TABLES (continued)

Table

15. Summary of Rater Characteristics - Indiana State Highway Commission Panel .... . . . . . . . . 55

16. Summary of Rater Characteristics - Purdue Panel . . . . . 56

17. Summary of Rater Characteristics - Laymen Panel . . . . . 57

18. Correlation Coefficients and Squared Correlation Coefficients of Present Serviceability Ratings with

Roughness Indices - Linear and Exponential Cases -

Rigid, Overlay, and Flexible Pavement Sections ...... 63

19. "F" Test Comparison of the Unexplained PSR Variability

for the Linear and Exponential Functions - Rigid, Overlay, and Flexible Pavement Sections . . . . . . . . . 69

20. Comparison of Thirty-Member Rating Panel PSRs with Linear and Exponential Regression Equation PSRs - Rigid Pavement Sections .. . . . . . . . . . . . . 70

21. Comparison of Thirty-Member Rating Panel PSRs with Linear and Exponential Regression Equation PSRs - Overlay Pavement

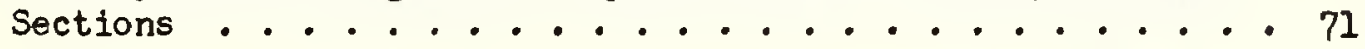

22. Comparison of Thirty-Member Rating Panel PSRs with Linear and Exponential Regression Equation PSRs - Flexible Pavement Sections ..................... 72

23. Approximate Cost for Evaluating Nineteen Rigid Pavement Sections - Rating Panel Evaluation Method . . . . . . 76

24. Rater Information . . . . . . . . . . . . 88

25. Description of Rigid Pavement Sections . . . . . . . . 90

26. Description of Overlay Pavement Sections . . . . . . . 91

27. Description of Flexible Pavement Sections . . . . . . . 93

28. Location of Rigid Pavement Sections . . . . . . . . . . 94

29. Location of Overlay Pavement Sections . . . . . . . . . 95

30. Location of Flexible Pavement Sections . . . . . . . 96 
LIST OF FIGURES

Figure

Page

1. Location of the Study Area . . . . . . . . . . . 14

2. Location of the Pavement Sections ............ . 17

3. Rating Card . . . . . . . . . . . . . . . 22

4. Closemup View of Indiana State Highway Roughometer . . . . 26

5. Indiana State Highway Roughometer and Tow Truck . . . . . 26

6. Acceptability Ratios vs Serviceability Ratings of Primary Sections - Overall . . . . . . . . . . 49

7. Acceptability Ratios vs Serviceability Ratings of Primary Sections - ISHC Panel ............ 49

8. Acceptability Ratios vs Serviceabliity Ratings of Primary Sections - Purdue Panel . . . . . . . . . 50

9. Acceptability Ratios vs Serviceability Ratings of Primary Sections - Laymen Panel . . . . . . . . 50

10. Acceptability Ratios vs Serviceability Ratings of Secondary Sections - Overall ............. 51

11. Acceptability Ratios vs Serviceability Ratings of Secondary Sections - ISHC Panel . . . . . . . . . 51

12. Acceptability Ratios vs Serviceability Ratings of Secondary Sections - Purdue Panel . . . . . . . . 52

13. Acceptability Ratios vs Serviceability Ratings of Secondary Sections - Laymen Panel . . . . . . . . 52

14. Present Serviceability Rating vs Roughness Index Rigid Pavement Sections .............. 60

15. Present Serviceability Rating vs Roughness Index Overlay Pavement Sections .............. . 61 


\section{LIST OF FIGURES (continued)}

Figure

16. Present Serviceability Rating vs Roughness Index -

Flexible Pavement Sections . . . . . . . . . . . 62

17. Present Serviceability Rating vs Roughness Index -

Log-log Scale - Rigid Pavement Sections . . . . . . . 65

18. Present Serviceability Rating vo Roughness Index -

Log-log Scale - Overlay Pavement Sections . . . . . . . 66

19. Present Serviceability Rating vs Roughness Index -

Log-log Scale - Flexible Pavement Sections . . . . . . . 67 


\section{ABSTRACT}

Nakamura, Velma F., MSCE Purdue University, June 1962. Serviceability Ratings of Highway Pavements. Major Professor: Harold L. Michael.

Two simple methods of evaluating the present serviceability of highway pavements are studied. Present serviceability is defined as the adequacy of a section of pavement in its existing condition to serve its intended use. One method utilizes a rating panel and the second method utilizes roughometer measurements to obtain present serviceability ratings.

The present serviceability of nineteen rigid pavement sections, nineteen flexible parement sections, and twenty-two overlay pavement sections were rated by three ten-member rating panels and measured by the Indiana roughometer. Two of the panels were composed of men professionally associated with highway engineering. The third panel consisted of "laymen" who were assumed to be typical road users.

Rating data were analyzed by an analysis of variance design. The serviceability ratings of the raters within each of the panels varied widely, but there was no significant difference between the mean servicoability ratings of the three panels.

Information relative to the number of raters to use on a panel is also included. Although the number of members for the rating panel is determined by the "accuracy" required, it is shown that for priority ranking purposes as few as three raters on a single panel may be sufficient. 
Linear and exponential least-squares regression equations were calculated for each pavement type with roughometer measurements as the independent variable and the present serviceability ratings as determined by the thirty raters as the dependent variable. When compared to serviceability ratings obtained by a large rating panel, the serviceability ratings obtained by the use of roughness measurements were only fair approximations for overlay and flexible pavement sections but were almost exactly the same for rigid pavements. 


\section{INTRODUCTION}

"....highways are for the comfort and convenience of the traveling public."

D. C. Greer, State Highway Engineer of Texas

This simple statement implies that the purpose for any road or highway pavement is to serve the highway user and that a good highway pavement is one on which the traveling public has a comfortable ride.

What is a comfortable ride? How can the comfort and convenience provided by a highway pavement be measured? These are the unanswered questions which plague the highway authority when the decision as to which highway to improve must be made.

One measure of the present serviceability* of a highway pavement is the mean evaluation given it by all highway users. However, it is difficult to collect from the many highway users their judgment of the serviceability of all highway pavements; furthermore, the opinions of highway users as to how well a pavement serves may vary widely and even differ. The human mind is very flexible and there are many variables. One person's fudgment or opinion today may also differ from his opinion tomorrow due to his temperament, perception, or other factors. It is also time consuming, tedious, and expensive for many individuals to evaluate each and every road.

* In this study, present serviceability is defined as the ability of a specific section of parement in its existing condition to serve relative to the intended use of the highway (i.e., the section may be part of a primary highway, secondary highway, city street, farm road, etc.). 
For many years state highway departments have developed construction and maintenance programs on the basis of the personal knowledge of their staffs relative to the needs of their highway systems. However, highway personnel in general have vague or varying knowledge of the condition of all portions of the highway systems and, thus, their concept of the serviceability for a highway pavement may vary widely. It is also probable that a poor highway pavement to one engineer might mean that the pavement has a few cracks, while to another it might mean that a considerable number of cracks and patches are present. One engineer might classify a highway pavement with ten foot lanes as excellent, while another might classify only highway parements with twelve foot lanes in the excellent category.

These differences of opinion as to what is good pavement serviceability are also evident in construction and maintenance practices. For example: there may be an evident difference in riding smoothness as one passes from maintenance section $A$ to maintenance section $B$ on highway $X$. The ride on section $A$ is much smoother than on section $B$. Why should this be? Both sections were constructed at the same time, are of similar design, have the same traffic volume, and have a similar underlying soil strata. However, the two sections were constructed under separate contracts and by two different construction companies. Moreover, they are in adjacent counties and, thus, are maintained separately and differently.

Mang of the variations in pavement serviceability ratings, however, may exist because there is no accepted definition of the various grades of serviceability, and in many cases there is no agreement in terminology that can be used in an evaluation of highway parements. (12)*

* Numbers in parenthesis refer to the references in the bibliography. 
It may be true that one pavement can perform its services better than another. The following questions, however, are raised: "How much better?" and "How can this comparison be determined?" What is needed is a method of measurement and evaluation of pavement serviceability -- one that provides accuracy, that is simple, and that is economical. The results of such a method should be as unprejudiced and consistent as possible.

A simple evaluation procedure, which would accurately rate the serviceablity of highway pavements by an objective measurement or measurements and which would be highly correlated with the subjective human judgment of the traveling public, would facilitate the efficient development of a highway improvement program. Such a procedure should also indicate the performance of any pavement throughout its life if evaluated periodically, be applicable to all roads, and could form the basis for highway improvement programs.

\section{Previous Investigations}

Mans studies have been devoted to the problem of the evaluation of highway pavement serviceability and/or performance. Various evaluation procedures have resulted from these studies and are being used by state highway departments throughout the country. These procedures may be classified into the following general types: 1) evaluation by sufficiency rating systems, 2) evaluation by surface riding quality indicators, and 3) evaluation by surface riding quality indicators and subjective serviceability ratings. The third type of evaluation is the most recently proposed and is the subject of this study. 
Evaluation by Sufficiency Ratings

The sufficiency rating system is a system through which a numerical value 18 assigned to each road section to aid in establishing priorities of highway improvements. As early as 1933 the Bureau of Public Roads (hereafter referred to as the BPR) pointed out the key features of condition, safety and service which have since become the basis for all sufflclency rating systems. KIpp (13) states that:

Sufficlency rating procedures have been devised so as to provide a means of evaluating the relative adequacy of each section of a highway according to certain prescribed standards. Since these standards are prescribed on the basis of traffic volume and the functionsl characteristics of the system, the resultant ratings give an evaluation of the road section's ability to carry its quota of traffic safely, rapidly and economically. Thus, the ratings have been used to measure, on a comparative basis with other highway sections, the relative importance and need for renewal and replacement.

The formulas have been designed and the rating procedures developed with the intention of eliminating, or at least minimizing, the element of personal judgment in determining the relative sufficiency of highway sections. This has been done chiefly so that the public would accept the method as an Impartial, unbiased appraisal, because any method of establishing improvement priorities to be of value must have the full understanding, acceptance, and confidence of all individuals and groups intereated in improving the adequacy of the highway network.

An excellent discussion and bibliography of sufficiency rating procedures in use by state and county highway departments for priority establishment is presented by Beerwald (3). The present Indiana State Highway Commission evaluation procedure is presented in a Sufficiencr Study Manual published in 1960 (21).

\section{Evaluation by Roughness Indicators}

One of the earliest ploneers in the development of a roughness indicator was the BPR. As early as 1923 the BPR collaborated with the Bureau 
of Tests of the Illinois Division of Highways in the development of the "Profilometer". In 1925 the BPR developed a second machine called the "Relative Roughness Determinator". In the 1930's the BPR developed a third machine called the "Relative Roughness Indicator" in an attempt to overcome the poor features of the previous machines (4). Holloway (9) states that:

This machine removed the uncertainties of vehicle operation that were present in earlier equipment when an automobile was a component part of the measuring apparatus. Also of importance was the fact that this machine was so designed that it could be duplicated and thereby duplicate results could be expected from any machine which was constructed according to the same plans and specifications as the original.

Many studies of the surface riding qualities of highways have been made utilizing duplicate or modified versions of the BPR "Relative Roughness Indicator" (hereafter referred to as the roughometer). Various standards for the evaluation and determination of the riding quality of highways by the different roughometers have been recommended in these studies $(1,9,10,15,16,17$ and 18$)$.

Moyer and Shupe (18) state that:

.... It should be recognized that the public judges whether a road is good or bad largely on the basis of its riding qualities and an accurate measure of roughness with a machine such as the Bureau of Public Roads Roughness Indicator should give the public and engineer a reliable measure of the riding qualities of all parement surfaces.

Evaluation by Riding Quality Indicators and Subjective Serviceability Ratings

Holloway (9) states that:

As a part of the "Inventory of Indiana State Highway Conditions", conducted during the winter of 1954 and 1955, the inventory parties recorded the surface riding qualities of the pavements as excellent, good, fair, or poor. This was largely a "seat of the pants" determination and was subject to the variations of 
opinions of different observers. These observers are engineers of the Indiana State Highway Department and as such it seems reasonable to assume that their opinions would be better than that of the ordinary layman. ..... The conclusion indicated by (a comparison between road roughness indices and surface riding qualities as expressed by the highway inventory observers) is that personal opinion is widespread concerning the surface riding quality of a road and is therefore an unsatisfactory evaluation method.

However, Hreem and Tremper in a discussion of the Housel and Stokstad study (10) state the following:

An examination of California pavements employing the jury system of rating indicates that there was usually good agreement as to which pavements were smooth, fair, or definitely rough.

Carey and Irick (6) in 1958-59 at the AASHO Road Test conducted an investigation, evolving a pavement serviceability-performance concept, which was very comprehensive and which employed many of the procedures used in the present study. In that study 138 parement sections in IIIInois, Minnesota, and Indiana were evaluated over a two jear period in three different ways: by a panel of experts, by a panel of laymen, and by objective measurements of selected characteristics of the pavement. The pavement sections were divided into two categories: rigid pavements and flexible pavements. About one-half were rigid pavements and one-half were flexible. Each pavement section was 1,200 feet long except for those at the AASHO Road Test, which averaged 215 feet. The panel of experts consisted of ten men long associated with highways and representing such interests as highway administration, highway maintenance, highway research, highway materials supply (cement and asphalt), and a federal highway agency. The panel of experts was intended to represent all highway users. The panel of laymen consisted of two truck drivers and twenty Canadian automobile drivers who were not professionally associated with 
highways. The parement sections were rated on a 0 to 5 point rating scale. By comparing the evaluations made by the panel of experts and the panel of laymen, it was found that "... the ratings given pavements by the Road Test Panel were quite similar to those that were given by the other user groups" and that "... if a greater number of sample groups had been studied, more positive statements could be made as to how well the Panel represents the universe of all users".

Objective measurements were made of the longitudinal and transverse roughness, surface cracking, and surface patching of the pavement sections. Roughness measurements of the wheelpaths were made by the Road Test longitudinal profilometer. The AASHO roughometer was not adapted for use at the Road Test until just prior to the rating of the Indiana pavements, therefore, only the Indiana and Road Test pavement sections were measured by the roughometer. However, ".... It may be noted that the roughometer values averaged for both wheelpaths, $\overline{A R}$, are correlated with the corresponding mean slope variances". The AASHO roughometer was operated at $10 \mathrm{mph}$.

By means of statistical analysis a high correlation was found to exist between the Road Test Panel ratings and the slope variance of the profilometer measurements for both rigid and flexible parements. A fair correlation was found to exist between the ratings and the rut depth gage measurements on the flexible pavements. There was also a fair degree of correlation between the ratings and the amount of cracks and patches on rigid pavements. However, there was little correlation between the ratings and the amount of cracks and patches on the flexible pavements.

Through multiple regression analyses the following predictive equations resulted: 
For flexible pavements:

$$
\text { PSI }=5.03-1.91 \log (1+\overline{S V})-1.38 \overline{R D}^{2}-0.01 \sqrt{C+P}
$$

For rigid pavements :

$$
\text { PSI }=5.41-1.78 \log (1+\overline{S V})-0.09 \sqrt{C+P}
$$

Where,

PSI = Present serviceability index; a mathematical combination of values, obtained from certain physical measurements of a large number of pavements, so formulated as to predict the present serviceability rating for those pavements within prescribed limits.

$\overline{\mathrm{SV}}=$ Average slope variance on both wheelpaths as obtained by the AASHO profilometer.

$\overline{R D}=$ Average rut depth of both wheelpaths in inches.

$C=$ Major cracking in ft. per 1000 sq. ft. of pavement area. $P=$ Bituminous patching in sq. ft. per 1000 sq. $\mathrm{ft}$. of pavement area.

The PSI formulas were found to account for 84.4 per cent and 91.6 per cent of the variation in PSR for the flexible and rigid pavements, respectively.

In a further study by the same group, Hudson and Hain (II) report that the AASHO profilometer and roughometer were run coincidentally on twenty rigid pavement sections either 120 or $240 \mathrm{ft}$. long. The slope variance of the profilometer (SV) was regressed on the roughometer output at $10 \mathrm{mph}$ $\left(A R_{10}\right)$ and the following equality resulted:

$$
\hat{\mathrm{SV}}=0.40 \mathrm{AR}_{10}-34
$$

Substitution in the Carey-Irick rigid pavement equation gave the following equation: 


$$
\text { PSI }=5.41-1.80 \log \left(0.40 \overline{A R}_{10}-33\right)-0.09 \sqrt{C+P}
$$

It is noted that this analysis assumes that the relationship between $S V$ and $A R_{10}$ is a linear one, but that "there are at least two reasons why slope variance and $A R_{10}$ will never be perfectly correlated.

1. The profilometer and roughometer probably do not measure the same elements of pavement roughness. The roughometer muns faster than the profilometer and has an entirely different tire and suspension system.

2. The instruments have different frequency response characteristics."

It was also found that "... the roughness recorded at $10 \mathrm{mph}$ is highly correlated with the roughness recorded at $20 \mathrm{mph}$, and "The roughometer is one answer to the problem of measuring roughness or performance." Therefore, theg"... hoped that the roughometer will help expand the use of the 'Pavement Serviceability-Performance' concept."

A more recent investigation of pavement performance was conducted on July 6, 1961 by the personnel of the AASHO Road Test (20). The object of this study was to correlate roughometer output with profilometer slopevariance and, thus, to utilize roughometer output, by substitution, as a predictor in the serviceability equations. The study consisted of measuring both wheelpaths of 12 rigid and 14 flexible pavement sections varying in length from 500 to 1200 feet. The pavement sections were measured by the AASHO Road Test profilometer, the Virginia Highway Department roughometer, and the Indiana State Highway Department roughometer.

The equations transforming the output of the Indiana roughometer at $20 \mathrm{mph}\left(\mathrm{InR}_{20}\right)$ to the profilometer slope variance from least-squares regression analyses are as follows:

For rigid pavements:

$$
\log (I+S V)=3.24 \log \operatorname{InR}_{20}-5.62
$$


For flexible pavements:

$$
\log (I+S V)=2.43 \log \operatorname{InR}_{20}-4.02
$$

The squared correlation coefficients $\left(r^{2}\right)$, which measure the association between the transformed roughometer output and profilometer slope-variance, were found to be 0.79 and 0.85 for flexible and rigid pavements, respectively. The root mean square residuals, which estima te the amount of error that is present in the prediction of an observation, were found to be 0.18 and 0.19 for flexible and rigid pavements, respectively. The values of these statistics are satisfactory for prediction purposes. However, it is to be noted that the $r^{2}$ for flexible pavements is somewhat lower than for rigid pavements. This characteristic "presumably reflects an inability to measure some characteristics of flexible pavement roughness."

Substitution of the above equalities into the Carey-Irick equations gives the following:

For rigid pavements:

PSI $=15.53-5.83 \log \overline{\operatorname{InR}}_{20}-0.09 \sqrt{C+P}$

Limitations: When $\operatorname{InR}_{20}<64$ and $C+P=0$, take

$\left(5.83 \log \overline{\operatorname{InR}}_{20}\right)=10.53$, since no section may rate more

than 5.0 by definition.

For flexible pavements:

PSI $=13.16-4.86 \log \overline{\operatorname{InR}}_{20}-0.01 \sqrt{\mathrm{C}+\mathrm{P}}$

Limitations: When $\overline{\operatorname{InR}}_{20}<49$ and $C+P=0$, take

$(4.86 \log \overline{\operatorname{InR}})=8.16$, since no section may rate more

than 5.0 by definition. 
It is noted that the PSI obtained with roughometer output as a prodictor is expected to have a somewhat larger error than that obtained by the original Carey-Irick equations. This results from the additive errors in predicting PSI from SV and in predicting SV from roughometer output. The PSI-roughometer relationship is an indirect one. No direct regression analysis of roughometer output with subjective human evaluations (PSR) was made. 


\section{PURPOSE}

This study is concerned with the traveling public's opinion of parement serviceability and Its desirable level and with the ability of highway personnel to understand the wants of the traveling public. It 1s also concerned with road roughness, as measured by the roughometer, as a method for the objective determination of highway pavement serviceability.

Therefore, the purpose of this study was 1) to determine the correlation of parement serviceability ratings made by experts in the field of highway engineering with ratings made by typlcal road users, 2) to determine the correlation of roughometer measurements with pavement serviceability ratings, and 3) to determine a simple, economical evaluation procedure which would accurately rate the serviceability of highway pavements. 


\section{SCOPE}

Sixty pavement sections located within a forty mile radius of Lafayette, Indiana were studied (see Figure 1, Location of the Study Area). The pavement sections varied in length from 0.5 to 12.75 miles, averaged 5 miles, and totaled approximately 300 miles. Nineteen of the sections were rigid parements; twenty-two were rigid with bituminous overlay; and nineteen were flexible pavements. All types of pavement condition were represented.

All of the pavement sections were rated by thirty persons, who represented the highway field and the general public, and were measured by the Indiana State Highway roughometer. All ratings and measurements were made in the fall of 1961. 


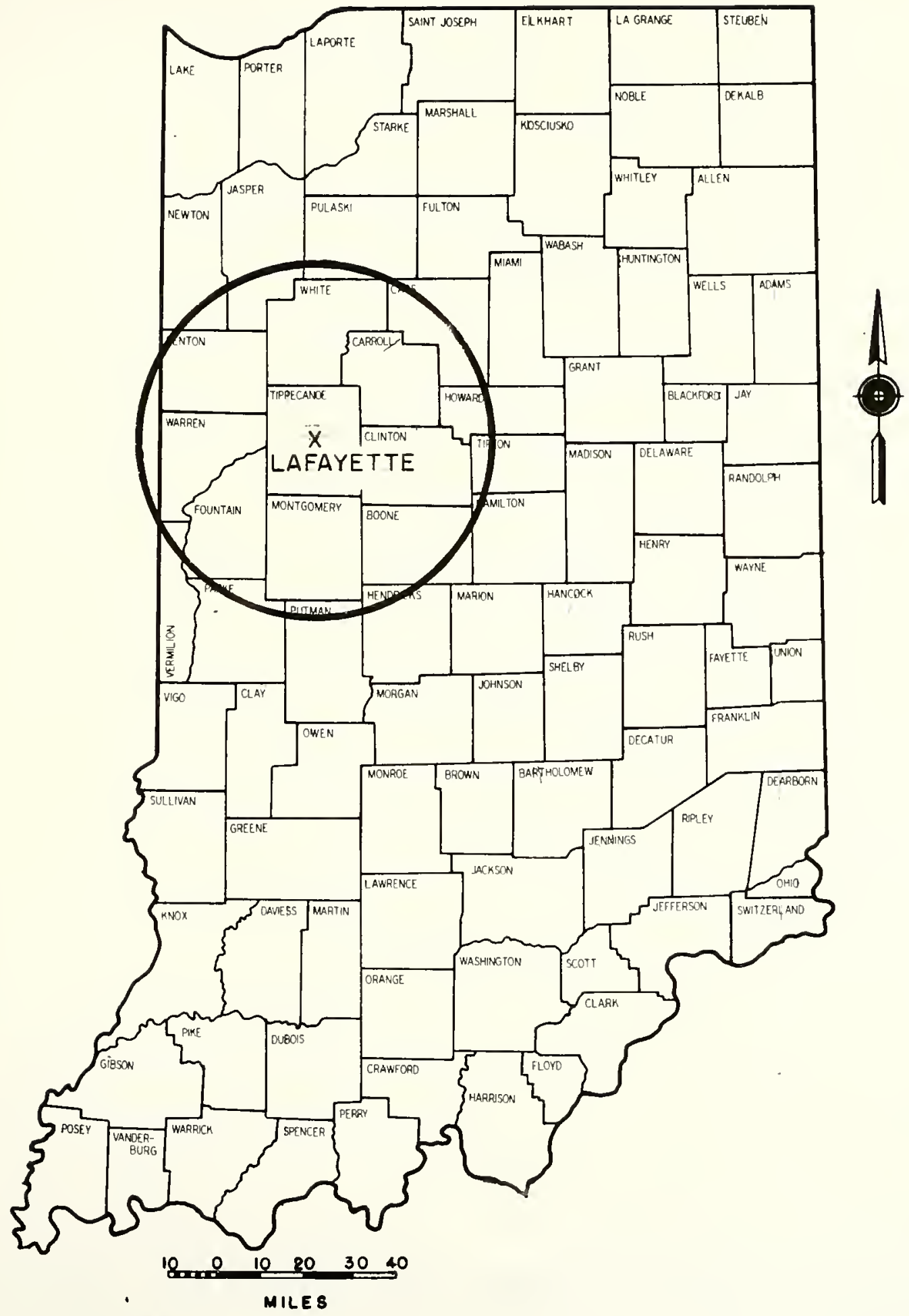

FIGURE I. LOCATION OF THE STUDY AREA 


\section{PROCEDURE}

\section{Selection of Pavement Sections}

It was assumed that the highways within a forty mile radius of Lafayette, Indiana are representative of the total population of highways (i.e., all types of pavement conditions varying from very good to very poor in Indiana). All State, United States, and Interstate highways within this area were categorized according to the following pavement types: rigid, rigid with bituminous overlay, and flexible.

Test sections of previous serviceability studies (6, 11, and 20 ) have all been of relatively short (120 and $1200 \mathrm{ft.}$ ) and similar lengths. While short test sections are ideally simple to measure and rate, the real test of an evaluation procedure is in its abilfty to evaluate the actual situation. State highway maintenance and construction programs are based on longer and variable length maintenance sections. Logical and ideal test sections, therefore, would be actual maintenance sections. Maintenance and sub-maintenance sections were employed as test sections in this study.

Maintenance sections which were "non-homogeneous" (1.e., there was evident variability within the maintenance section of such characteristics as surface texture, surface riding quality, etc.) were divided into subsections. Reasonably homogeneous test sections were desired and selected.*

* It should be noted that the non-homogeneity or homogeneity of a test section was determined subjectively by human observers. Some of the test sections (see Tables 25, 26 and 27, Appendix A) were judged to be non-homogeneous by some of the raters. This caused some distress since it was thought that the non-homogeneity might influence the variability of the serviceability ratings. A scatter-plot of the range of the roughometer values for onefourth mile lengths versus the range of the ratings showed a "shot-gun" pattern. Apparently the relative non-homogeneity of the test sections had no direct bearing on the variability of the serviceability ratings. 
The sections were then preliminarily rated. A rating scale similar to that finally utilized by the raters was employed. The sections of each pavement type were then stratifled according to their preliminary rating into the following general classes: very good, good, fair, poor, and very poor. Economical limitations determined that sixty test sections - twenty of each parement type -- would be studied. A atratified random sample was then taken for each pavement type, so that there would be twenty pavement sections of each type with conditions varying from very good to very poor for each type (see Figure 2).

The preliminary rating and selection of the test sections took place during the summer of 1961. The measurement and ratings of the sections were made during the fall of 1961. In the interim, two of the selected rigid pavement sections were resurfaced. The Union St. section (section 59) was substituted for one of these resurfaced sections; hence, only nineteen rigid pavement sections were rated. Also, a pavement section which was preliminarily classified as a flexible pavement section was discovered to be an overlay; hence, only nineteen flexible pavement sections were rated. It should also be noted that one of the flexible pavement sections (section 33) has a brick base.

\section{Marking of the Pavement Sections}

To aid and confirm the identification of the pavement sections by the raters and roughometer crew, the beginning and end of each pavement section was marked with yellow paint near the edge of the parement. A two foot strip of paint perpendicular to the edge of the pavement indicated the beginning and end of the pavement section; an arrow pointed in the direction of the pavement section to be rated; and a number identified the pavement section. 


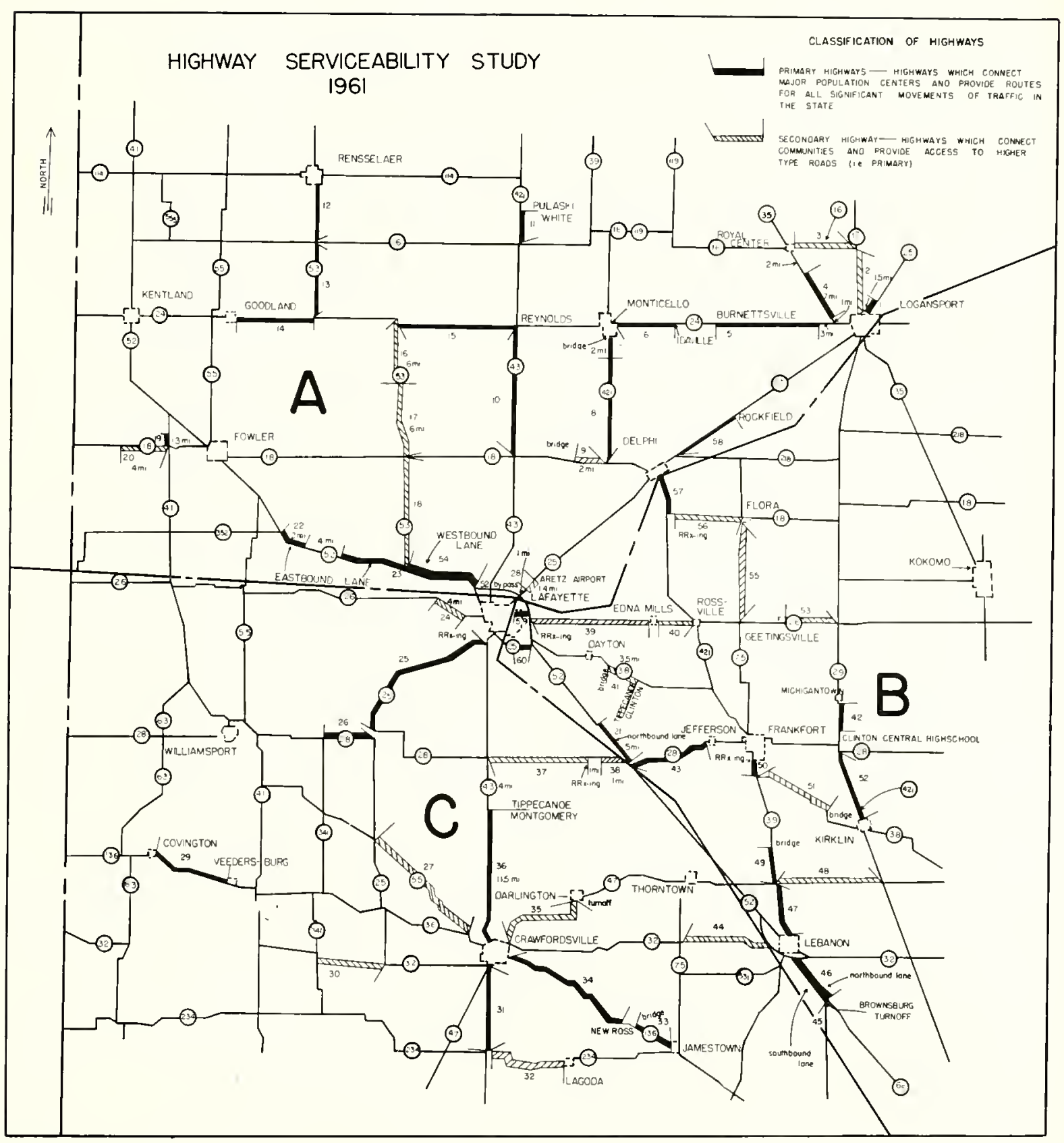

FIGURE 2. LOCATION OF THE PAVEMENT SECTIONS 


\section{Selection of the Panels of Raters}

The sixty pavement sections were rated by three panels of raters. There were ten raters in each panel. Two of the panels were composed of experts in the field of highway engineering. One panel represented the Indiana State Highway Commission (ISHC); the other was composed of faculty members of the Purdue University School of Civil Engineering. The third panel was composed of laymen; that is, typical road users not professionalif associated with highway engineering.

The members of the ISHC panel were selected by officials of the Indiana State Highway Comalssion from their engineering personnel. The personnel were selected on the basis of their availabilfty at the time of the rating and on their familiarity with the state highway system. All personnel were from the central office in Indianapolis or from the Crawfordsville district (the district serving the Lafayette area). They represented such interests as planning, road design, road construction, bituminous construction, maintenance, and traffic. The ages of these men ranged from 31 to 62 years with 53 being the mean age. Driving experience ranged from 15 to 45 years with a mean of 34 years; and annual driving mileage ranged from 15,000 to 60,000 miles with a mean of 30,700 miles.

The members of the Purdue panel were selected from the staff of the School of Civil Engineering at Purdue University. Those selected were from the Transportation staff or from an area directly interested in transportation. They represented such areas as pavement design, structures, soils, bituminous materials, air photos, planning, and research. The ages of the men ranged from 34 to 56 years with 41 being the mean age. Driving experience ranged from 15 to 46 years with a mean of 25 gears; and annual 
driving mileage ranged from 9,000 to 20,000 miles with a mean of 12,900 miles.

The sampling method used in obtaining the ten "laymen" raters was as follows: The sampling population was confined to the West LafayetteLafayette telephone directory and the Purdue University student directory. Sixty names from the telephone directory and fifteen names from the student directory were randomly selected. All of the people were then telephoned, briefly informed of the project, and asked if they would be interested in participating as raters. Those who gave positive responses were then visited and given more information. Those who were interested filled out application forms (see Appendix A). The selection of the ten raters from the applicants was based on the following factors: age, sex, occupation, type of vehicle owned, years of driving experience, annual driving mileage, and amount of liability and property damage insurance. The last factor was used only for administrative reasons.

The laymen panel consisted of seven men and three women who were assumed to be typical road users and representative of the traveling public. The occupations of the raters were as follows: student, graduate-staff member, plant supervisor, professor of electrical engineering, welder, tavern manager, truck driver, housewife, housewife-former teacher, and school nurse. The ages of the raters ranged from 23 to 53 with 38 being the mean age. Driving experience ranged from 4 to 35 years with a mean of 19 jears; and annual driving mileage ranged from 2,000 to 20,000 miles with a mean of 7,800 miles. 


\section{Rating Instructions}

Unlike the AASHO rating instruction procedure, where the rating instructions were orally presented at a business meeting of the rating group; the raters in the present study were individually instructed. This was done to keep them from being influenced by the other raters. Also, it was thought that rater response would be better under individual instruction. That is, the rater, if in doubt about any aspect of the instructions, would be more apt to ask questions. Thus, a better understanding of the rating procedure could be gained under individual instruction than in group instruction. It was very important that the raters clearly understand the "rules of the game". All raters were given identical instructions.

The instruction given to raters in this study was as follows:

1) The rater was briefly informed of the general purpose and scope of the study as follows:

The Joint Highway Research Project at Purdue University is undertaking a Pavement Serviceability Study in which you are to participate. Since highways are for the comfort and convenience of the general public, we are interested in finding out how the motorist rates the serviceability of highway pavements. Therefore, we want you to tell us what you think of the riding qualities of a selected sample of highway pavement sections.

There will be twenty-nine persons, representing the highway field and the general public, besides jou rating the same sixty pavement sections. We want to know if people more or less agree on the serviceability of highway pavements. Therefore, it is very important that we get your frank opinion. Do not ask anyone else for his or her opinion.

You are to drive a car similar to one you normally drive over the sixty pavement sections alone in the given order in three days, not necessarily three consecutive days.

2) The rater was given the following items:

a. A written set of the Rating Instructions (see Appendix A) 


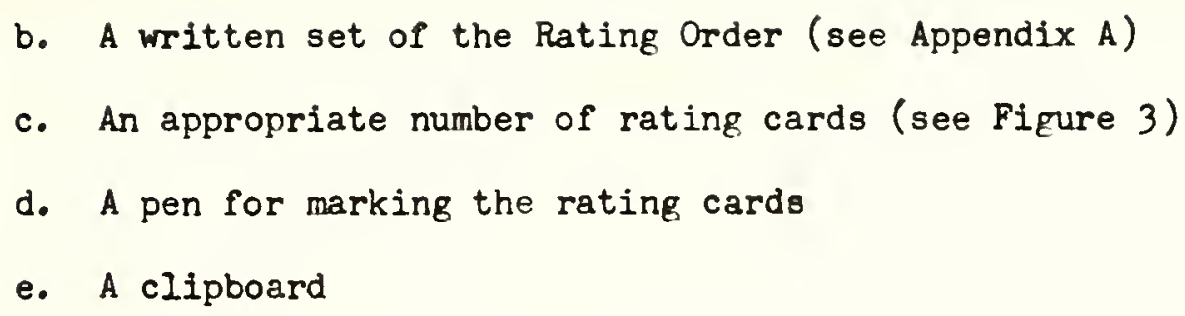

3) The instructor read aloud the Rating Instructions. To avoid misinterpretation of the instructions, the rater was encouraged to ask questions if he was in doubt about any aspect of the instructions.

The rater was instructed to always keep the following question in mind when rating the pavement sections: If I were to ride over a pavement that is just like that represented by this section of pavement every day for the usual purposes, how well would the pavement serve me? For secondary highway pavements this service would be primarily for short trips, such as to work or to town, while for primary highway pavements the service would be, in general, for some longer trips. The location map denoted the classification (i.e., primary or secondary) of the pavement sections and also defined the two classifications. A primary highway was defined as a highway which connects mejor population centers and provides routes for all significant movements of traffic in the state. A secondary highway was defined as a highway which connects communities and provides access to higher type roads (i.e., primary).

It was stressed that the serviceability of the pavement only was to be rated. All features not part of the parement itself, such as right of way and median width, grade, alignment, and shoulder and ditch conditions, were not to be considered in the rating of the pavement section. Also, the existing condition of the parement section was to be rated.

The rater was requested to drive over the pavement sections in a vehicle similar to one that he normally drove. The members of the Laymen 


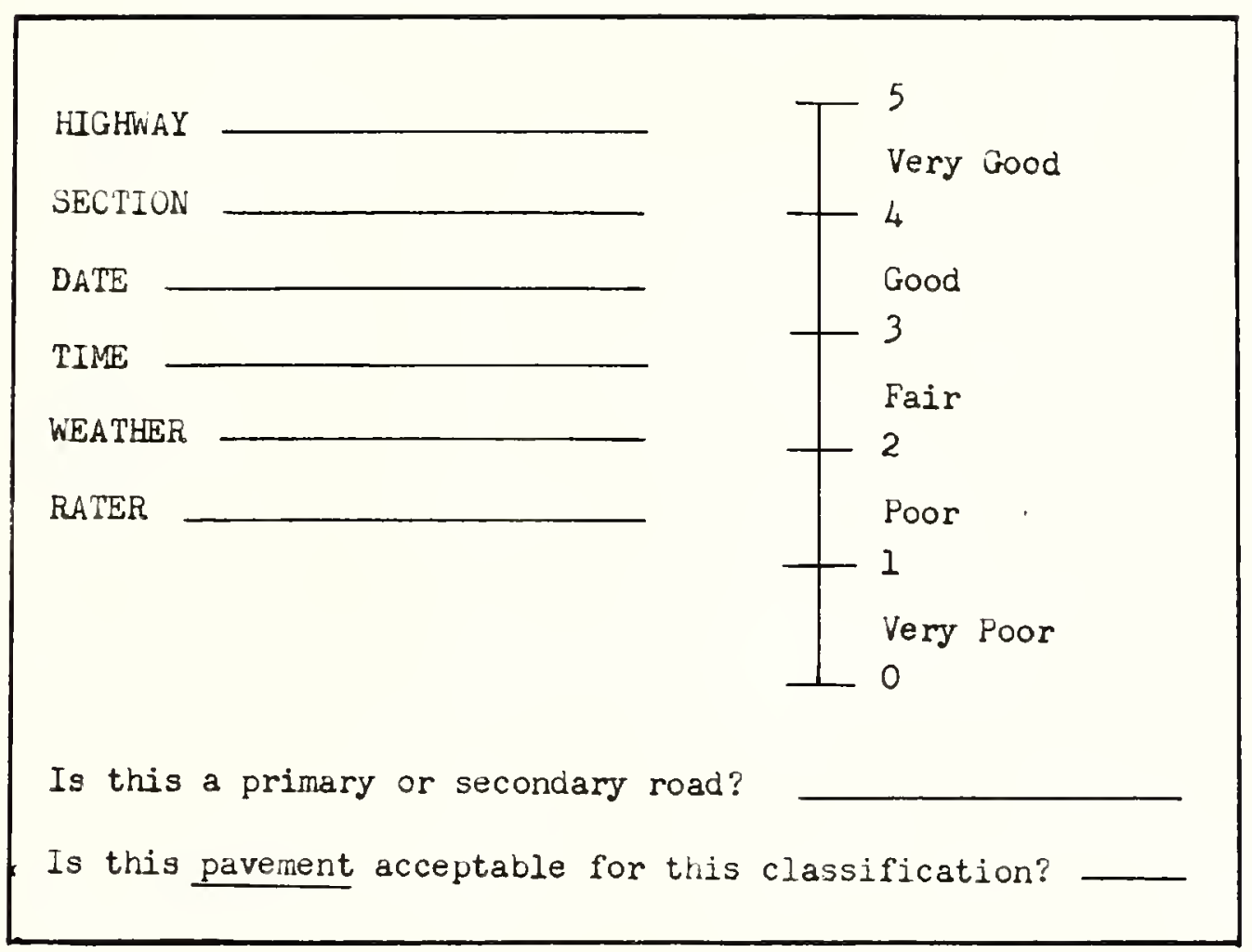

FIGURE 3. RATING CARD 
and Purdue panels drove their own personal vehicles. Most of the members of the ISHC panel drove state highway vehicles. The rater could ride over the pavement sections at any speed he desired. Rating was not to be done during rain or other inclement weather conditions.

It was also stressed that the rater was to travel alone and work Independent 17 . It was very important that the rater not be influenced by the opinions of others.

The rater was instructed to rate the serviceability of each pavement section on the 0 to 5 point rating scale. The rating scale utilized in the present study was similar to that employed in the AASHO serviceabilityperformance studies.

The rater was also instructed to rate the acceptability (Yes or No) of each pavement section, after noting its highway classification. The AASHO raters also rated the acceptability of the pavement sections. However, all of the AASHO pavement sections were of the same classification (i.e., primary), and there were three acceptability responses: Yes, No and Undecided.

4) The Rating Order was explained. The rater was required to rate the sixty parement sections according to a specified rating order.

Since approximately 300 miles of highways and 4,000 square miles of land ares were involved in the rating of the pavement sections, it was decided that the rating of the sixty sections would be done in three days, not necessarily three consecutive days. The land area was then divided into three parts: A, B, and C (see Figure 2). Each part represented a full day of rating. Part A consisted of 25 pavement sections; part $B$ consisted of 20; and part C consisted of 15. For statistical randomizing 
purposes, three different rating routes within each of the three parts and four different sequences in rating the parts were determined. The four sequences are as follows: $A B C, B C A, C A B$, and $C B A$. From the four different sequences and the three different rating routes, ten different rating orders were determined. In this way, three raters, one from each of the three panels, had the same rating order. A sample Rating Order can be found in Appendix A.

As an example: If given the sequence $B C A$ and the rating route 1 , the rater would rate part $B$ on the first day of rating, part $C$ on the second day of rating, and part $A$ on the third day. On the first day of rating he would rate section 59 flrst, section 60 second, section 41 third, ......, and section 39 last. On the second day he would rate section 36 first, section 31 second, section 32 third, ....., and section 24 last. On the third day he would rate section 28 first, section 54 second, section 18 third, ....., and section 23 last.

\section{Road Roughness Measurement}

The Indiana State Highway roughometer is a modified version of the BPR "Relative Roughness Indicator". A general description of the roughometer is given by Yoder (22). He states the following:

The roughometer is a device which, when towed over a paved surface, is assumed to stay in a relatively fixed plane due to its own Inertia. Changes in elevation are measured by means of a floating wheel which follows the paved surface and deviates from the machine proper.

The device consists of a rectangular frame, inside of which is a single wheel equipped with a pneumatic tire that has its axle attached to the center of two single-leaf springs, one on each side of the wheel. The integrator unit is mounted on the cross frame over the wheel, and the pistons of two dash-pot-spring damping devices are also attached to the cross piece. 
A detailed description of the Indiana State Highway roughometer is given by Holloway (9). A close-up view of the Indiana roughometer and tow truck can be seen in Figures 4 and 5 .

The entire lengths of all sixty pavement sections were measured by the Indiana State Highway roughometer. Roughometer roughness was measured in the right wheelpath of the traffic lane. The roughometer was operated at $20 \mathrm{mph}$. Two runs were made on each traffic lane, thus, four runs were made on two-lane highway sections. On four-lane highway sections, two runs were made on the outside lanes; passing lanes were not measured. Roughness readings were recorded at quarter-mile intervals.

The roughness index for any pavement section is the total inches of accumulated roughness divided by the length of the section in miles. The roughness values given for two-lane highway sections represent the average of four test runs, while those for sections on four-lane highways represent the average of two test runs.

Tire inflation pressure, air temperature, and fluid temperature were checked both before and after each run. Roughometer calibration and servicing were made in accordance with the BPR "Manual of Information Regarding the Operation and Maintenance of the Public Roads Relative Road Roughness Indicator" $(14)$. 


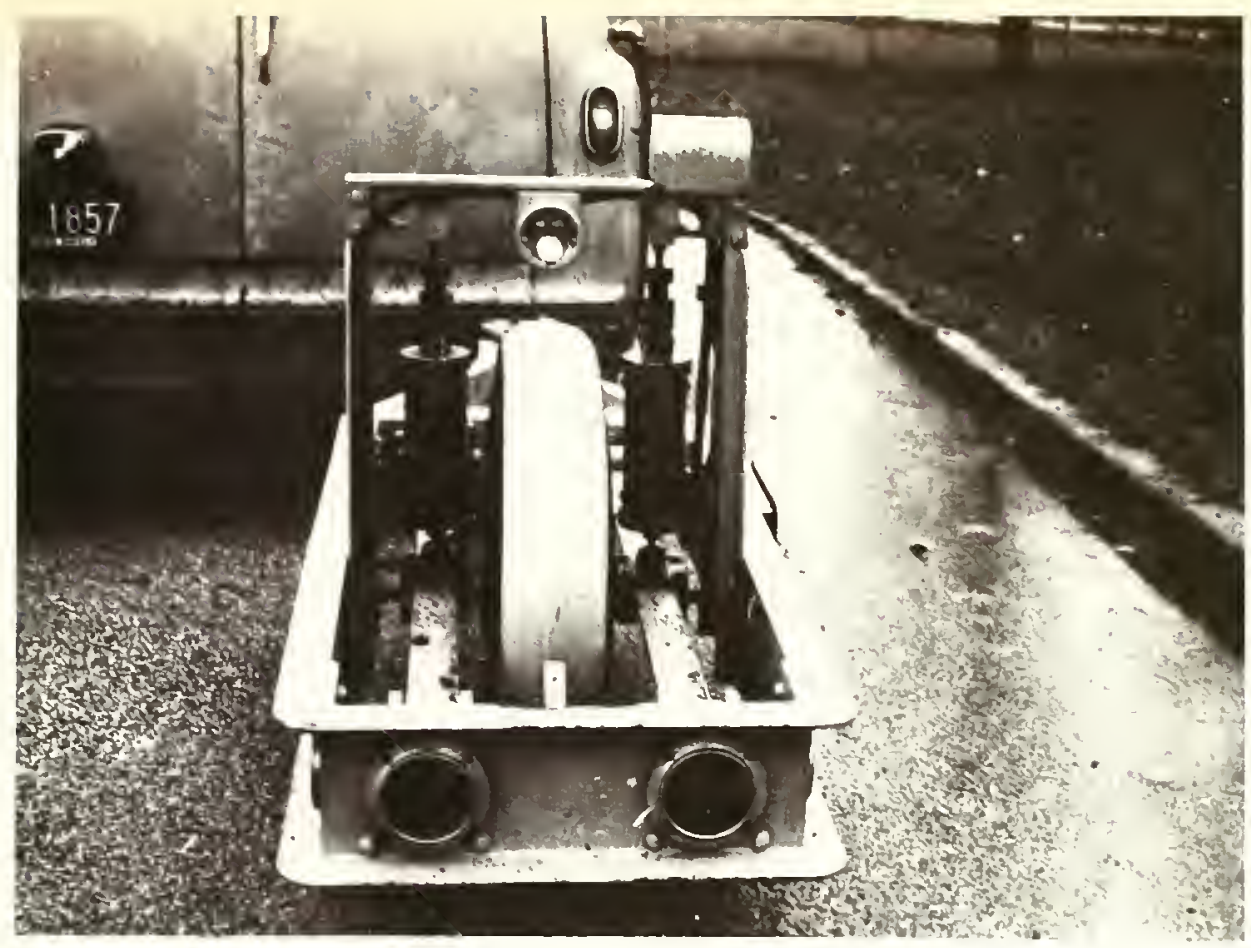

FIGURE 4. CLOSE-UP VIEW OF INDIANA STATE HIGHWAY ROUGHOMETER

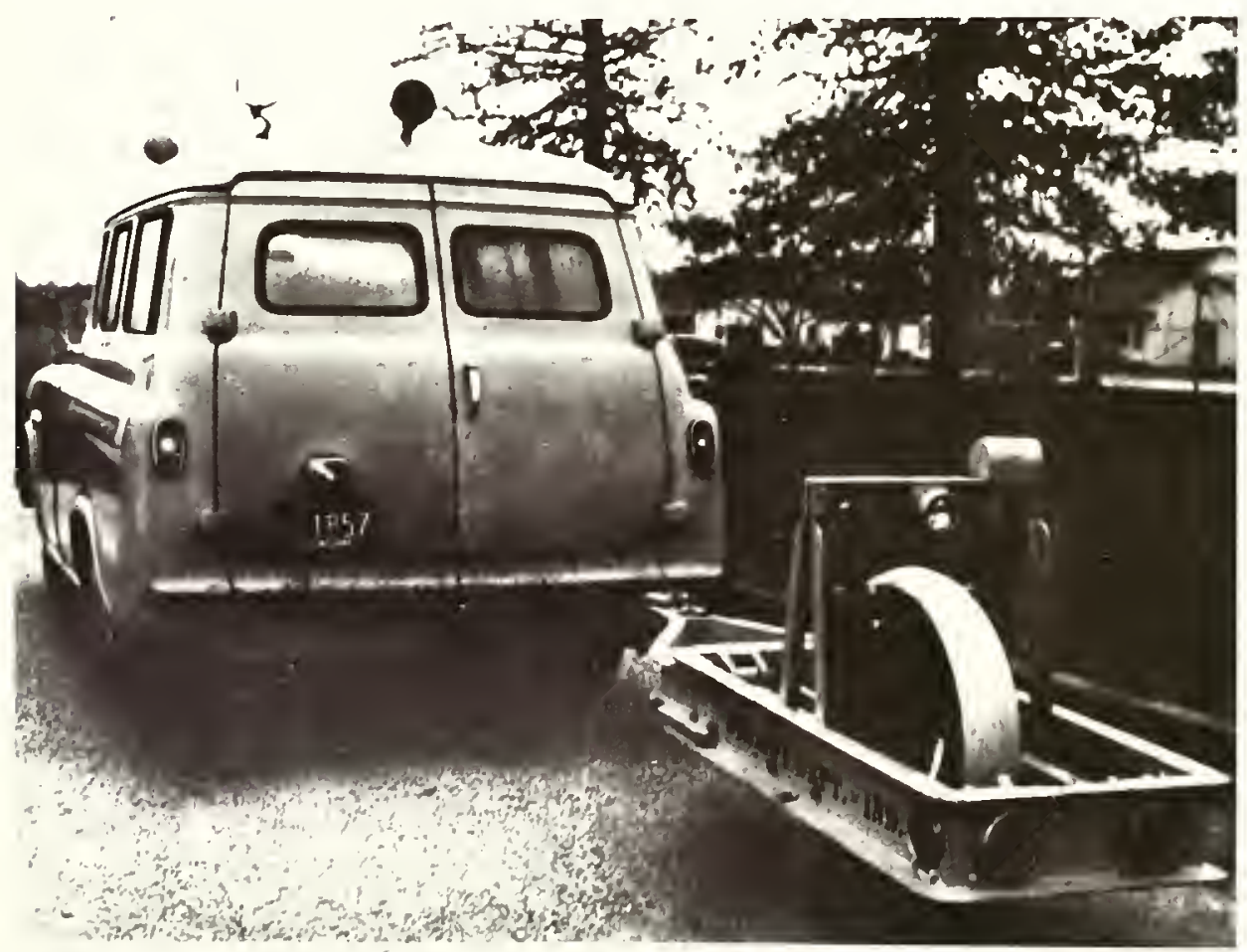

FIGURE 5. INDIANA STATE HIGHWAY ROUGHOMETER AND TOW TRUCK. 


\section{RESULTS - SERVICEABIIITY RATINGS}

\section{Analysis of Variance}

A mixed model, cross-classified nested analysis of variance (ANOV) design was utilized to analyze the rating data. Basically, the ANOV consists of classifying and cross-classifying data and testing whether the means of a specifled classification differ significantly. In this way the highway serviceability ratings made by experts in the field of highway engineering could be tested for a significant difference from the highway serviceability ratings made by typical road users. Also, the means of the individual raters within each of the rating panels could be tested to determine the validity of the statement made in the introduction that "the opinions of highway users as to how they are being served may vary widely and even differ."

The assumptions which underlie this method include: homogeneity of variances, normal distribution of errors, fixed pavement type and panel type, random pavement section samples within each pavement type, and random rater samples within each panel type. Because a good estimate of the number of raters required to estimate the "true" rating required an equal number of pavement sections for each pavement type, three overlay pavement sections (sections 2, 8, and 15) were randomly eliminated. This left an ANOV with an equal number of pavement sections for each of the three pavement types from which exact estimates of the components of variance could be obtained. 
One of the raters did not rate pavement section 55 . The missing rating was estimated using the randomized block method (7). Calculations for the value herein discussed are presented in Appendix B. The estimated rating was 2.6 . The average rating of this section as determined by the other twenty-nine raters was 2.3 . The rater's mean absolute deviation from the "true" ratings* for the other fifty-nine sections was 0.4, and he had a tendency to rate higher than the "true"; therefore, it was assumed that 2.6 was a good estimate.

Table 1 shows the results of the ANOV. The model used was:

$$
\begin{aligned}
I_{(1) j(k) 1}=\mu & +P_{1}+S_{(i) j}+G_{k}+R_{(k) I}+(P G)_{1, k}+(P R)_{1(k) 1} \\
& +(S G)_{(1) j, k}+(S R)_{(1) j(k) 1}+{ }_{(1, j, k, 1)}
\end{aligned}
$$

where,

$$
\begin{aligned}
I(1) f(k) I & =\text { the rating of the }(k) I^{\text {th }} \text { rater on the }(1) f^{\text {th }} \text { strip. } \\
\mu & =\text { the mean } \\
P & =\text { pavement type } \\
S & =\text { pavement section within pavement type } \\
G & =\text { rating panel type } \\
R & =\text { rater within rating panel type } \\
P G= & \text { pavement type-rating panel type interaction } \\
P R= & \text { pavement type-rater within rating panel type interaction } \\
S G= & \text { section within pavement type-rating panel type } \\
& \text { interaction }
\end{aligned}
$$

* In the present study, the mean rating of the thirty raters is assumed to be the "true" rating of the pavement section. The present serviceability rating (PSR) is defined as the mean of the individual serviceability ratings made by the thirty raters. Therefore, in the present study the "true" rating and the PSR of a speciflc section are identical and are used interchangeably. 


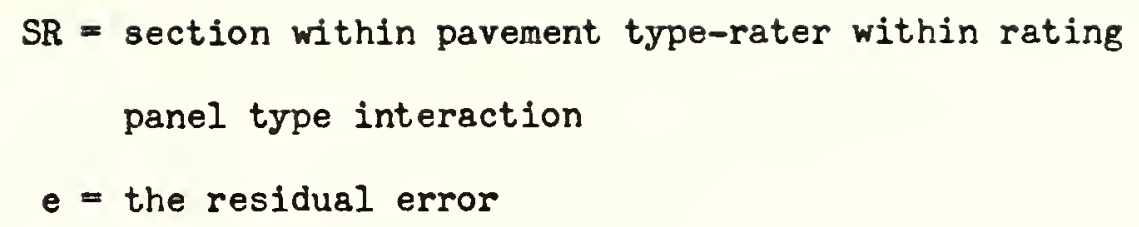

TABLE I

SUMMARY OF ANALYSIS OF VARIANCE SERVICEABILITY RATINGS

\begin{tabular}{|c|c|c|c|c|c|c|c|}
\hline Source & $\begin{array}{c}\text { Degrees of } \\
\text { Freedom }\end{array}$ & $\begin{array}{r}\text { Sum of } \\
\text { Squares }\end{array}$ & $\begin{array}{c}\text { Mean } \\
\text { Squares }\end{array}$ & $\begin{array}{l}\text { Variance } \\
\text { Ratio }\end{array}$ & $F_{\alpha}$ & $\begin{array}{c}\text { Level of } \\
a\end{array}$ & Conclusion \\
\hline$P$ & 2 & 93.265 & 46.632 & 2.328 & 2.39 & 0.10 & NSI \\
\hline$s$ & 54 & 996.840 & 18.460 & 60.924 & 1.53 & 0.005 & $s^{2}$ \\
\hline G & 2 & 1.613 & 0.806 & 0.094 & 1.41 & 0.25 & NS \\
\hline$R$ & 27 & 230.475 & 8.536 & 28.172 & 1.79 & 0.005 & $s$ \\
\hline PXG & 4 & 8.236 & 2.059 & 1.211 & 1.35 & 0.25 & NS \\
\hline$P x R$ & 54 & 91.780 & 1.700 & 5.611 & 1.53 & 0.005 & $S$ \\
\hline SxG & 108 & 31.604 & 0.293 & 0.967 & 1.08 & 0.25 & NS \\
\hline $\mathrm{SxR}$ & 1457 & 480.619 & 0.303 & & & & \\
\hline Total & 1708 & 1934.432 & & & & & \\
\hline
\end{tabular}

Differences between the pavement sections within pavement types, between the raters within panel types, and the pavement type-rater within panel type interaction were significant at the 0.005 level of probability. Differences between the rating panels, the pavement type-rating panel interaction, and the pavement section within pavement type-rating panel Interaction were not significant at the 0.25 level of probability; differences between the pavement types were not significant at the 0.10 level of probability. 
The finding that raters within a panel type differed significantly supports the above mentioned statement that "the opinions of highway users as to how they are being served may vary widely and even differ." The significant pavement type-rater within panel type interaction means that the differences between the raters within a panel type differed over the three pavement types. As an example: one rater might tend to rate the rigid pavement sections "higher" than the other raters while he might tend to rate the overlay and flexible sections "lower" than the others. Whereas, another rater might tend to rate the rigid sections "lower" than the other raters while rating the flexible and overlay sectlons "higher" than the other raters.

It was expected that the pavement sections within a pavement type would differ significantly since they were selected to represent all types of pavement conditions varying from very good to very poor. The PSRs of the rigid pavement sections ranged from 1.1 to 4.5 ; the PSRs of the overlay pavement sections ranged from 2.2 to 4.1 ; and the PSRs of the flexible parement sections ranged from 1.5 to 4.1 . There was a non-significant difference between the pavement types; that is, the overall means of the three parement types did not differ significantly. Tables 2, 3 , and 4 show the overall means to be $3.1,3.1$, and 2.7 , for the rigid, overlay, and flexible pavement types, respectively.

There was a non-significant difference between the rating panels. This is compatible with a conclusion that the mean highway serviceability ratings of highway authorities are similar to the mean serviceability ratings of the traveling public. The non-significant pavement type-rating panel interaction and section within pavement type-rating panel interaction Indicate that the difference between the means of the three panels did 
not differ significantly over the three pavement types and over the pavement sections within the pavement types at the 0.25 level of probability. The panel serviceability ratings for the rigid, overlay, and flexible pavement sections are presented in Tables 2, 3, and 4, respectively. It can be seen in these tables that there are no marked differences between the serviceability ratings of the three panels for each pavement section. The PSR for each pavement section is also given in the tables.

\section{Individual Serviceability Rating Variability}

As stated earlier, the ANOV results supported the statement that "the opinions of highway users as to how they are being served vary wideIy and even differ". The widely varying opinions are further evidenced in Tables 5, 6, and 7. The overall and panel ranges* are given in these tables for the rigid, overlay, and flexible sections, respectively. The 100 per cent (i.e., all of the individual serviceability ratings of the specific group are taken into account) mean ranges of the overall, ISHC, Purdue, and Laymen panels were $2.9,2.4,1.9$, and 2.4 , respectively, for the sixty pavement sections. Assuming the possibility of individual rating blunders, the 90 per cent ranges were also determined (i.e., one rating from each panel range and three ratings from each overall range which contributed most to the range were eliminated). The 90 per cent mean ranges of the overall, ISHC, Purdue, and Laymen panels were 2.0, 1.8, 1.4, and 1.7, respectively for the sixty sections. A substantial decrease occurred in the ranges at the 90 per cent level. The Purdue panel had the

* In the present study, panel serviceability rating is defined as the mean of the individual serviceability ratings made by members of a specific rating panel.

* The range of a pavement section is the difference between the highest individual serviceability rating and the lowest individual serviceability rating given to the pavement section by a stated group of raters. 


\begin{tabular}{|c|c|c|c|}
\hline $\begin{array}{l}\text { Pavement } \\
\text { Section }\end{array}$ & $\begin{array}{l}\text { Highwai } \\
\text { Number }\end{array}$ & $\frac{\text { Ratios }}{\text { Laymen }}$ & AII \\
\hline 1 & 25 & 0.8 & 0.8 \\
\hline 4 & 35 & 0.7 & 0.7 \\
\hline 7 & 421 & 0.7 & 0.7 \\
\hline 17 & 53 & 0.9 & 0.87 \\
\hline 18 & 53 & 1.0 & 0.97 \\
\hline 19 & 41 & 0.5 & 0.23 \\
\hline 21 & 52 & 0.9 & 0.87 \\
\hline 22 & 52 & 1.0 & 1.0 \\
\hline 23 & 52 & 0.9 & 0.93 \\
\hline 28 & 25 & 1.0 & 1.0 \\
\hline 45 & 65 & 1.0 & 1.0 \\
\hline 46 & 65 & 1.0 & 1.0 \\
\hline 47 & 39 & 1.0 & 1.0 \\
\hline 49 & 39 & 1.0 & 1.0 \\
\hline 50 & 39 & 1.0 & 1.0 \\
\hline 54 & 52 & 0.9 & 0.9 \\
\hline 57 & 421 & 1.0 & 0.9 \\
\hline 59 & Untor & 0.0 & 0.07 \\
\hline 60 & 25 & 0.8 & 0.73 \\
\hline
\end{tabular}

Sub-Total

Type Mean 
TABLE 2

SUMMARY OF DATA - RIGID PAVEMENT SECTIONS

\begin{tabular}{|c|c|c|c|c|c|c|c|c|c|c|c|c|}
\hline \multirow{2}{*}{$\begin{array}{l}\text { Pavement } \\
\text { Section }\end{array}$} & \multirow{2}{*}{$\begin{array}{l}\text { Highway } \\
\text { Number }\end{array}$} & \multirow[b]{2}{*}{ Classification } & \multirow[b]{2}{*}{ length } & Mear & \multicolumn{3}{|c|}{ Serviceability Ratings } & \multirow{2}{*}{$\begin{array}{l}\text { Roughness } \\
\text { Index } \\
\text { (in./mi.) }\end{array}$} & \multicolumn{4}{|c|}{ Accoptability Ratioe } \\
\hline & & & & ISHC & Purdue & Laymen & $\mathrm{PSE}$ & & ISHC & Pundue & Laymen & III \\
\hline 1 & 25 & $\mathbf{P}$ & 1.25 & 2.7 & 2.8 & 2.5 & 2.7 & 128 & 0.9 & 0.7 & 0.8 & 0.8 \\
\hline 4 & 35 & $\mathbf{P}$ & 6.50 & 2.6 & 2.6 & 2.3 & 2.5 & 129 & 0.7 & 0.7 & 0.7 & 0.7 \\
\hline 7 & 421 & $\mathbf{P}$ & 1.75 & 2.6 & 2.4 & 2.2 & 2.4 & 116 & 0.6 & 0.8 & 0.7 & 0.7 \\
\hline 17 & 53 & s & 4.75 & 2.4 & 2.2 & 2.2 & 2.3 & 128 & 0.8 & 0.9 & 0.9 & 0.87 \\
\hline 18 & 53 & s & 8.75 & 2.6 & 2.6 & 2.4 & 2.6 & 124 & 0.9 & 1.0 & 1.0 & 0.97 \\
\hline 19 & 42 & $\mathbf{P}$ & 1.25 & 1.3 & 1.3 & 1.5 & 1.4 & 175 & 0.1 & 0.1 & 0.5 & 0.23 \\
\hline 21 & 52 & $P$ & 4.50 & 3.1 & 3.1 & 3.0 & 3.1 & 115 & 0.9 & 0.8 & 0.9 & 0.87 \\
\hline 22 & 52 & $\mathbf{P}$ & 1.75 & 3.8 & 4.1 & 4.0 & 4.0 & 89 & 1.0 & 1.0 & 1.0 & 1.0 \\
\hline 23 & 52 & $\mathbf{P}$ & 11.00 & 3.3 & 3.6 & 3.3 & 3.4 & 99 & 0.9 & 1.0 & 0.9 & 0.93 \\
\hline 28 & 25 & $s$ & 1.00 & 4.1 & 4.0 & 3.7 & 3.9 & 87 & 1.0 & 1.0 & 1.0 & 1.0 \\
\hline 45 & 65 & $\mathbf{P}$ & 3.25 & 4.4 & 4.7 & 4.2 & 4.4 & 85 & 1.0 & 1.0 & 1.0 & 1.0 \\
\hline 46 & 65 & $P$ & 3.25 & 4.6 & 4.6 & 4.4 & 4.5 & 91 & 1.0 & 1.0 & 1.0 & 1.0 \\
\hline 47 & 39 & $P$ & 3.75 & 4.4 & 4.3 & 3.9 & 4.2 & 90 & 1.0 & 1.0 & 1.0 & 1.0 \\
\hline 49 & 39 & $\mathbf{P}$ & 2.25 & 4.2 & 4.1 & 4.0 & 4.1 & 91 & 1.0 & 1.0 & 1.0 & 1.0 \\
\hline 50 & 39 & $P$ & 2.25 & 4.3 & 4.3 & 3.9 & 4.2 & 75 & 1.0 & 1.0 & 1.0 & 1.0 \\
\hline 54 & 52 & $P$ & 5.50 & 3.4 & 3.2 & 3.1 & 3.2 & 107 & 1.0 & 0.8 & 0.9 & 0.9 \\
\hline 57 & 421 & $P$ & 2.00 & 3.0 & 2.9 & 2.7 & 2.9 & 112 & 0.7 & 1.0 & 1.0 & 0.9 \\
\hline 59 & Unton & $P_{c}$ & 0.50 & 1.4 & 0.9 & 1.0 & 1.1 & 237 & 0.2 & 0.0 & 0.0 & 0.07 \\
\hline 60 & 25 & P & 0.75 & 2.4 & 2.3 & 2.5 & 2.4 & 132 & 0.8 & 0.6 & 0.8 & 0.73 \\
\hline Totsl & & & 66.00 & 60.8 & 60.0 & 56.8 & 59.3 & 2210 & & & & \\
\hline Mean & & & 3.50 & 3.2 & 3.2 & 3.0 & 3.1 & 116 & & & & \\
\hline
\end{tabular}




\begin{tabular}{|c|c|c|c|}
\hline \multirow{2}{*}{$\begin{array}{l}\text { Pavement } \\
\text { Section }\end{array}$} & \multicolumn{3}{|c|}{ Highility Ratios } \\
\hline & Numbere & Laymen & All \\
\hline 2 & 19 & 0.9 & 0.87 \\
\hline 5 & $2 k$ & 0.9 & 0.67 \\
\hline 6 & 26 & 0.7 & 0.63 \\
\hline 8 & 42) & 1.0 & 0.9 \\
\hline 10 & 4) & 1.0 & 0.93 \\
\hline 11 & 42) & 1.0 & 1.0 \\
\hline 12 & 5) & 1.0 & 1.0 \\
\hline 13 & 5) & 1.0 & 0.97 \\
\hline 14 & $2 b$ & 0.9 & 0.93 \\
\hline 15 & $2 p$ & 0.9 & 0.8 \\
\hline 16 & 5) & 0.9 & 0.93 \\
\hline 25 & 29 & 1.0 & 0.93 \\
\hline 26 & 20 & 1.0 & 0.97 \\
\hline 29 & 130 & 1.0 & 1.0 \\
\hline 31 & 4) & 1.0 & 1.0 \\
\hline 34 & 130 & 0.9 & 0.9 \\
\hline 36 & 4D & 1.0 & 1.0 \\
\hline 38 & 20 & 1.0 & 1.0 \\
\hline 42 & 29 & 0.7 & 0.8 \\
\hline 43 & 26 & 0.9 & 0.73 \\
\hline 52 & 42. & 1.0 & 1.0 \\
\hline 58 & 20 & 1.0 & 1.0 \\
\hline
\end{tabular}

Sub-Total

Type Mean 
TABLE 3

SUMMARY OF DATA - OVERLAY PAVEMENT SECTIONS

\begin{tabular}{|c|c|c|c|c|c|c|c|c|c|c|c|c|}
\hline \multirow{2}{*}{$\begin{array}{l}\text { Pavement } \\
\text { Section }\end{array}$} & \multirow{2}{*}{$\begin{array}{l}\text { Hughway } \\
\text { Mumber }\end{array}$} & \multirow[b]{2}{*}{ Claseiflcation } & \multirow[b]{2}{*}{ Length } & \multicolumn{4}{|c|}{ Mean Serviceability Ratings } & \multirow{2}{*}{$\begin{array}{c}\text { Roughness } \\
\text { Index } \\
\text { (in./mi.) }\end{array}$} & \multicolumn{4}{|c|}{ Acceptability Ratios } \\
\hline & & & & ISAC & Purdue & Laymen & PSR & & $\overline{\mathrm{ISHC}}$ & Purdue & Laymen & A11 \\
\hline 2 & 17 & $\mathrm{~s}$ & 6.00 & 2.0 & 2.6 & 2.4 & 2.3 & 167 & 0.7 & 1.0 & 0.9 & 0.87 \\
\hline 5 & 24 & $\mathbf{P}$ & 7.75 & 2.7 & 2.2 & 2.3 & 2.4 & 93 & 0.6 & 0.5 & 0.9 & 0.67 \\
\hline 6 & 24 & $P$ & 4.25 & 2.6 & 2.2 & 1.9 & 2.2 & 98 & 0.7 & 0.5 & 0.7 & 0.63 \\
\hline 8 & 421 & $\mathrm{P}$ & 7.50 & 3.0 & 3.1 & 3.3 & 3.1 & 89 & 0.8 & 0.9 & 1.0 & 0.9 \\
\hline 10 & 43 & $P$ & 9.25 & 3.1 & 2.7 & 3.1 & 3.0 & 105 & 0.9 & 0.9 & 1.0 & 0.93 \\
\hline 11 & 421 & $P$ & 3.00 & 4.1 & 4.0 & 4.2 & 4.1 & 75 & 1.0 & 1.0 & 1.0 & 1.0 \\
\hline 12 & 53 & $P$ & 3.75 & 3.6 & 3.6 & 3.9 & 3.7 & 80 & 1.0 & 1.0 & 1.0 & 1.0 \\
\hline 13 & 53 & $P$ & 6.50 & 3.6 & 3.6 & 3.6 & 3.6 & 87 & 1.0 & 0.9 & 1.0 & 0.97 \\
\hline 14 & 24 & $P$ & 6.50 & 2.9 & 2.9 & 2.8 & 2.8 & 85 & 0.9 & 1.0 & 0.9 & 0.93 \\
\hline 15 & 24 & $P$ & 8.25 & 2.7 & 2.5 & 2.8 & 2.7 & 98 & 0.8 & 0.7 & 0.9 & 0.8 \\
\hline 16 & 53 & $s$ & 4.50 & 2.4 & 2.4 & 2.4 & 2.4 & 154 & 0.9 & 1.0 & 0.9 & 0.93 \\
\hline 25 & 25 & $P$ & 12.75 & 3.8 & 3.5 & 3.3 & 3.5 & 91 & 0.9 & 0.9 & 1.0 & 0.93 \\
\hline 26 & 28 & $P$ & 3.50 & 3.9 & 3.8 & 3.9 & 3.9 & 76 & 0.9 & 1.0 & 1.0 & 0.97 \\
\hline 29 & 136 & $P$ & 5.75 & 3.9 & 3.9 & 3.5 & 3.8 & 79 & 1.0 & 1.0 & 1.0 & 1.0 \\
\hline 31 & 43 & $P$ & 2.50 & 4.0 & 4.0 & 3.4 & 3.8 & 73 & 1.0 & 1.0 & 1.0 & 1.0 \\
\hline 34 & 136 & $P$ & 9.00 & 3.1 & 3.0 & 3.0 & 3.0 & 91 & 0.9 & 0.9 & 0.9 & 0.9 \\
\hline 36 & 43 & $P$ & 10.75 & 3.9 & 3.9 & 3.6 & 3.8 & 88 & 1.0 & 1.0 & 1.0 & 1.0 \\
\hline 38 & 28 & $S$ & 0.50 & 2.7 & 3.0 & 3.2 & 3.0 & 124 & 1.0 & 1.0 & 1.0 & 1.0 \\
\hline 42 & 29 & $P$ & 1.50 & 2.6 & 2.6 & 2.6 & 2.6 & 92 & 0.8 & 0.9 & 0.7 & 0.8 \\
\hline 43 & 28 & $P$ & 2.50 & 2.5 & 2.5 & 2.6 & 2.6 & 106 & 0.7 & 0.6 & 0.9 & 0.73 \\
\hline 52 & 421 & $P$ & 5.25 & 3.7 & 4.0 & 3.8 & 3.8 & 85 & 1.0 & 1.0 & 1.0 & 1.0 \\
\hline 58 & 25 & $P$ & 4.25 & 4.0 & 4.2 & 4.1 & 4.1 & 82 & 1.0 & 1.0 & 1.0 & 1.0 \\
\hline Total & & & 125.50 & 70.8 & 70.2 & 69.7 & 70.2 & 2108 & & & & \\
\hline Hoan & & & 5.70 & 3.2 & 3.2 & 3.2 & 3.2 & 96 & & & & \\
\hline
\end{tabular}




\begin{tabular}{crcc}
\hline $\begin{array}{l}\text { Pavement } \\
\text { Section }\end{array}$ & $\begin{array}{r}\text { Highwity Ratios } \\
\text { Numbe }\end{array}$ & Laywen & All \\
\hline 3 & 16 & 0.9 & 0.83 \\
9 & 18 & 1.0 & 0.93 \\
20 & 18 & 0.9 & 0.9 \\
24 & 26 & 1.0 & 0.97 \\
27 & 55 & 0.7 & 0.53 \\
30 & 32 & 0.9 & 0.87 \\
32 & 234 & 1.0 & 1.0 \\
33 & 136 & 1.0 & 0.97 \\
35 & 47 & 1.0 & 0.97 \\
37 & 28 & 1.0 & 0.87 \\
39 & 26 & 1.0 & 1.0 \\
40 & 26 & 1.0 & 0.93 \\
41 & 38 & 0.9 & 0.73 \\
44 & 32 & 1.0 & 1.0 \\
48 & 47 & 0.7 & 0.8 \\
51 & 38 & 1.0 & 0.9 \\
53 & 18 & 1.0 & 0.73 \\
55 & 1.0 & 0.83 \\
56 & 1.0 & 0.93
\end{tabular}

Sub-Total

Type Mean 
TABLE 4

SUMMARY OF DATA - FLEXIBLE PAVEMENT SECTIONS

\begin{tabular}{|c|c|c|c|c|c|c|c|c|c|c|c|c|}
\hline \multirow{2}{*}{$\begin{array}{l}\text { Pavement } \\
\text { Section }\end{array}$} & \multirow{2}{*}{$\begin{array}{l}\text { Highway } \\
\text { Number }\end{array}$} & \multirow[b]{2}{*}{ Classification } & \multirow[b]{2}{*}{ Length } & \multicolumn{4}{|c|}{ Mean Serviceability Ratinge } & \multirow{2}{*}{$\begin{array}{l}\text { Roughness } \\
\text { Index } \\
\text { (in./m1.) }\end{array}$} & \multicolumn{4}{|c|}{ Acceptability Ratiog } \\
\hline & & & & $\overline{\mathrm{ISHC}}$ & Purdue & Laymen & PSR & & $\overline{\mathrm{ISHC}}$ & Purdue & Laymen & AII \\
\hline 3 & 16 & $S$ & 5.75 & 2.1 & 2.3 & 2.1 & 2.2 & 116 & 0.8 & 0.8 & 0.9 & 0.83 \\
\hline 9 & 18 & 3 & 1.75 & 2.5 & 2.3 & 2.6 & 2.5 & 134 & 0.9 & 0.9 & 1.0 & 0.93 \\
\hline 20 & 18 & $s$ & 3.75 & 2.7 & 2.9 & 3.1 & 2.9 & 139 & 0.8 & 1.0 & 0.9 & 0.9 \\
\hline 24 & 26 & $s$ & 3.75 & 2.8 & 3.1 & 3.0 & 2.9 & 110 & 0.9 & 1.0 & 1.0 & 0.97 \\
\hline 27 & 55 & s & 20.50 & 1.3 & 1.8 & 1.5 & 1.5 & 144 & 0.3 & 0.6 & 0.7 & 0.53 \\
\hline 30 & 32 & $s$ & 5.00 & 2.7 & 2.5 & 2.8 & 2.7 & 255 & 0.8 & 0.9 & 0.9 & 0.87 \\
\hline 32 & 234 & $s$ & 5.50 & 3.5 & 3.6 & 4.0 & 3.7 & 87 & 1.0 & 1.0 & 1.0 & 1.0 \\
\hline 33 & 136 & $P$ & 3.25 & 4.1 & 4.2 & 3.9 & 4.1 & 62 & 1.0 & 1.0 & 1.0 & 0.97 \\
\hline 35 & 47 & $\mathrm{~S}$ & 7.00 & 2.7 & 3.1 & 3.0 & 2.9 & 103 & 0.9 & 1.0 & 1.0 & 0.97 \\
\hline 37 & 28 & $\mathrm{~s}$ & 8.50 & 2.1 & 2.3 & 2.4 & 2.2 & 152 & 0.7 & 0.9 & 1.0 & 0.87 \\
\hline 39 & 26 & $s$ & 9.50 & 3.2 & 3.3 & 3.1 & 3.2 & 92 & 1.0 & 1.0 & 1.0 & 1.0 \\
\hline 40 & 26 & $s$ & 3.00 & 2.3 & 2.7 & 2.9 & 2.6 & 110 & 0.8 & 1.0 & 1.0 & 0.93 \\
\hline 41 & 38 & $S$ & 3.25 & 1.6 & 2.1 & 2.3 & 2.0 & 144 & 0.6 & 0.7 & 0.9 & 0.73 \\
\hline 44 & 32 & $S$ & 6.75 & 3.7 & 3.7 & 3.7 & 3.7 & 64 & 1.0 & 2.0 & 1.0 & 1.0 \\
\hline 48 & 47 & $S$ & 7.75 & 2.1 & 2.6 & 1.7 & 2.1 & 94 & 0.8 & 0.9 & 0.7 & 0.8 \\
\hline 51 & 38 & $\mathrm{~s}$ & 6.25 & 2.9 & 2.9 & 3.2 & 3.0 & 108 & 0.8 & 0.9 & 2.0 & 0.9 \\
\hline 53 & 26 & $S$ & 3.50 & 1.8 & 2.0 & 2.2 & 2.0 & 137 & 0.5 & 0.7 & 1.0 & 0.73 \\
\hline 55 & 75 & $S$ & 8.25 & 2.2 & 2.4 & 2.4 & 2.3 & 133 & 0.7 & 0.8 & 1.0 & 0.83 \\
\hline 56 & 18 & $\mathrm{~S}$ & 5.25 & 2.8 & 2.9 & 3.1 & 2.9 & 131 & 0.8 & 1.0 & 1.0 & 0.93 \\
\hline Total & & & 108.25 & 49.2 & 52.7 & 53.0 & 51.4 & 2215 & & & & \\
\hline Mean & & & 5.70 & 2.6 & 2.8 & 2.8 & 2.7 & 127 & & & & \\
\hline
\end{tabular}


TABLE 5

ONE-HUNDRED PERCENT AND NINETY PERCENT OVERALL AND PANEL RANGES - RIGID PAVEMENT SECTIONS

\begin{tabular}{ccccccccc}
\hline $\begin{array}{c}\text { Pavement } \\
\text { Section }\end{array}$ & \multicolumn{2}{c}{$\begin{array}{c}\text { Overall } \\
\text { Range }\end{array}$} & \multicolumn{2}{c}{$\begin{array}{c}\text { ISHC } \\
\text { Panel }\end{array}$} & \multicolumn{2}{c}{$\begin{array}{c}\text { Purdue } \\
\text { Panel }\end{array}$} & \multicolumn{2}{c}{$\begin{array}{c}\text { Laymen } \\
\text { Panel }\end{array}$} \\
\hline 1 & $100 \%$ & $90 \%$ & 100 \% & $90 \%$ & $100 \%$ & $90 \%$ & $100 \%$ & $90 \%$ \\
\hline 4 & 2.8 & 2.1 & 2.5 & 2.1 & 2.3 & 1.1 & 2.4 & 1.6 \\
7 & 3.5 & 1.4 & 1.1 & 0.9 & 2.6 & 1.1 & 2.0 & 1.5 \\
17 & 3.0 & 2.6 & 3.0 & 2.6 & 2.4 & 1.5 & 2.2 & 1.7 \\
18 & 4.5 & 1.5 & 3.6 & 1.7 & 1.3 & 0.7 & 2.9 & 1.5 \\
19 & 3.5 & 2.1 & 3.0 & 1.9 & 1.4 & 0.8 & 2.4 & 2.0 \\
21 & 2.7 & 2.1 & 2.5 & 2.3 & 1.8 & 1.5 & 2.5 & 2.0 \\
22 & 3.8 & 2.6 & 3.3 & 2.2 & 2.5 & 2.2 & 3.5 & 2.2 \\
23 & 2.4 & 1.9 & 2.2 & 2.1 & 1.5 & 1.3 & 1.9 & 1.7 \\
28 & 3.7 & 2.5 & 3.0 & 2.6 & 2.4 & 1.7 & 3.7 & 2.4 \\
45 & 3.0 & 2.0 & 2.0 & 1.5 & 2.0 & 1.8 & 3.0 & 2.1 \\
46 & 2.8 & 1.1 & 1.6 & 1.1 & 1.2 & 0.9 & 2.8 & 1.0 \\
47 & 1.8 & 1.0 & 1.0 & 0.9 & 1.4 & 1.0 & 1.8 & 1.0 \\
49 & 1.8 & 1.3 & 1.3 & 1.1 & 1.5 & 1.3 & 1.1 & 0.6 \\
50 & 2.3 & 2.0 & 2.0 & 1.1 & 2.2 & 2.0 & 2.3 & 1.8 \\
54 & 3.9 & 2.4 & 2.7 & 2.1 & 1.6 & 1.5 & 3.7 & 2.4 \\
57 & 2.8 & 1.4 & 2.8 & 1.6 & 1.4 & 0.9 & 1.0 & 0.8 \\
50 & 2.2 & 1.9 & 1.9 & 1.7 & 1.5 & 1.2 & 2.0 & 1.6 \\
Sub-mean & 2.9 & 1.9 & 2.3 & 1.7 & 1.9 & 1.3 & 2.5 & 1.7 \\
\hline 13 Mean & 2.9 & 2.0 & 2.4 & 1.8 & 1.9 & 1.4 & 2.4 & 1.7
\end{tabular}


TABLE 6

ONE-HUNDRED PERCENT AND NINETY PERCENT OVERALL AND PANEL RANGES - OVERLAY PAVEMENT SECTIONS

\begin{tabular}{|c|c|c|c|c|c|c|c|c|}
\hline \multirow[t]{2}{*}{$\begin{array}{l}\text { Pavement } \\
\text { Section }\end{array}$} & \multicolumn{2}{|c|}{$\begin{array}{c}\text { Overall } \\
\text { Range }\end{array}$} & \multicolumn{2}{|c|}{$\begin{array}{l}\text { ISHC } \\
\text { Panel }\end{array}$} & \multicolumn{2}{|c|}{$\begin{array}{l}\text { Purdue } \\
\text { Panel }\end{array}$} & \multicolumn{2}{|c|}{$\begin{array}{l}\text { Laymen } \\
\text { Panel }\end{array}$} \\
\hline & $100 \%$ & $90 \%$ & $100 \%$ & $90 \%$ & $100 \%$ & $90 \%$ & $100 \%$ & $90 \%$ \\
\hline 2 & 2.6 & 2.1 & 1.8 & 1.6 & 2.0 & 1.6 & 1.8 & 1.4 \\
\hline 5 & 3.3 & 2.9 & 3.2 & 2.6 & 2.3 & 1.1 & 2.3 & 1.3 \\
\hline 6 & 3.5 & 3.1 & 3.5 & 2.6 & 2.8 & 1.6 & 2.2 & 2.0 \\
\hline 8 & 2.5 & 1.9 & 2.3 & 1.4 & 2.2 & 1.4 & 1.6 & 1.1 \\
\hline 10 & 3.5 & 2.1 & 2.6 & 1.9 & 2.7 & 1.7 & 1.8 & 1.5 \\
\hline 11 & 2.0 & 1.5 & 1.8 & 1.5 & 1.8 & 1.3 & 1.7 & 1.4 \\
\hline 12 & 3.0 & 1.6 & 1.9 & 1.7 & 2.6 & 1.5 & 2.3 & 2.0 \\
\hline 13 & 2.1 & 1.9 & 2.1 & 1.8 & 1.8 & 1.3 & 1.7 & 1.2 \\
\hline 14 & 3.1 & 2.3 & 3.1 & 2.6 & 1.7 & 0.9 & 2.5 & 1.9 \\
\hline 15 & 3.2 & 2.2 & 3.2 & 2.6 & 1.3 & 1.2 & 2.3 & 1.2 \\
\hline 16 & 2.9 & 1.6 & 2.9 & 1.6 & 1.2 & 1.0 & 2.1 & 1.8 \\
\hline 25 & 2.6 & 2.0 & 1.9 & 1.7 & 2.1 & 1.9 & 2.5 & 1.3 \\
\hline 26 & 2.2 & 1.9 & 1.7 & 1.6 & 2.2 & 1.6 & 2.2 & 1.9 \\
\hline 29 & 2.2 & 1.7 & 2.0 & 1.6 & 2.0 & 1.2 & 1.7 & 1.2 \\
\hline 31 & 3.5 & 2.2 & 3.5 & 1.6 & 2.0 & 1.6 & 2.9 & 1.9 \\
\hline 34 & 2.4 & 2.0 & 2.3 & 2.0 & 2.3 & 1.9 & 1.8 & 1.5 \\
\hline 36 & 2.7 & 2.1 & 2.0 & 1.8 & 1.9 & 1.7 & 2.6 & 2.1 \\
\hline 38 & 3.1 & 2.2 & 1.8 & 1.7 & 1.9 & 1.7 & 2.9 & 2.4 \\
\hline 42 & 1.9 & 1.2 & 1.6 & 1.0 & 1.2 & 1.0 & 1.7 & 1.4 \\
\hline 43 & 4.2 & 2.6 & 2.8 & 1.8 & 2.2 & 1.8 & 4.2 & 2.4 \\
\hline 52 & 3.7 & 2.0 & 3.7 & 2.0 & 1.5 & 1.0 & 2.8 & 1.9 \\
\hline 58 & 2.0 & 1.7 & 2.0 & 1.7 & 0.9 & 0.7 & 2.0 & 1.8 \\
\hline Sub-mean & 2.8 & 2.0 & 2.4 & 1.8 & 1.9 & 1.4 & 2.3 & 1.7 \\
\hline Overall Mear & n 2.9 & 2.0 & 2.4 & 1.8 & 1.9 & 1.4 & 2.4 & 1.7 \\
\hline
\end{tabular}


TABLE 7

ONE-HUNDRED PERCENT AND NINETY PER CENT OVERALL AND PANEL RANGES - FLEXIBLE PAVEMENT SECTIONS

\begin{tabular}{ccccccccc}
\hline $\begin{array}{c}\text { Pavement } \\
\text { Section }\end{array}$ & \multicolumn{2}{c}{$\begin{array}{c}\text { Overall } \\
\text { Range }\end{array}$} & \multicolumn{2}{c}{$\begin{array}{c}\text { ISHC } \\
\text { Panel }\end{array}$} & \multicolumn{2}{c}{$\begin{array}{c}\text { Purdue } \\
\text { Panel }\end{array}$} & \multicolumn{2}{c}{$\begin{array}{c}\text { Paymen } \\
\text { Panel }\end{array}$} \\
\hline 3 & $100 \%$ & $90 \%$ & $100 \%$ & $90 \%$ & $100 \%$ & $90 \%$ & $100 \%$ & $90 \%$ \\
\hline 9 & 2.4 & 1.9 & 2.2 & 2.0 & 1.9 & 1.2 & 2.2 & 1.5 \\
20 & 3.1 & 1.4 & 2.6 & 1.4 & 1.6 & 1.0 & 2.9 & 1.8 \\
24 & 2.2 & 2.0 & 2.0 & 1.5 & 2.1 & 1.6 & 3.0 & 2.0 \\
27 & 2.1 & 1.7 & 2.0 & 1.6 & 1.3 & 1.0 & 2.0 & 1.6 \\
30 & 3.3 & 2.5 & 3.1 & 2.2 & 2.1 & 1.8 & 3.2 & 2.2 \\
32 & 3.2 & 2.1 & 3.0 & 2.2 & 3.2 & 2.3 & 1.8 & 1.5 \\
33 & 2.2 & 1.5 & 2.2 & 1.4 & 1.4 & 1.2 & 1.5 & 1.1 \\
35 & 4.3 & 2.5 & 2.0 & 1.7 & 2.4 & 2.1 & 4.3 & 1.8 \\
37 & 2.0 & 1.2 & 1.5 & 1.3 & 1.4 & 1.1 & 1.4 & 1.2 \\
39 & 3.3 & 2.3 & 3.3 & 2.7 & 2.3 & 2.0 & 2.1 & 1.8 \\
40 & 3.0 & 2.4 & 2.8 & 2.3 & 2.1 & 1.4 & 2.9 & 1.8 \\
41 & 2.4 & 1.6 & 1.6 & 1.2 & 1.3 & 0.8 & 1.5 & 1.3 \\
44 & 2.0 & 1.4 & 2.0 & 1.3 & 1.7 & 1.4 & 1.4 & 1.3 \\
48 & 3.4 & 2.4 & 2.7 & 1.8 & 1.6 & 1.3 & 2.9 & 2.3 \\
51 & 3.8 & 2.4 & 3.8 & 3.0 & 2.0 & 1.5 & 2.8 & 2.1 \\
53 & 2.4 & 1.9 & 2.4 & 1.8 & 1.6 & 0.9 & 2.3 & 1.9 \\
55 & 3.0 & 2.3 & 3.0 & 1.6 & 2.0 & 1.3 & 2.0 & 1.3 \\
Sub-mean & 2.9 & 2.0 & 2.5 & 1.8 & 1.9 & 1.4 & 2.4 & 1.7 \\
& 3.7 & 2.1 & 2.4 & 1.2 & 1.3 & 1.2 & 3.7 & 2.7 \\
& 2.9 & 2.0 & 2.4 & 1.8 & 1.9 & 1.4 & 2.4 & 1.7
\end{tabular}


smallest 100 and 90 per cent mean ranges, while the ranges of the ISHC and Laymen panelswere similar.

The widely varying concepts of serviceability by highway authorities is evidenced when one compares the individual serviceability ratings and priority rankings. Raters \#1, 2, and 9 of the ISHC panel were selected at random. They were not the most variable persons in the ISHC panel, neither were they the least variable. Raters \#I and 9 are maintenance engineers; rater \#2 is a planning engineer. The individual serviceability ratings and priority rankings of these three "highway authorfties" are presented in Tables 8,9 , and 10 for the rigid, overlay, and flexible pavement sections, respectively. The priority ranks are based on the individual serviceability ratings; i.e., the lower the serviceability rating, the higher the maintenance or reconstruction priority.

Therefore, if rater \#1, a maintenance engineer, were to deternine the maintenance program for the nineteen flexible pavement sections (see Table 10), pavement sections $48,41,27$, and 37 would be the first four sections to be improved. However, if rater \#9, also a maintenance engineer, were to determine the maintenance program, pavement sections 27 , 41, 55, and 48 or 3 would be the first four sections to be improved. Section 37, which was ranked number four by rater \#1, would be number ten on the priority list of rater \#9. Rater \#2 agrees with rater \#1 that section 48 should receive top priority and ranks sections 55,40 , and 53 as the next three to be improved. However, he ranks sections 41,27 , and 37: seventh, fifth, and tenth, respectively.

The Individual serviceability ratings also vary widely. Section 48 , which is ranked number one by both rater $\# 1$ and 2 , is given a 2.1 serviceability rating by rater \#1 and a 0.9 serviceability rating by rater \#2. 
TABLE 8

COMPARISON OF INDIVIDUAL PRIORITY RANKINGS AND SERVICEABIIITY RATINGS OF THREE RATERS - RIGID PAVEMENT SECTIONS

\begin{tabular}{|c|c|c|c|c|c|c|}
\hline \multirow{2}{*}{$\begin{array}{l}\text { Pavement } \\
\text { Section }\end{array}$} & \multicolumn{2}{|c|}{ Rater \#1 } & \multicolumn{2}{|c|}{ Rater \#2 } & \multicolumn{2}{|c|}{ Rater \#9 } \\
\hline & Rank & Rating & Rank & Rating & Rank & Rating \\
\hline 59 & 1 & 2.2 & 2 & 0.7 & 2 & 0.8 \\
\hline 19 & 2 & 2.5 & 1 & 0.4 & 1 & 0.2 \\
\hline 18 & 2 & 2.5 & 7 & 1.7 & 4 & 1.5 \\
\hline 17 & 2 & 2.5 & 4 & 1.0 & 4 & 1.5 \\
\hline 4 & 5 & 2.8 & 9 & 2.2 & 9 & 2.7 \\
\hline 60 & 6 & 3.3 & 6 & 1.3 & 6 & 2.0 \\
\hline 21 & 6 & 3.3 & 11 & 2.7 & 11 & 3.1 \\
\hline 1 & 8 & 3.8 & 7 & 1.7 & 8 & 2.3 \\
\hline 7 & 8 & 3.8 & 3 & 0.9 & 2 & 0.8 \\
\hline 57 & 10 & 4.0 & 5 & 1.2 & 10 & 3.0 \\
\hline 54 & 10 & 4.0 & 12 & 2.8 & 7 & 2.2 \\
\hline 23 & 12 & 4.2 & 9 & 2.2 & 12 & 3.2 \\
\hline 22 & 13 & 4.6 & 14 & 3.8 & 13 & 3.8 \\
\hline 49 & 14 & 4.7 & 15 & 4.2 & 16 & 4.5 \\
\hline 47 & $u_{4}$ & 4.7 & 16 & $4 \cdot 3$ & 16 & 4.5 \\
\hline 50 & 16 & 4.8 & 17 & 4.4 & 19 & 4.8 \\
\hline 28 & 16 & 4.8 & 13 & 3.6 & 14 & 4.1 \\
\hline 45 & 18 & 4.9 & 18 & 4.7 & 16 & 4.5 \\
\hline 46 & 18 & 4.9 & 19 & 4.8 & 15 & 4.2 \\
\hline
\end{tabular}


TABLE 9

COMPARISON OF INDIVIDUAL PRIORITY RANKINGS AND SERVICEABILITY RATINGS OF THREE RATERS - OVERLAY PAVEMENT SECTIONS

\begin{tabular}{|c|c|c|c|c|c|c|}
\hline \multirow{2}{*}{$\begin{array}{l}\text { Pavement } \\
\text { Section }\end{array}$} & \multicolumn{2}{|c|}{ Rater \#I } & \multicolumn{2}{|c|}{ Rater \#2 } & \multicolumn{2}{|c|}{ Rater \#9 } \\
\hline & Rank & Rating & Rank & Rating & Rank & Rating \\
\hline 2 & 1 & 2.2 & 4 & 1.5 & 9 & 2.8 \\
\hline 42 & 2 & 2.4 & 7 & 2.1 & 9 & 2.8 \\
\hline 16 & 3 & 3.0 & 2 & 1.4 & 5 & 1.8 \\
\hline 43 & 4 & 3.2 & 7 & 2.1 & 3 & 1.0 \\
\hline 38 & 5 & 3.3 & 15 & 3.5 & 5 & 1.8 \\
\hline 10 & 6 & 3.8 & 11 & 3.1 & 9 & 2.8 \\
\hline 15 & 7 & 3.9 & 5 & 1.6 & 4 & 1.3 \\
\hline 5 & 8 & 4.0 & 2 & 1.4 & 1 & 0.8 \\
\hline 14 & 9 & 4.1 & 1 & 1.3 & 8 & 2.4 \\
\hline 6 & 9 & 4.1 & 6 & 1.7 & $I$ & 0.8 \\
\hline 34 & II & $4 \cdot 3$ & 12 & 3.2 & 12 & 3.0 \\
\hline 8 & 11 & $4 \cdot 3$ & 12 & 3.2 & 7 & 2.1 \\
\hline 52 & 13 & $4 \cdot 5$ & 17 & 4.1 & 28 & 4.0 \\
\hline 25 & 13 & $4 \cdot 5$ & 14 & 3.4 & 18 & 4.0 \\
\hline 13 & 13 & 4.5 & 9 & 2.7 & 15 & 3.5 \\
\hline 29 & 16 & $4 \cdot 6$ & 20 & $4 \cdot 5$ & 13 & 3.2 \\
\hline 36 & 16 & 4.6 & 21 & 4.8 & 17 & 3.8 \\
\hline 58 & 16 & 4.6 & 19 & $4 \cdot 3$ & 22 & $4 \cdot 7$ \\
\hline 12 & 16 & 4.6 & 10 & 3.0 & 14 & 3.4 \\
\hline 26 & 20 & $4 \cdot 7$ & 16 & 3.8 & 16 & 3.7 \\
\hline 11 & 21 & 4.8 & 17 & $4 \cdot 1$ & 18 & 4.0 \\
\hline 31 & 22 & 4.9 & 21 & 4.8 & 18 & 4.0 \\
\hline
\end{tabular}


TABLE 10

COMPARISON OF INDIVIDUAL PRIORITY RANKINGSAND SERVICEABILITY RATINGS OF THREE RATERS - FLEXI BLE PAVEMTENT SECTIONS

\begin{tabular}{|c|c|c|c|c|c|c|}
\hline \multirow{2}{*}{$\begin{array}{l}\text { Pavement } \\
\text { Section }\end{array}$} & \multicolumn{2}{|c|}{ Rater \#1 } & \multicolumn{2}{|c|}{ Rater $\# 2$} & \multicolumn{2}{|c|}{ Rater \#3 } \\
\hline & Rank & Rating & Rank & Rating & Rank & Rating \\
\hline 48 & 2 & 2.1 & 1 & 0.9 & 4 & 1.5 \\
\hline 41 & 1 & 2.1 & 7 & 2.1 & 2 & 1.0 \\
\hline 27 & 3 & 2.2 & 5 & 1.8 & 1 & 0.5 \\
\hline 37 & 4 & 2.5 & 10 & 2.7 & 10 & 2.0 \\
\hline 3 & 5 & 3.2 & 8 & 2.5 & 4 & 1.5 \\
\hline 53 & 6 & 3.3 & 4 & 1.5 & 9 & 1.9 \\
\hline 40 & 7 & 3.5 & 3 & 1.3 & 7 & 1.8 \\
\hline 35 & 7 & 3.5 & 14 & 3.5 & 7 & 1.8 \\
\hline 24 & 7 & 3.5 & 15 & 3.8 & 17 & 4.0 \\
\hline 20 & 10 & 3.8 & 11 & 2.9 & 14 & 3.1 \\
\hline 55 & 11 & 4.0 & 2 & 1.2 & 2 & 1.0 \\
\hline 30 & 12 & 4.1 & 13 & 3.2 & 12 & 3.0 \\
\hline 9 & 13 & 4.2 & 5 & 1.8 & 6 & 1.7 \\
\hline 56 & 14 & 4.3 & 12 & 3.1 & 14 & 3.1 \\
\hline 52 & 14 & 4.3 & 8 & 2.5 & 12 & 3.0 \\
\hline 39 & 16 & 4.4 & 15 & 3.8 & 11 & 2.2 \\
\hline 44 & 17 & 4.8 & 17 & 4.1 & 17 & 4.0 \\
\hline 32 & 18 & 4.9 & 18 & 5.0 & 14 & 3.1 \\
\hline 33 & 18 & 4.9 & 18 & 5.0 & 19 & 4.1 \\
\hline
\end{tabular}


Rater \#9, who ranked section 48 fourth, gives it a 1.5 serviceability rating.

It is apparent that altogether different priority and maintenance programs would result if they were determined by different individuals.

\section{Number of Raters Required to Estimate the "True" Rating}

The panel evaluation method minimizes the varability in serviceability ratings and priority rankings of pavement sections by individuals. In this method, members of a rating panel individually rate a pavement section, and the mean of the individual ratings is the PSR of the section.

The following equation was used to estimate the number of raters that would be required to estimate the "true" rating of any pavement section:

$$
N=\frac{t^{2} s^{2}}{d^{2}}
$$

where,

$$
\begin{aligned}
& t^{2}=t_{a / 27}^{2} d \cdot f . \\
& d^{2}=\text { interval squared } \\
& s^{2}=\text { variance of } \bar{Y}_{(i) j k}
\end{aligned}
$$

An unbiased estimate of the variance $\left(s^{2}=0.658\right)$ was obtained from the estimated variance components of the previously discussed ANOV. The model used in the estimation of the variance is presented in Appendix $B$. The number of raters required at the 0.05 and 0.10 levels of probability to rate a section within deviations ranging from 0.3 to 1.0 of the "true" rating are shown in Table 11. 
TABLE 11

NUMBER OF RATERS REQUIRED TO ESTIMATE THE "TRUE" RATING RATING PANEL EVALUATION METHOD

\begin{tabular}{ccc}
\hline Permissible Error & \multicolumn{2}{c}{ Probability Level } \\
\hline 0.3 & 0.05 & 0.10 \\
0.4 & 31 & 21 \\
0.5 & 17 & 12 \\
0.6 & 11 & 8 \\
0.7 & 8 & 5 \\
0.8 & 6 & 4 \\
0.9 & 4 & 3 \\
1.0 & 3 & 2
\end{tabular}

A typical panel study, unlike this study which utilized a total of thirty raters and three panels, would use only one rating panel. The number of raters within the rating panel would depend on the accuracy and level of probability desired. That is, if it were desired that the PSRs of the pavement sections be within 0.5 of the "true" ratings of the section 95 per cent of the time, eleven raters would be required. The 0.05 level of probability states that the chances are nineteen out of twenty that the PSRs will deviate less than or will be equal to 0.5 from the "true" rating.

Evaluation of the Rating Panel Method As noted previously, there was a difference between the ratings and rankings of raters $\# 1,2$, and 9 of the ISHC. By combining the ratings of these three men and referring to Table $I 1$ one can note that the chances 
are nineteen out of twenty that the mean serviceability ratings of the three men will deviate less than or will be equal to 0.9 from the "true" ratings, and nine out of ten that the mean serviceablitity ratings will deviate less than or will be equal to 0.8 from the "true" ratings. Moreover, If we utilize the mean serviceability ratings of all ten ISHC raters we are informed that the chances are better than eighteen out of twenty that the mean serviceability ratings will deviate less than or will be equal to 0.5 from the "true" ratings.

The individual ratings of raters $\# 1,2$, and 9 , the mean ratings of the three raters, the ISHC panel ratings, and the "true" ratings are presented in Tables 12, 13, and 14 for the rigid, overlay, and flexible pavement sections, respectively. The deviations from the "true" ratings and priority rankings are also presented. As previously noted, in the present study the mean of the thirty individual serviceability ratings is assumed to be the "true" rating of a section. The individual ratings of the three selected raters and the ISHC panel ratings are also represented in the "true" ratings.

Of the sixty ISHC panel serviceability ratings not one deviated 0.5 from the "true" and only two deviated 0.4 from the "true". Of the sixty ratings made by the selected threo-member-panel only one deviated 0.8 from the "true" and one deviated 0.9 from the "true". Of rater H1's sixty ratings twenty-three deviated 1.0 or greater from the "true", while seventeen of rater $\# 2$ 's ratings and sixteen of rater $\# 9$ 's ratings deviated 1.0 or greater from the "true".

There is a marked difference between the mean absolute deviations of the panels and of the selected individuals. The mean absolute deviation of the ISHC panel for the rigid pavement sections was 0.111 , and the 


\begin{tabular}{|c|c|c|c|c|c|c|c|}
\hline \multirow{2}{*}{$\begin{array}{l}\text { Pavement } \\
\text { Section }\end{array}$} & \multirow{2}{*}{30 Raters } & \multicolumn{6}{|c|}{ Priority Rankings } \\
\hline & & 10 Raers & 10 Raters & 3 Raters & H1 & $\$ 2$ & 19 \\
\hline 59 & 1.1 & . & 2 & 2 & 1 & 2 & 2 \\
\hline 19 & 1.4 & 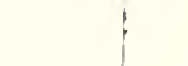 & 1 & 1 & 2 & 1 & 1 \\
\hline 17 & 2.3 & ? & 3 & 3 & 2 & 4 & 4 \\
\hline 60 & 2.4 & $p$ & 3 & 6 & 6 & 6 & 6 \\
\hline 7 & 2.4 & . & 5 & 4 & 8 & 3 & 2 \\
\hline 4 & 2.5 & , & 5 & 7 & 5 & 9 & 9 \\
\hline 18 & 2.6 & ' & 5 & 5 & 2 & 7 & 4 \\
\hline 1 & 2.7 & 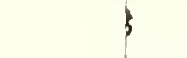 & 8 & 7 & 8 & 7 & 8 \\
\hline 57 & 2.9 & l & 9 & 9 & 10 & 5 & 10 \\
\hline 21 & 3.1 & 1 & 10 & 10 & 6 & 11 & 11 \\
\hline 54 & 3.2 & . & 12 & 10 & 10 & 12 & 7 \\
\hline 23 & 3.4 & ? & 11 & 12 & 12 & 9 & 12 \\
\hline 28 & 3.9 & 3 & 14 & 14 & 16 & 13 & 14 \\
\hline 22 & 4.0 & , & 13 & 13 & 13 & 14 & 13 \\
\hline 49 & 4.1 & 5 & 15 & 15 & 14 & 15 & 16 \\
\hline 47 & 4.2 & 3 & 17 & 15 & 14 & 16 & 16 \\
\hline 50 & 4.2 & 3 & 16 & 18 & 16 & 17 & 19 \\
\hline 45 & 4.4 & 3 & 17 & 18 & 18 & 18 & 16 \\
\hline 46 & 4.5 & 3 & 19 & 17 & 18 & 19 & 15 \\
\hline & To & $\begin{array}{l}\text { otal Af } \\
\text { Mean Ak }\end{array}$ & & & & & \\
\hline
\end{tabular}


TABLE 12

COMPARISON OF SERVICEABILITY RATINGS AND PRIORITY RANKINGS

OF THIRTY, TEN, AND THREE MGMBER RATING PANELS AND INDIVIDUALS

RIGID PAVEMENT SECTIONS

\begin{tabular}{|c|c|c|c|c|c|c|c|c|c|c|c|c|c|c|c|c|c|}
\hline \multirow{2}{*}{$\begin{array}{l}\text { Pavoment } \\
\text { Section } \\
\end{array}$} & \multirow{2}{*}{\multicolumn{11}{|c|}{$\begin{array}{l}\text { Serviceabillity Ratinge } \\
0 \text { Raters } 10 \text { Raters Deviation } 3 \text { Raters Deviation Rater fl Deviation Rater f/2 Deviation Rater fo Deviation }\end{array}$}} & \multicolumn{6}{|c|}{$\frac{\text { Priority Rankinge }}{30 \text { Ratera }}$} \\
\hline & & & & 3 Raters & Deviation & Rater \#1 & Deviation & Rater $\mathbb{R}^{2}$ & Deviation & Reter & Deviation & 30 Raters & 10 Katers & 3 Ratere & $\pi 1$ & $\$ 2$ & 19 \\
\hline 59 & 1.2 & 1.4 & +0.3 & 2.2 & +0.1 & 2.2 & +1.1 & 0.7 & -0.4 & 0.8 & -0.3 & 1 & 2 & 2 & 2 & 2 & 2 \\
\hline 19 & 1.4 & 1.3 & -0.1 & 1.0 & -0.4 & 2.5 & +1.1 & 0.4 & -2.0 & 0.2 & -1.2 & 2 & 1 & 1 & 2 & 1 & 1 \\
\hline 17 & 2.3 & 2.4 & +0.1 & 1.7 & -0.6 & 2.5 & +0.2 & 1.0 & -1.3 & 1.5 & -0.8 & 3 & 3 & 3 & 2 & 4 & 4 \\
\hline 60 & 2.4 & 2.4 & 0.0 & 2.2 & -0.2 & 3.3 & +0.9 & 1.3 & -1.1 & 2.0 & -0.4 & 4 & 3 & 6 & 6 & 6 & 6 \\
\hline 7 & 2.4 & 2.6 & +0.2 & 1.8 & -0.6 & 3.8 & +2.4 & 0.9 & -1.5 & 0.8 & -1.6 & 4 & 5 & 4 & 8 & 3 & 2 \\
\hline 4 & 2.5 & 2.6 & +0.1 & 2.6 & +0.1 & 2.8 & +0.3 & 2.2 & -0.3 & 2.7 & +0.2 & 6 & 5 & 7 & 5 & 9 & 9 \\
\hline 18 & 2.6 & 2.6 & $0: 0$ & 2.9 & -0.7 & 2.5 & -0.1 & 1.7 & -0.9 & 1.5 & -1.1 & 7 & 5 & 5 & 2 & 7 & 4 \\
\hline 1 & 2.7 & 2.7 & 0.0 & 2.6 & -0.1 & 3.8 & +1.1 & 1.7 & -1.0 & 2.3 & -0.4 & 8 & 8 & 7 & 8 & 7 & 8 \\
\hline 57 & 2.9 & 3.0 & +0.1 & 2.7 & -0.2 & 4.0 & +1.1 & 1.2 & -2.7 & 3.0 & +0.1 & 9 & 9 & 9 & 10 & 5 & 10 \\
\hline 21 & 3.1 & 3.1 & .0 .0 & 3.0 & -0.1 & 3.3 & +0.2 & 2.7 & -0.4 & 3.1 & 0.0 & 10 & 10 & 20 & 6 & 11 & 21 \\
\hline 54 & 3.2 & 3.4 & +0.2 & 3.0 & -0.2 & 4.0 & +0.8 & 2.8 & -0.4 & 2.2 & -1.0 & 11 & 12 & 10 & 10 & 12 & 7 \\
\hline 23 & 3.4 & 3.3 & -0.1 & 3.2 & -0.2 & 4.2 & +0.8 & 2.2 & -1.2 & 3.2 & -0.2 & 12 & 11 & 12 & 12 & 9 & 12 \\
\hline 28 & 3.9 & 4.1 & +0.2 & 4.2 & +0.3 & 4.8 & +0.9 & 3.6 & -0.3 & 4.1 & +0.2 & 13 & 24 & 14 & 16 & 13 & 14 \\
\hline 22 & 4.0 & 3.8 & -0.2 & 4.1 & +0.1 & 4.6 & +0.6 & 3.8 & -0.2 & 3.8 & -0.2 & 24 & 23 & 13 & 13 & 14 & 23 \\
\hline 49 & 4.1 & 4.2 & +0.1 & 4.5 & +0.4 & 4.7 & +0.6 & 4.2 & +0.1 & 4.5 & +0.4 & 15 & 15 & 15 & 14 & 15 & 16 \\
\hline 47 & 402 & 4.4 & $\neq 0.2$ & 4.5 & +0.3 & 4.7 & +0.5 & 4.3 & +0.1 & 4.5 & +0.3 & 16 & 27 & 15 & 14 & 16 & 16 \\
\hline 50 & 4.2 & 4.3 & +0.2 & 4.7 & +0.5 & 4.8 & +0.6 & 4.4 & +0.2 & 4.8 & +0.6 & 16 & 16 & 18 & 16 & 17 & 19 \\
\hline 45 & 4.4 & 4.4 & 0.0 & 4.7 & +0.3 & 4.9 & +0.5 & 4.7 & +0.3 & 4.5 & +0.1 & 18 & 27 & 18 & 18 & 18 & 16 \\
\hline \multirow[t]{3}{*}{46} & 4.5 & 4.6 & +0.1 & 4.6 & +0.1 & 4.9 & +0.4 & 4.8 & +0.3 & 4.2 & -0.3 & 29 & 19 & 17 & 18 & 19 & 15 \\
\hline & & tal Abs. De & vo 2.1 & & 5.5 & & 13.2 & & 12.7 & & 9.4 & & & & & & \\
\hline & & doan Abs. De & $v_{0} \quad 0.111$ & & 0.289 & & 0.695 & & 0.668 & & 0.495 & & & & & & \\
\hline
\end{tabular}




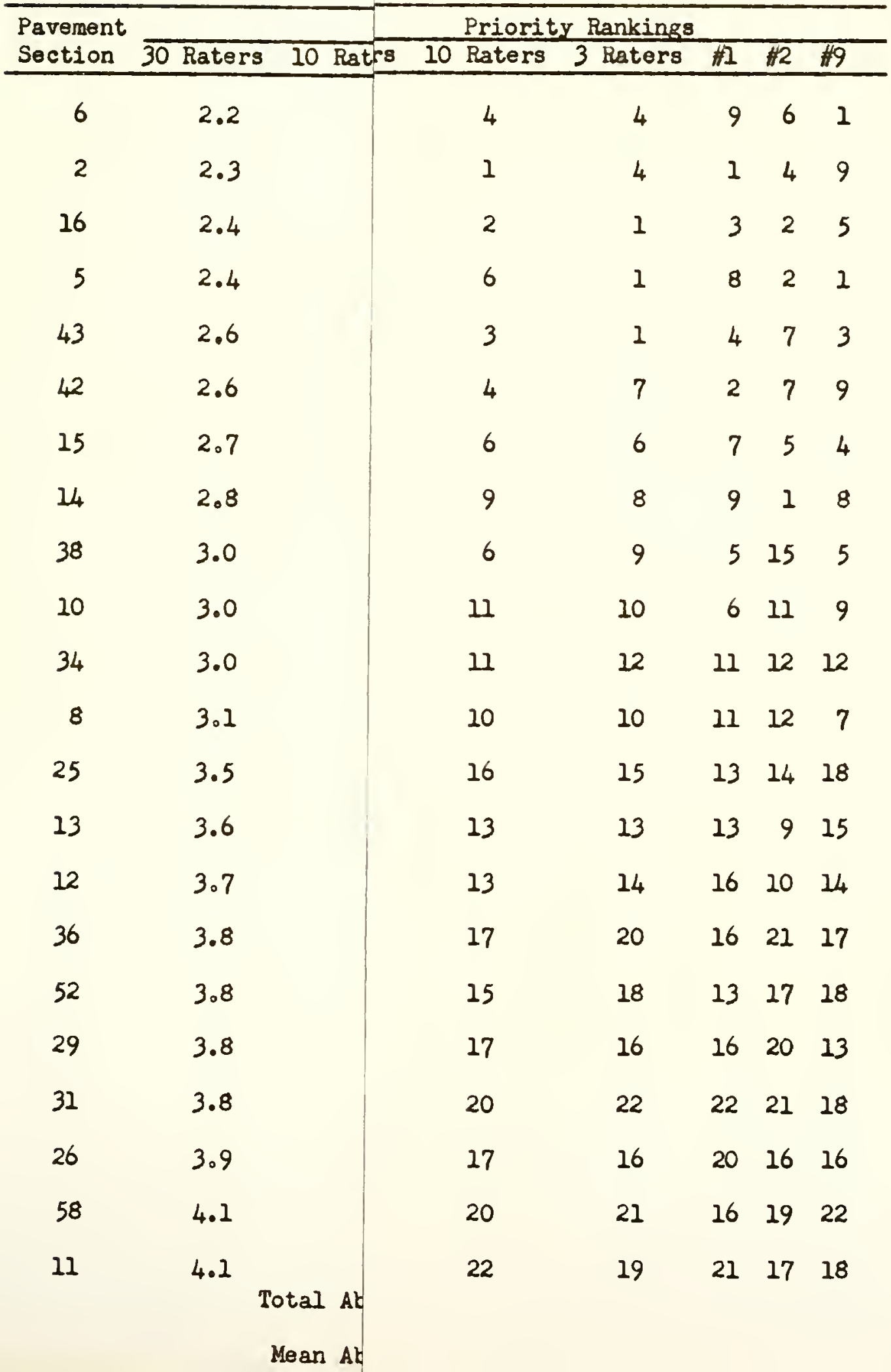




\section{TABLE 13}

COMPARISON OF SERVICEABILITY RATINGS AND PRIORITY RANKINGS

OF THIBTY, TEN, AND THREE MEMBER RATING PANELS AND INDIVIDUALS OVERLAY PAVEMENT SECTIONS

\begin{tabular}{|c|c|c|c|c|c|c|c|c|c|c|c|c|c|c|c|c|c|c|}
\hline \multirow{2}{*}{$\begin{array}{l}\text { Pavement } \\
\text { Section }\end{array}$} & \multirow[b]{2}{*}{30 Raters } & \multirow[b]{2}{*}{10 Ratere } & \multirow[b]{2}{*}{ Deviation } & \multicolumn{8}{|c|}{ Servicoability Ratings } & \multicolumn{7}{|c|}{ Priority Rankings } \\
\hline & & & & 3 Raters & Devietion & Bater fil & Deviation & Rater th & Deviation & Rater th & Devlation & 30 Rater & 10 & Raters & 3 Ratera & h & $\$ 2$ & $\$ 9$ \\
\hline 6 & 2.2 & 2.6 & +0.4 & 2.2 & 0.0 & 4.1 & +1.9 & 1.7 & -0.5 & 0.8 & -1.4 & 1 & & 4 & 4 & 9 & 6 & 1 \\
\hline 2 & 2.3 & 2.0 & -0.3 & 2.2 & -0.1 & 2.2 & -0.1 & 1.5 & -0.8 & 2.8 & $\neq 0.5$ & 2 & & 1 & 4 & 1 & 4 & 9 \\
\hline 16 & 2.4 & 2.4 & 0.0 & 2.1 & -0.3 & 3.0 & +0.6 & 1.4 & -1.0 & 1.8 & -0.6 & 3 & & 2 & 1 & 3 & 2 & 5 \\
\hline 5 & 2.4 & 2.7 & +0.3 & 2.1 & -0.3 & 4.0 & +1.6 & 1.4 & -1.0 & 0.8 & -1.6 & 3 & & 6 & 1 & 8 & 2 & 1 \\
\hline 43 & 2.6 & 2.5 & -0.1 & 2.1 & -0.5 & 3.2 & +0.6 & 2.1 & -0.5 & 1.0 & -1.6 & 5 & & 3 & 1 & 4 & 7 & 3 \\
\hline 42 & 2.6 & 2.6 & 0.0 & 2.4 & -0.2 & 2.4 & -0.2 & 2.1 & -0.5 & 2.8 & +0.2 & 5 & & 4 & 7 & 2 & 7 & 9 \\
\hline 15 & 2.7 & 2.7 & 0.0 & 2.3 & -0.4 & 3.9 & +1.2 & 1.6 & -1.1 & 1.3 & -1.4 & 7 & & 6 & 6 & 7 & 5 & 4 \\
\hline 14 & 2.8 & 2.9 & +0.1 & 2.6 & -0.2 & 4.1 & +1.3 & 1.3 & -1.5 & 2.4 & -0.4 & 8 & & 9 & 8 & 9 & 1 & 8 \\
\hline 38 & 3.0 & 2.7 & -0.3 & 2.9 & -0.1 & 3.3 & +0.3 & 3.5 & $\neq 0.5$ & 1.8 & -1.2 & 9 & & 6 & 9 & 5 & 15 & 5 \\
\hline 10 & 3.0 & 3.1 & +0.1 & 3.2 & +0.2 & 3.8 & +0.8 & 3.1 & +0.1 & 2.8 & -0.2 & 9 & & 11 & 10 & 6 & 11 & 9 \\
\hline 34 & 3.0 & 3.1 & +0.1 & 3.5 & +0.5 & 4.3 & +1.3 & 3.2 & +0.2 & 3.0 & 0.0 & 9 & & 11 & 12 & 11 & 12 & 12 \\
\hline 8 & 3.1 & 3.0 & -0.1 & 3.2 & $\neq 0.1$ & 4.3 & +1.2 & 3.2 & $\neq 0.1$ & 2.1 & -1.0 & 12 & & 10 & 10 & 11 & 12 & 7 \\
\hline 25 & 3.5 & 3.8 & +0.3 & 4.0 & +0.5 & 4.5 & +1.0 & 3.4 & -0.1 & 4.0 & +0.5 & 13 & & 16 & 15 & 13 & 14 & 18 \\
\hline 13 & 3.6 & 3.6 & 0.0 & 3.6 & 0.0 & 4.5 & +0.9 & 2.7 & -0.9 & 3.5 & -0.1 & 14 & & 13 & 13 & 13 & 9 & 15 \\
\hline 12 & 3.7 & 3.6 & -0.1 & 3.7 & 0.0 & 4.6 & +0.9 & 3.0 & -0.7 & 3.4 & -0.3 & 15 & & 13 & 14 & 16 & 10 & 14 \\
\hline 36 & 3.8 & 3.9 & +0.1 & 4.4 & +0.6 & 4.6 & +0.8 & 4.8 & +1.0 & 3.8 & 0.0 & 16 & & 17 & 20 & 16 & 21 & 17 \\
\hline 52 & 3.8 & 3.7 & -0.1 & 4.2 & +0.4 & 4.5 & +0.7 & 4.1 & +0.3 & 4.0 & +0.2 & 16 & & 15 & 18 & 13 & 17 & 18 \\
\hline 29 & 3.8 & 3.9 & $\neq 0.1$ & 4.1 & $\neq 0.3$ & 4.6 & +0.8 & 4.5 & +0.7 & 3.2 & -0.6 & 16 & & 17 & 16 & 16 & 20 & 13 \\
\hline 31 & 3.8 & 4.0 & +0.2 & 4.6 & +0.8 & 4.9 & +1.1 & 4.8 & +1.0 & 4.0 & +0.2 & 16 & & 20 & 22 & 22 & 21 & 18 \\
\hline 26 & 3.9 & 3.9 & 0.0 & 4.1 & +0.2 & 4.7 & +0.8 & 3.8 & -0.1 & 3.7 & -0.2 & 20 & & 17 & 16 & 20 & 16 & 16 \\
\hline 58 & 4.1 & 4.0 & -0.1 & 4.5 & +0.4 & 4.6 & +0.5 & 4.3 & +0.2 & 4.7 & +0.6 & 21 & & 20 & 21 & 16 & 19 & 22 \\
\hline 11 & 4.1 & $\begin{array}{l}4.1 \\
\text { Total Abs. }\end{array}$ & Dev. $\frac{0.0}{2.8}$ & 4.3 & $\frac{+0.2}{6.3}$ & 4.8 & $\frac{+0.7}{19.3}$ & 4.1 & $\frac{0.0}{12.8}$ & 4.0 & $\frac{-0.1}{12.9}$ & 21 & & 22 & 19 & 21 & 17 & 18 \\
\hline & & Mean Abs. & Dev. 0.127 & & 0.286 & & 0.877 & & 0.582 & & 0.586 & & & & & & & \\
\hline
\end{tabular}




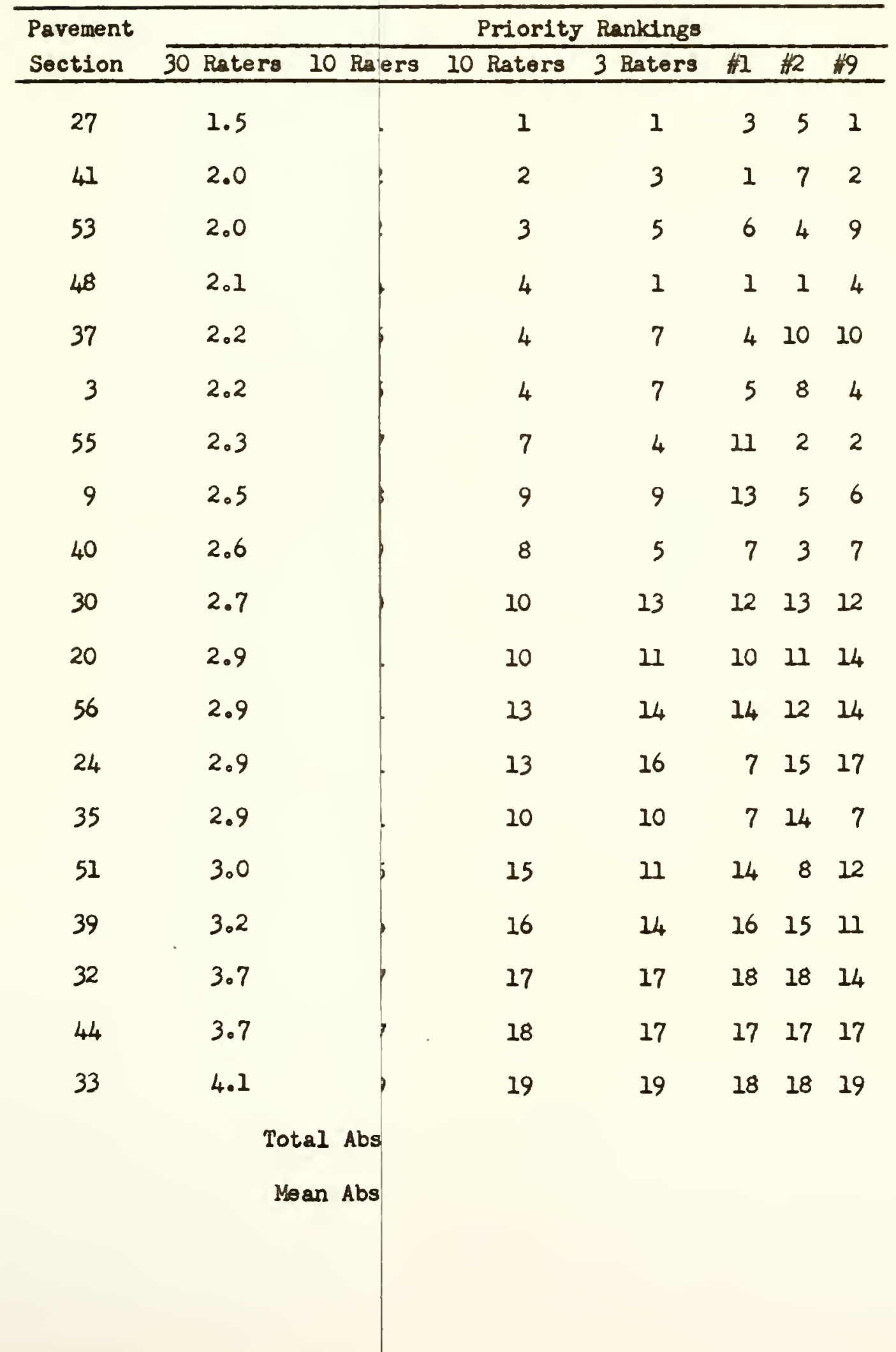


TABLE, 14

COMPARISON OP SERVICEABILITY RATINGS AND PRIORITY RANKINGS

OF THIRTY, TELN, AND THREE MEMBER RATTNG PANELS AND INDIVIDUALS

FLEXIBLE PAVEMENT SECTIONS

\begin{tabular}{|c|c|c|c|c|c|c|c|c|c|c|c|c|c|c|c|c|c|c|}
\hline \multirow{2}{*}{$\begin{array}{l}\text { Pavement } \\
\text { Sootion }\end{array}$} & \multicolumn{12}{|c|}{ Servicoebillty Ratinge } & \multicolumn{6}{|c|}{ Prlority Rankings } \\
\hline & 30 Ratera & 10 & Ratere & Doviation & 3 Raters & Deviation & Rater \#1 & Deviation & Rater $\$ 2$ & Devietion & Rater 49 & Deviation & 30 Ratere & 10 Ratsrs & 3 Ratera & 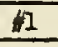 & 12 & $\$ 9$ \\
\hline 27 & 1.5 & & 1.3 & -0.2 & 1.5 & 0.0 & 2.2 & +0.7 & 1.8 & +0.3 & 0.5 & -1.0 & 1 & 1 & 1 & 3 & 5 & 1 \\
\hline 41 & 2.0 & & 1.6 & -0.4 & 1.7 & -0.3 & 2.1 & +0.1 & 2.1 & $\neq 0.1$ & 1.0 & -1.0 & 2 & 2 & 3 & 1 & 7 & 2 \\
\hline 53 & 2.0 & & 1.8 & -0.2 & 2.2 & $\neq 0.2$ & 3.3 & +1.3 & 1.5 & -0.5 & 1.9 & -0.1 & 2 & 3 & 5 & 6 & 4 & 9 \\
\hline 48 & 2.1 & & 2.1 & 0.0 & 1.5 & -0.6 & 2.1 & 0.0 & 0.9 & -1.2 & 1.5 & -0.6 & 4 & 4 & 1 & 1 & 1 & 4 \\
\hline 37 & 2.2 & & 2.1 & -0.1 & 2.4 & $\neq 0.2$ & 2.5 & $\neq 0.3$ & 2.7 & $\neq 0.5$ & 2.0 & -0.2 & 5 & 4 & 7 & 4 & 10 & 10 \\
\hline 3 & 2.2 & & 2.1 & -0.1 & 2.4 & +0.2 & 3.2 & $\neq 1.0$ & 2.5 & $\neq 0.3$ & 1.5 & -0.7 & 5 & 4 & 7 & 5 & 8 & 4 \\
\hline 55 & 2.3 & & 2.2 & -0.1 & 2.1 & -0.2 & 4.0 & +1.7 & 1.2 & -1.1 & 1.0 & -1.3 & 7 & 7 & 4 & 11 & 2 & 2 \\
\hline 9 & 2.5 & & 2.5 & 0.0 & 2.6 & $\neq 0.1$ & 4.2 & +1.7 & 1.8 & -0.7 & 1.7 & -0.8 & 8 & 9 & 9 & 13 & 5 & 6 \\
\hline 40 & 2.6 & & 2.3 & -0.3 & 2.2 & -0.4 & 3.5 & +0.9 & 1.3 & -1.3 & 1.8 & -0.8 & 9 & 8 & 5 & 7 & 3 & 7 \\
\hline 30 & 2.7 & & 2.7 & 0.0 & 3.4 & +0.7 & 4.1 & +1.4 & 3.2 & +0.5 & 3.0 & +0.3 & 10 & 10 & 13 & 12 & 13 & 12 \\
\hline 20 & 2.9 & & 2.7 & -0.2 & 3.3 & +0.4 & 3.8 & +0.9 & 2.9 & 0.0 & 3.1 & $f 0.2$ & 11 & 10 & 11 & 10 & 11 & 14 \\
\hline 56 & 2.9 & & 2.8 & -0.1 & 3.5 & +0.6 & 4.3 & +1.4 & 3.1 & +0.2 & 3.1 & +0.2 & 11 & 13 & 14 & 14 & 12 & 14 \\
\hline 24 & 2.9 & & 2.8 & -0.1 & 3.8 & +0.9 & 3.5 & +0.6 & 3.8 & $\neq 0.9$ & 4.0 & +1.1 & 11 & 13 & 16 & 7 & 15 & 17 \\
\hline 35 & 2.9 & & 2.7 & -0.2 & 2.9 & 0.0 & 3.5 & +0.6 & 3.5 & +0.6 & 1.8 & -1.1 & 11 & 10 & 10 & 7 & 14 & 7 \\
\hline 51 & 3.0 & & 2.9 & -0.1 & 3.3 & +0.3 & 4.3 & +1.3 & 2.5 & -0.5 & 3.0 & 0.0 & 15 & 15 & 11 & $u_{4}$ & 8 & 12 \\
\hline 39 & 3.2 & & 3.2 & 0.0 & 3.5 & +0.3 & 4.4 & +1.2 & 3.8 & +0.6 & 2.2 & -1.0 & 16 & 16 & 14 & 16 & 15 & 11 \\
\hline 32 & 3.7 & & 3.5 & -0.2 & 4.3 & +0.6 & 4.9 & +1.2 & 5.0 & $f 1.3$ & 3.1 & -0.6 & 17 & 17 & 17 & 18 & 18 & 14 \\
\hline 44 & 3.7 & & 3.7 & 0.0 & 4.3 & +0.6 & 4.8 & +1.1 & 4.1 & +0.4 & 4.0 & +0.3 & 17 & 18 & 17 & 17 & 17 & 17 \\
\hline \multirow[t]{3}{*}{33} & 4.1 & & 4.1 & 0.0 & 4.7 & +0.6 & 4.9 & $\neq 0.8$ & 5.0 & +0.9 & 4.1 & 0.0 & 19 & 19 & 19 & 18 & 18 & 19 \\
\hline & Tot & & Abs. Dev & - .2 .3 & & 7.2 & & 18.2 & & 11.9 & & 11.3 & & & & & & \\
\hline & Mo & an $A$ & bs. Dev & 0.121 & & 0.379 & & 0.958 & & 0.626 & & 0.595 & & & & . & & \\
\hline
\end{tabular}


mean absolute deviation of the three-rater panel was 0.289 . Whereas, the mean absolute deviations were $0.695,0.668$, and 0.495 for raters \#1,2, and 9 , respectively.

The ISHC panel priority ranking of the three types of pavement sections is quite similar to the priority ranking as determined by all thirty raters. Even the three-rater panel priority ranking is in fair agreement, but the individual priority rankings are in poor agreement (see Tables 12, 13, and 14 ).

It is evident that the panel method of rating is superior to a method which utilizes individual ratings as the "accuracy" of prlority ranking is appreciably improved.

\section{Acceptability Ratios}

The Acceptability Ratio (AR) of a pavement section is defined as the number of raters stating "Yes" divided by the total number of raters. Therefore, the panel acceptability ratios for this study are the number of members of the specific panel stating "Yes" divided by ten; and the overall acceptability ratios are the number of all of the raters stating "Yes" divided by thirty.

The panel and overall ARs are presented in Tables 2, 3, and 4 for the rigid, overlay, and flexible sections, respectively. Scatter-diagrams were plotted with the ARs as ordinates and PSRs as abscissas. Scatterdiagrams for the primary highway sections are shown in Figures $6,7,8$, and 9 for the overall, ISHC panel, Purdue panel, and Laymen panel, respectively. Scatter-diagrams for the secondary highway sections are shown in Figures 10, 11, 12, and 13. 

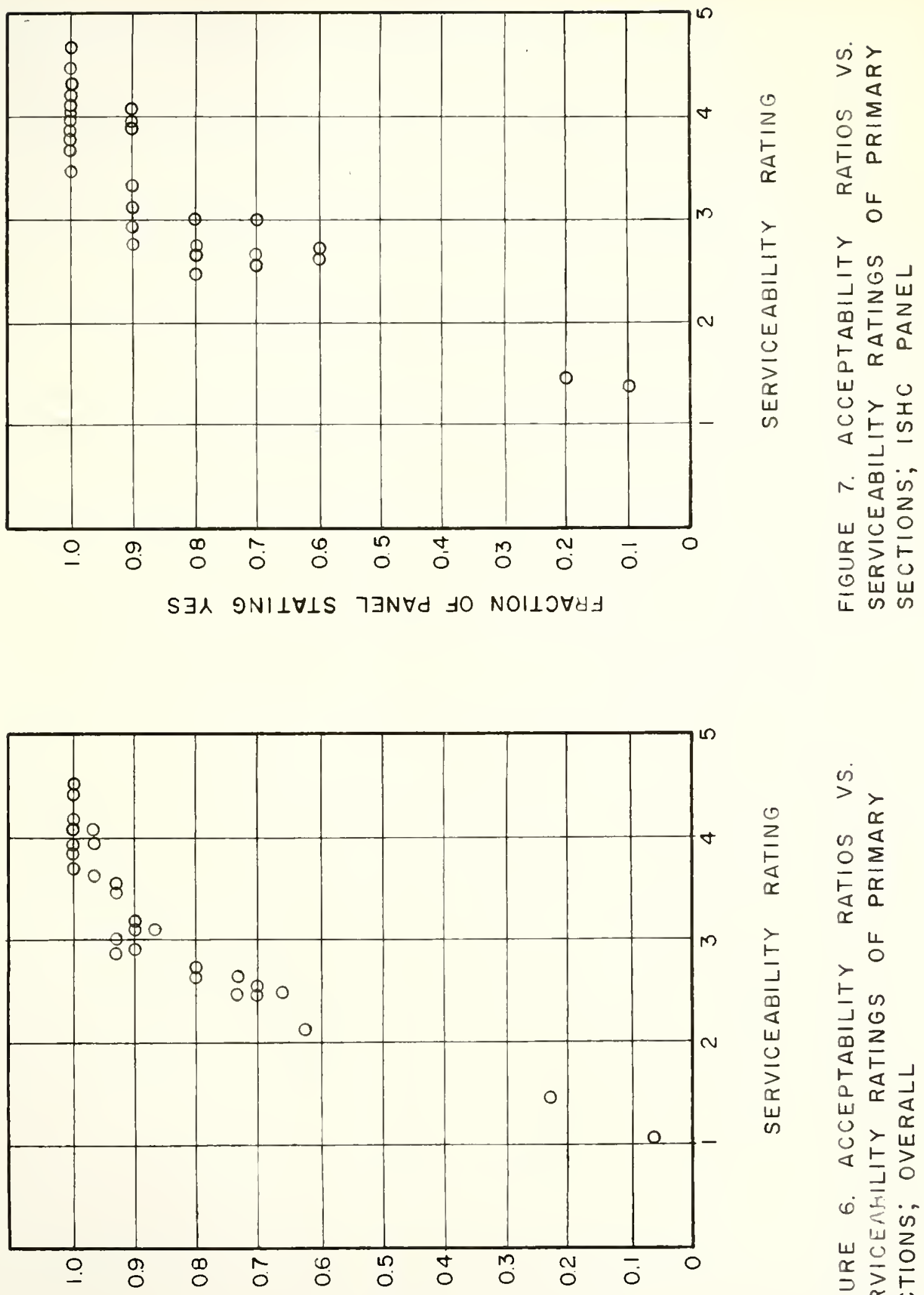

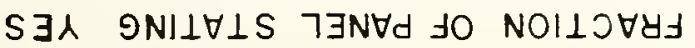

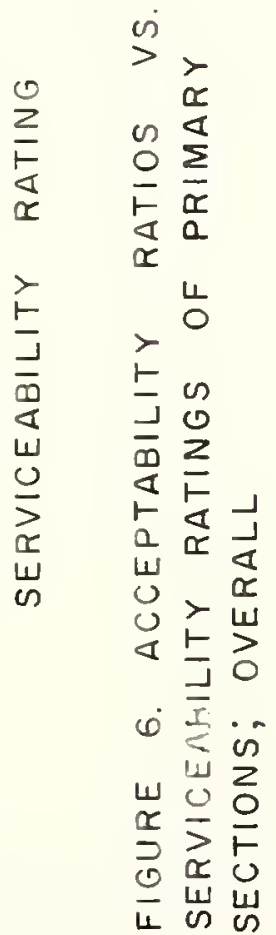




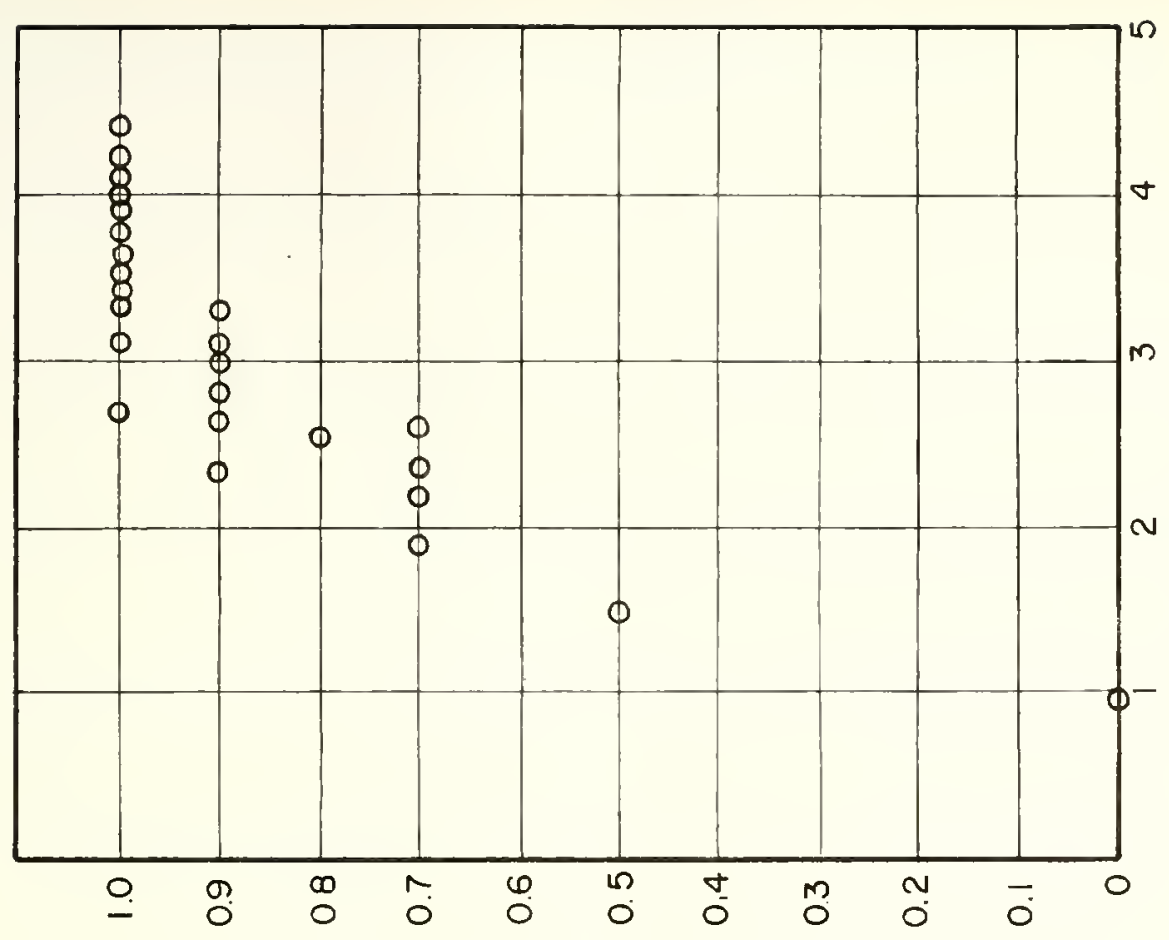

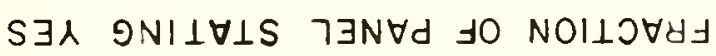
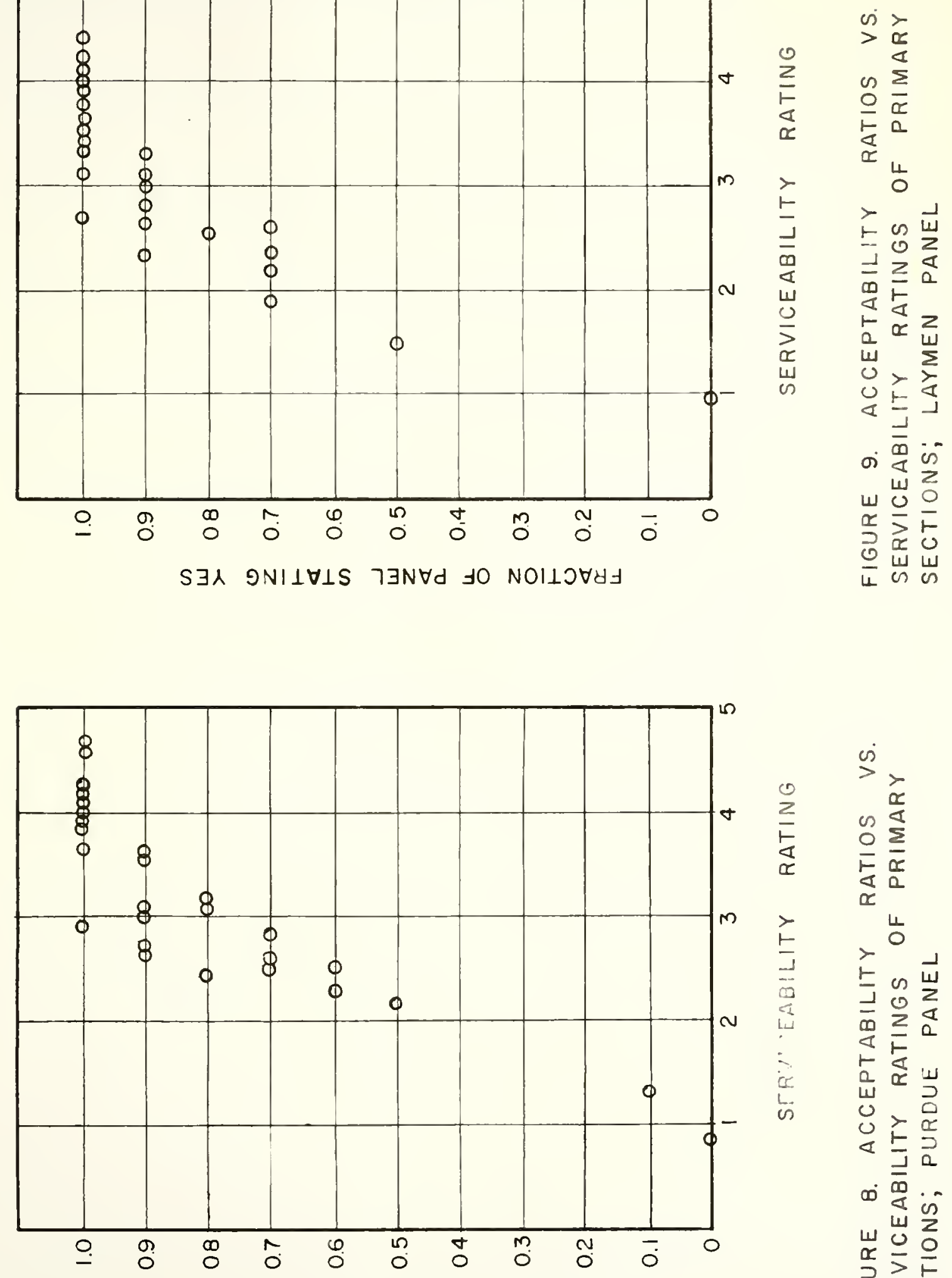

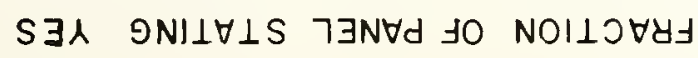

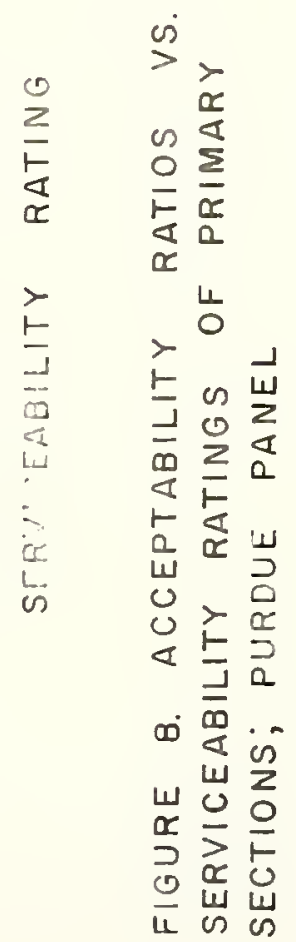




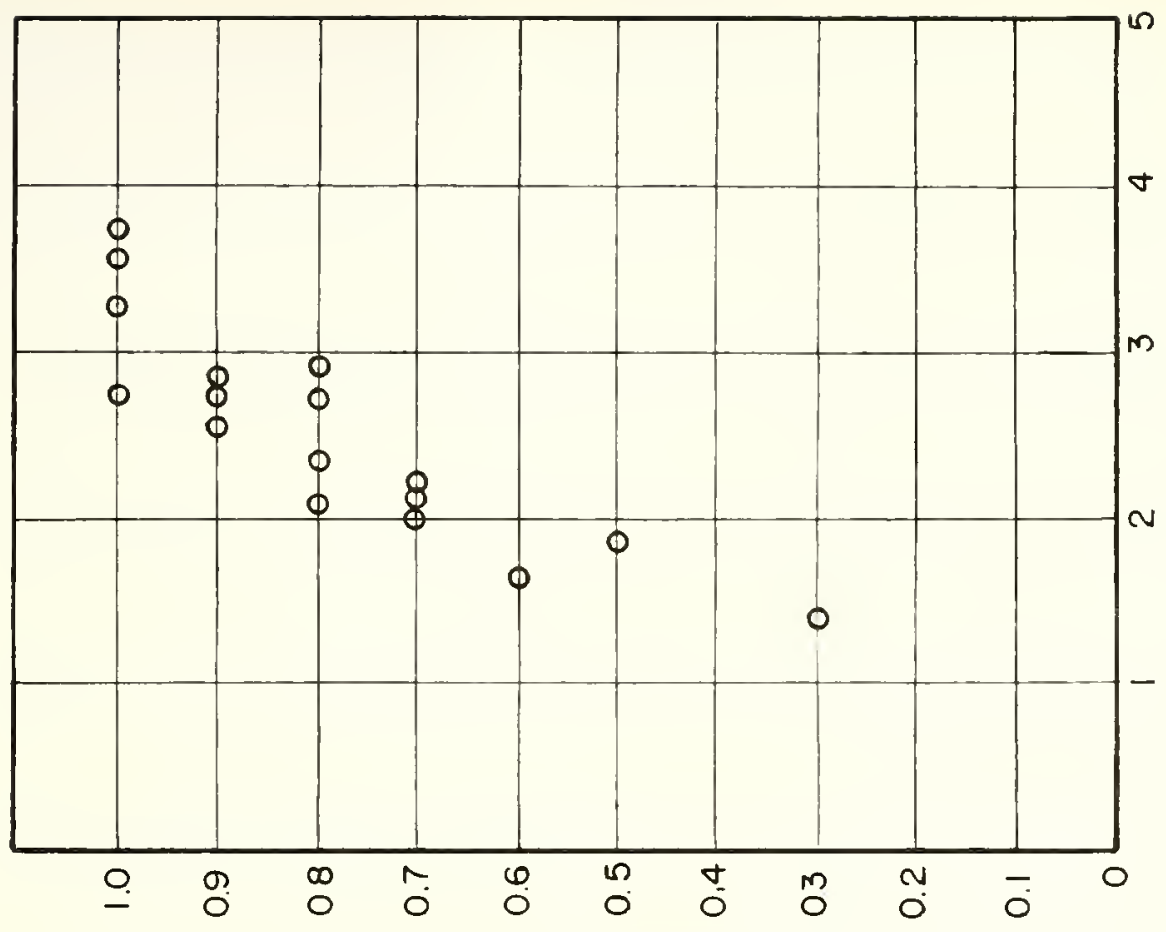

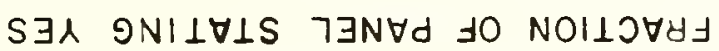
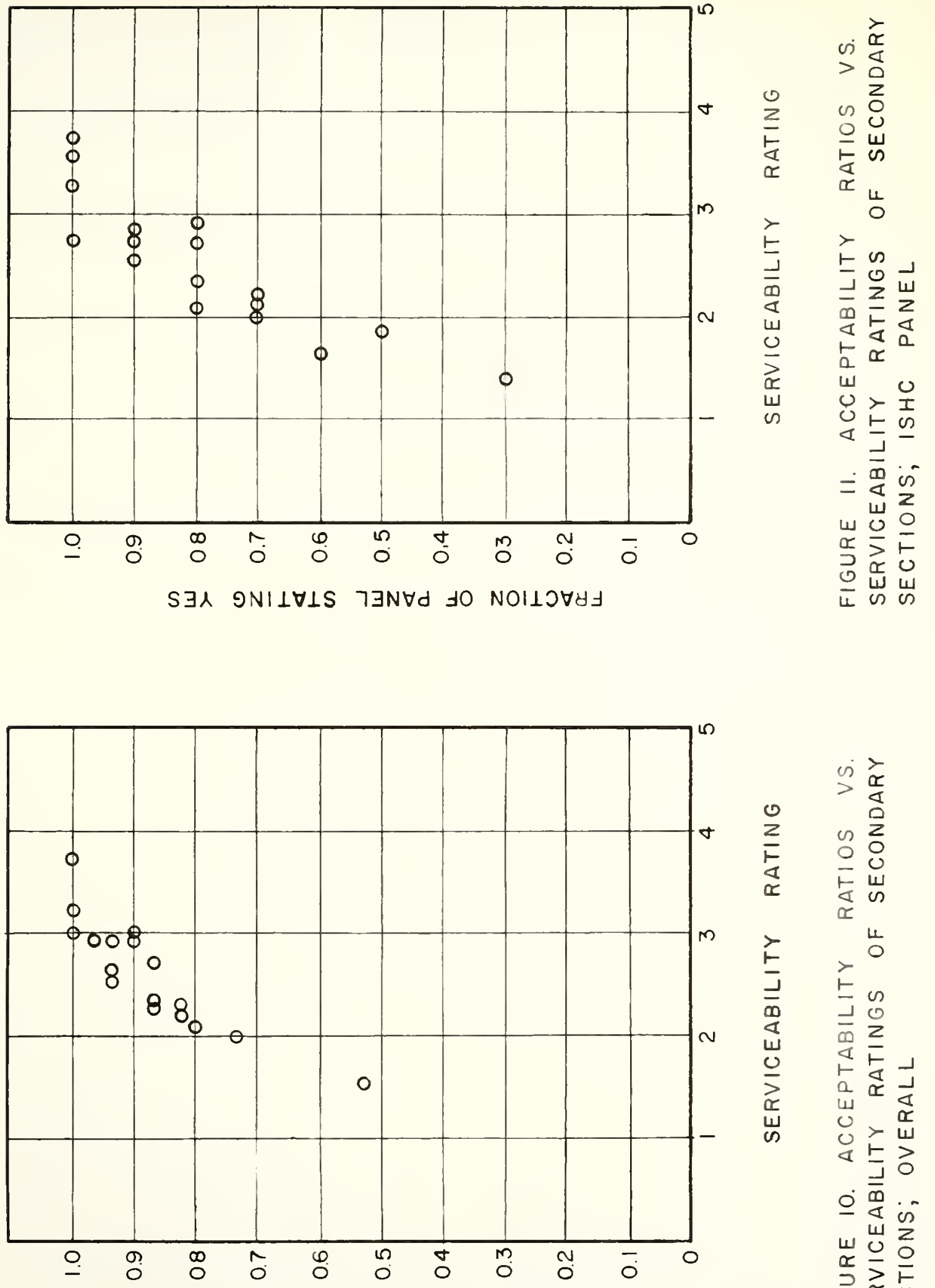

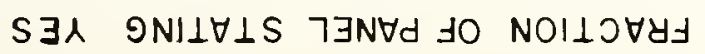

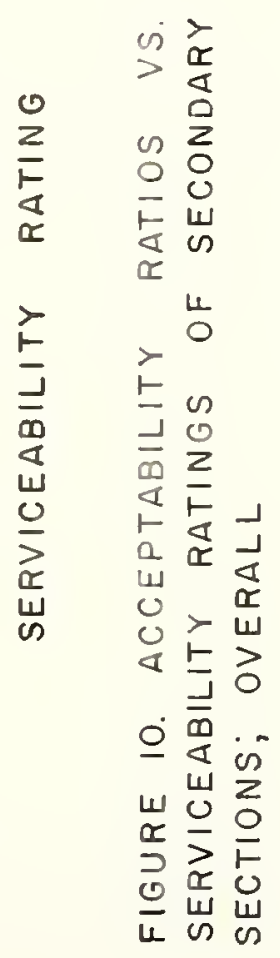



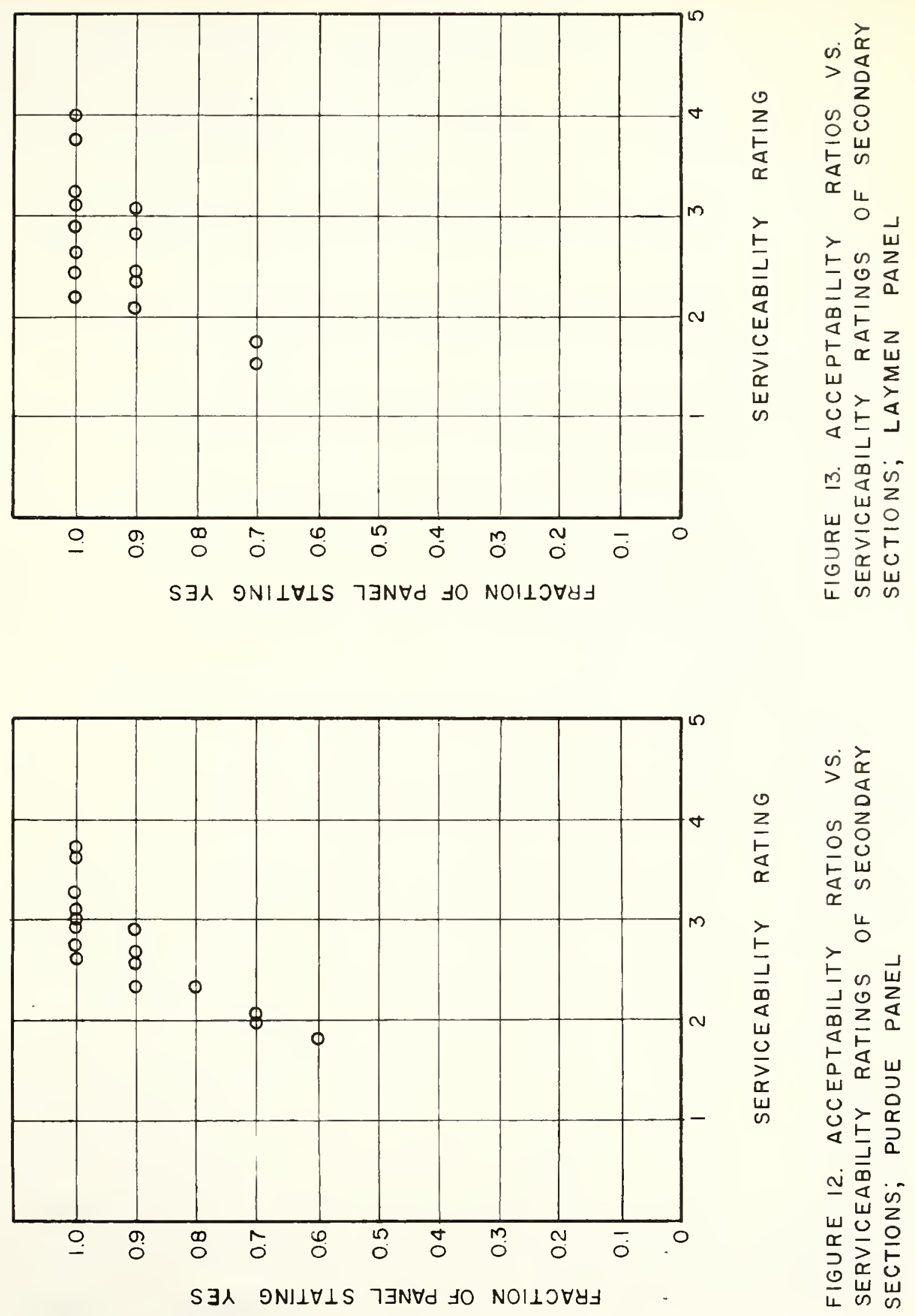

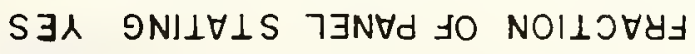


Although there is agreement by the highway authorities and laymen on the serviceability of pavements, there is some variation of opinion as to the acceptability of pavement condition. From observation of the figures, the ISHC panel appears to have the highest standards for acceptability of pavement sections and the laymen panel sppears to have the lowest.

It was arbitrarily essumed for this study that if 70 per cent of all the raters accepted a section, the section would be considered "acceptable". (1.e., the section is all right as it 1s, and no reconstruction is required); and if 50 per cent of all the raters did not accept a section, the section would be "unacceptable" (i.e., reconstruction is required). Therefore, all pavement sections with ARs equal to or greater than 0.7 were clsssified as acceptable; and all pavement sections with ARs equal to or less than 0.5 were classified as unacceptable. Pavement sections within the 0.5 and 0.7 lints were classified as "doubtful" relative to reconstruction. The condition of these pavement sections is not as poor or serious as those classified as "unscceptable". Pavement sections which were classified as unscceptable definitely require reconstruction and should receive top priority.

From observation of the scatter-diagrams, primary sections with ARs equal to or greater than 0.7 were given PSRs of 2.5 or higher, while secondary sections with ARs equal to or greater than 0.7 were given PSRs of 2.0 or higher. Primary sections with ARs equal to or less than 0.5 were given PSRs of 2.0 or less, whlle a PSR of 1.5 or less would have been unacceptable for secondary highways. The zones of doubt of PSRs in this study as to acceptability, therefore, were 2.0 to 2.5 for primary highways and 1.5 to 2.0 for secondary highways. 


\section{Rater Characteristics}

Various rater characteristics -- range of ratings, sum of ratings, sum difference, mean absolute deviation, standard deviation of mean absolute deviation, and the respective ranking orders -- and panel and overall totals and means are summarized in Tables 15, 16, and 17. These characteristics are explained below.

The range indicates the amount of the rating scale utilized by the rater, the lowest rating, and the highest rating. This characteristic, like the sum of ratings and sum difference, indicates the "high" and "low" raters. It is interesting to note that only one rater utilized the entire rating scale and that this rater ranked 27 th and 30 th according to the mean deviation and standard deviation rankings, respectively.

The sum of ratings is the sum of the rater's sixty ratings. The sum difference is the difference of the sum of ratings from the sum of the sixty "true" ratings which was 180.7. A positive sum difference indicates a higher than "true" sum of ratings and indicates a tendency of the rater to rate sections "higher" than the "true" value. A negative sum difference indicates a tendency of the rater to rate the sections "lower" than the "true" value. All thirty raters are ranked from high to low according to the sum differences, thus, the rater ranked number one by this measure is the "highest" rater and the rater ranked number thirty is the "lowest" rater.

The mean deviation is the sum of the absolute differences of the individual ratings from the "true" ratings for each of the sections divided by the number of sections. The mean deviation indicates the average "closeness" of the individual's ratings to the "true" ratings with the 


\begin{tabular}{|c|c|c|c|}
\hline Rater & Iow & $\begin{array}{l}\text { Standard } \\
\text { Deviation }\end{array}$ & $\begin{array}{c}\text { St. Dev. } \\
\text { Rank }\end{array}$ \\
\hline 1 & 2.1 & 0.438 & 21 \\
\hline 2 & 0.4 & 0.437 & 20 \\
\hline 3 & 1.5 & 0.445 & 23 \\
\hline 4 & 1.2 & 0.358 & 21 \\
\hline 5 & 1.0 & 0.365 & 12 \\
\hline 6 & 0.7 & 0.336 & 9 \\
\hline 7 & 1.2 & 0.479 & 26 \\
\hline 8 & 0.2 & 0.520 & 28 \\
\hline 9 & 0.2 & 0.464 & 24 \\
\hline 10 & 0.3 & 0.412 & 17 \\
\hline otal & 8.8 & 4.254 & \\
\hline Mean & 0.88 & 0.4254 & \\
\hline Total & 22.4 & 11.835 & \\
\hline Mean & 0.75 & 0.3945 & \\
\hline
\end{tabular}


TABLE 15

SUMMARY OF RATER CHARACTERISTICS

INDIANA STATE HIGHWAY COMMISSION PANEL

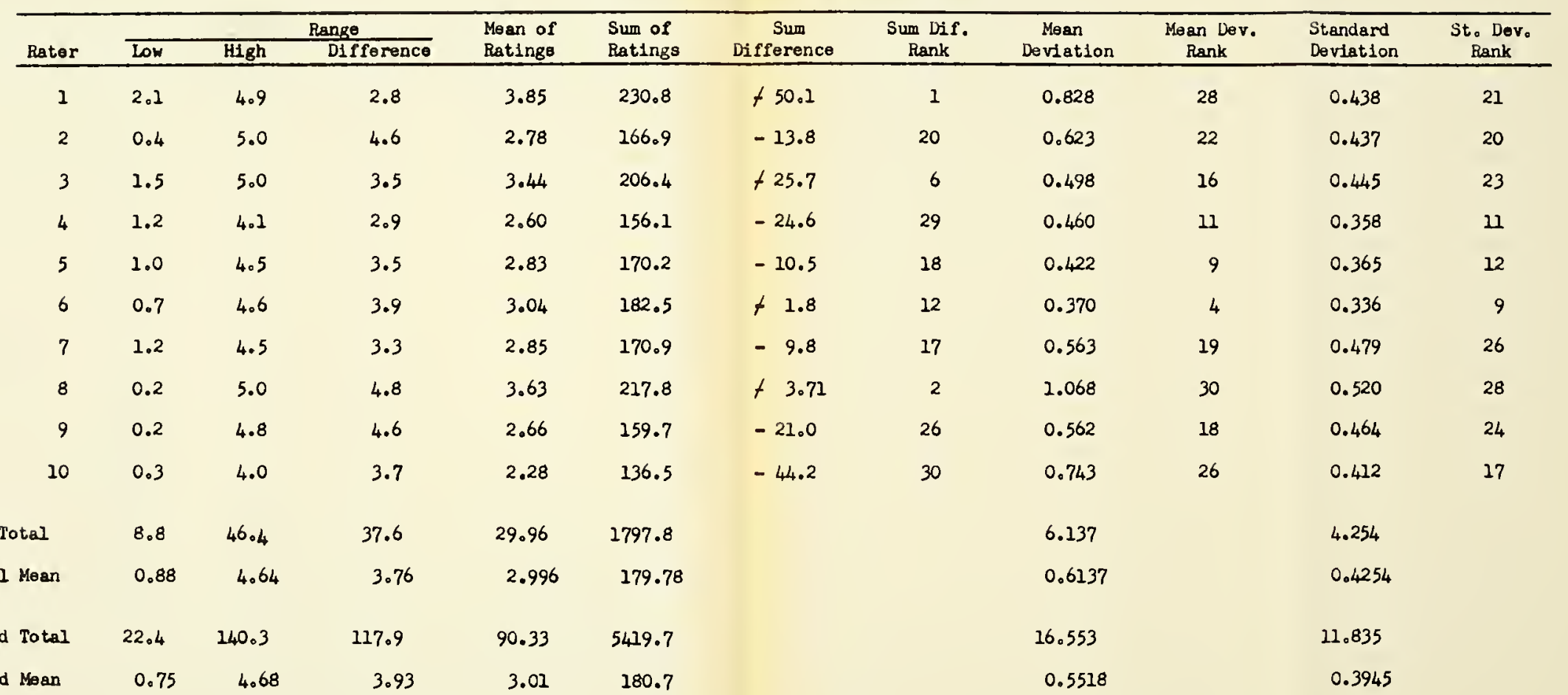




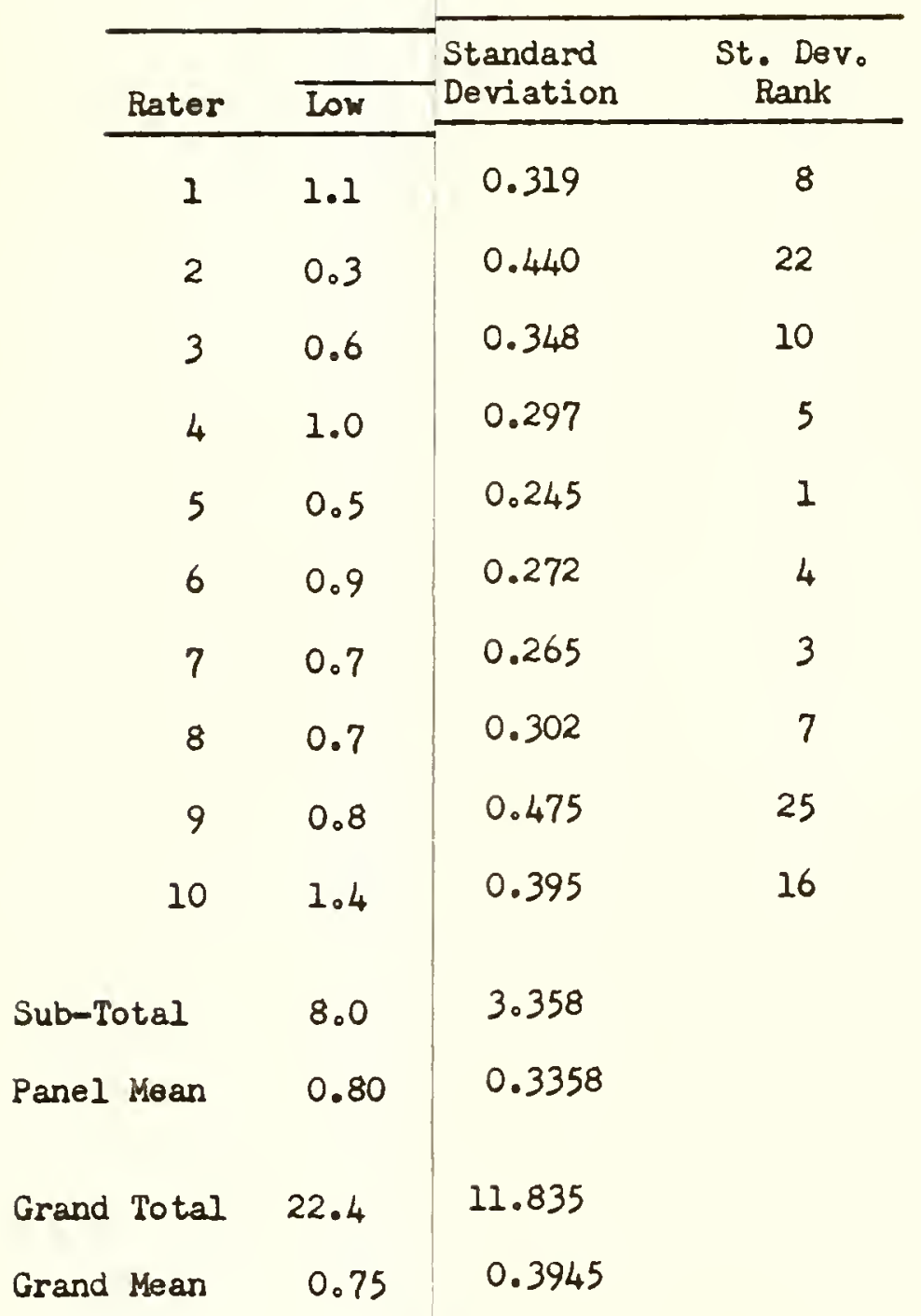


TABLE 16

SUMMARY OF RATER CHARACTERISTICS

PURDUE PANEL

\begin{tabular}{|c|c|c|c|c|c|c|c|c|c|c|c|}
\hline Rater & Iow & High & $\frac{\text { Range }}{\text { Difference }}$ & $\begin{array}{l}\text { Mean of } \\
\text { Ratinge }\end{array}$ & $\begin{array}{l}\text { Sum of } \\
\text { Ratings }\end{array}$ & $\begin{array}{c}\text { Sum } \\
\text { Difference }\end{array}$ & $\begin{array}{c}\text { Sum D1f. } \\
\text { Rank }\end{array}$ & $\begin{array}{c}\text { Mean } \\
\text { Deviation }\end{array}$ & $\begin{array}{l}\text { Mean Dev. } \\
\text { Rank }\end{array}$ & $\begin{array}{l}\text { Standard } \\
\text { Deviation }\end{array}$ & $\begin{array}{l}\text { St. Devo } \\
\text { Rank }\end{array}$ \\
\hline 1 & 1.1 & 4.9 & 3.8 & 3.16 & 189.7 & +9.0 & & 0.437 & 10 & 0.319 & 8 \\
\hline 2 & 0.3 & 5.0 & 4.7 & 2.75 & 165.4 & -15.3 & 22 & 0.672 & 24 & 0.440 & 22 \\
\hline 3 & 0.6 & 4.2 & 3.6 & 2.66 & 159.3 & -21.4 & 27 & 0.477 & 12 & 0.348 & 10 \\
\hline 4 & 1.0 & 4.6 & 3.6 & 2.73 & 163.6 & -17.1 & 25 & 0.378 & 5 & 0.297 & 5 \\
\hline 5 & 0.5 & 4.1 & 3.6 & 2.90 & 173.9 & -6.8 & 15 & 0.307 & 1 & 0.245 & 1 \\
\hline 6 & 0.9 & 4.9 & 4.0 & 3.24 & 194.6 & f13.9 & 9 & 0.402 & 7 & 0.272 & 4 \\
\hline 7 & 0.7 & 4.7 & 4.0 & 3.28 & 197.0 & $A 16.3$ & 8 & 0.408 & 8 & 0.265 & 3 \\
\hline 8 & 0.7 & 4.8 & 4.1 & 2.82 & 169.0 & -11.7 & 19 & 0.392 & 6 & 0.302 & 7 \\
\hline 9 & 0.8 & 4.9 & 4.1 & 3.41 & 204.9 & +24.2 & 7 & 0.620 & 21 & 0.475 & 25 \\
\hline 10 & 1.4 & 5.0 & 3.6 & 3.56 & 213.3 & +32.6 & 3 & 0.658 & 23 & 0.395 & 16 \\
\hline otal & 8.0 & 47.1 & 39.1 & 30.51 & 1830.7 & & & 4.751 & & 3.358 & \\
\hline Mean & 0.80 & 4.71 & 3.91 & 3.051 & 183.07 & & & 0.4751 & & 0.3358 & \\
\hline Total & 22.4 & 140.3 & 117.9 & 90.33 & 5419.7 & & & 16.553 & & 11.835 & \\
\hline Mean & 0.75 & 4.68 & 3.93 & 3.01 & 180.7 & & & 0.5518 & & 0.3945 & \\
\hline
\end{tabular}




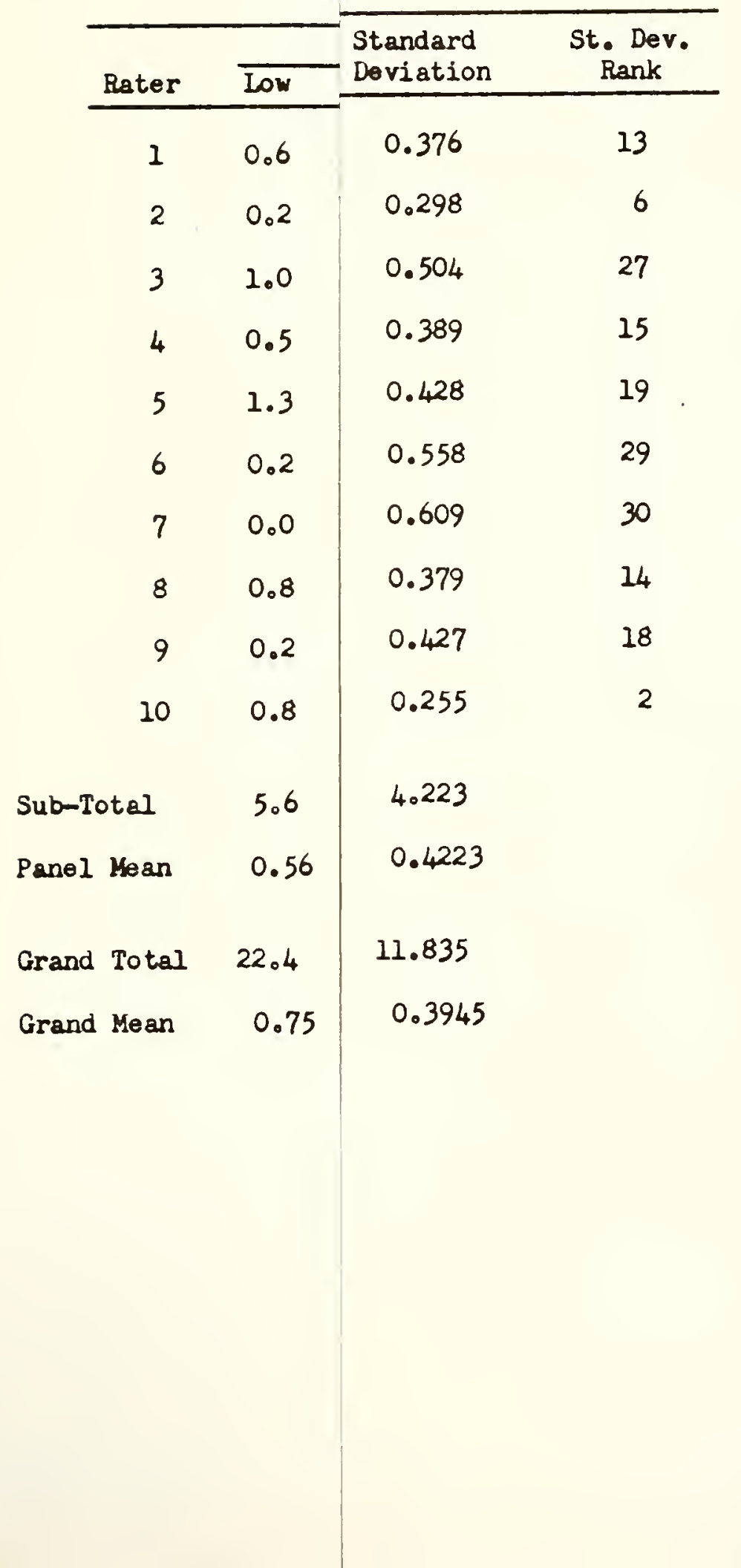


TABLE 17

SUMAARY OF RATER CHARACTERISTICS

LAYMEN PANEL

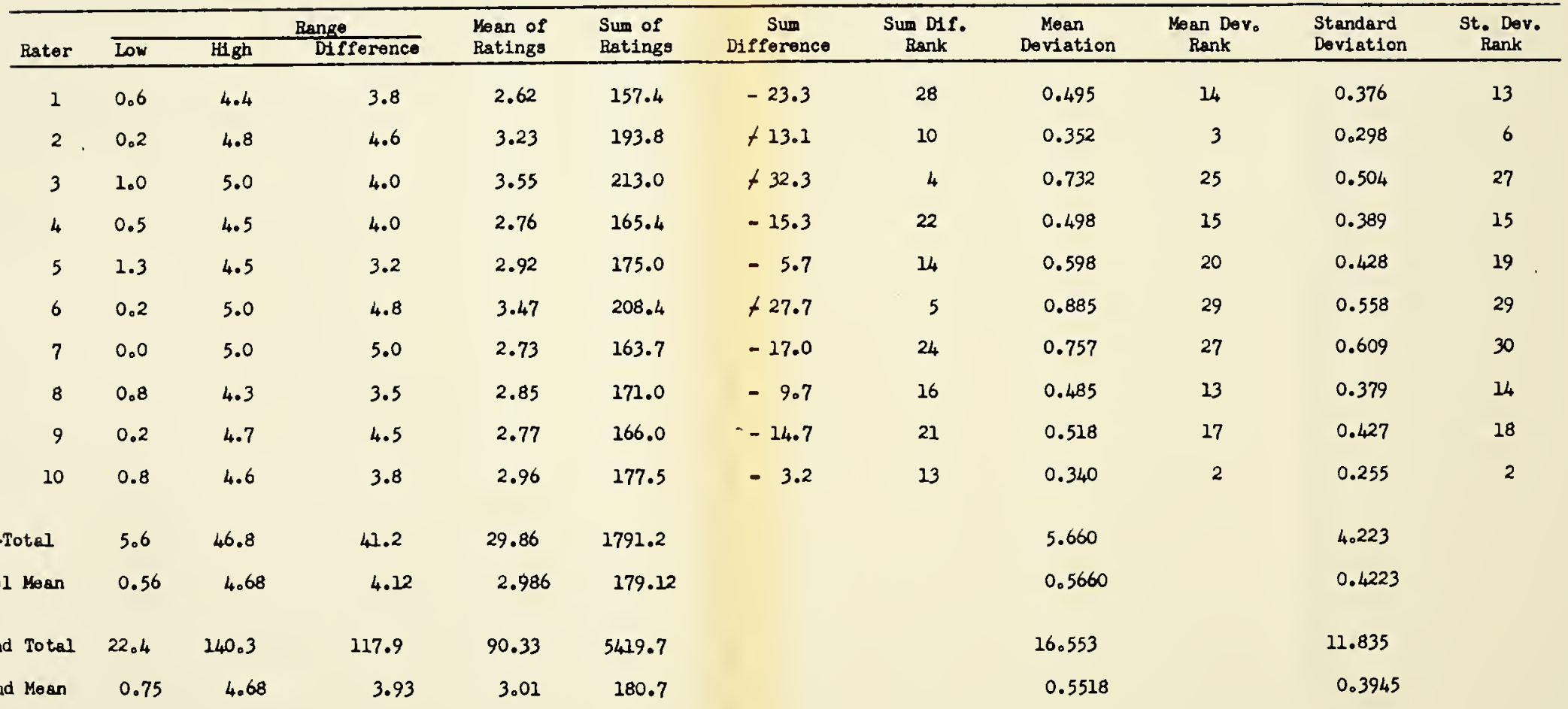


smallest numerical value being the "closest". The standard deviation of the mean deviation is a measure of the variability of the individual's ratings. It is an indication of the raterts consistency. Thus, the rater with the lowest standard deviation is the most consistent rater. Each of the thirty raters are ranked as to their closeness (column 10, Tables 15, 16, and 17) and consistency (column 12, Tables 15, 16, and 17) to the "true" ratings. The individual who was closest or most consistent received the ranking of 1 in the appropriate column.

It is interesting to note that the Purdue panel had the smallest panel mean deviation and standard deviation, and that seven of its members ranked in the top twelve according to mean deviation. The same seven raters ranked in the top ten according to standard deviations. The close agreement of these seven raters was offset by the three remaining raters who ranked $24 \mathrm{th}, 218 \mathrm{t}, 23 \mathrm{rd}$, and $22 \mathrm{nd}, 25 \mathrm{th}$, 16th for their mean deviations and standard deviations, respectively.

Two of the laymen were in the top ten for both mean deviations and standard deviations. The three women raters ranked $20 t h, 29 t h, 27 t h$ and $19 t h, 29 t h, 30 t h$ for their mean deviations and standard deviations, respectively.

The ISHC panel had the largest mean deviation and standard deviation and had two of its members in the top ten for mean deviations but only one for standard deviations. Also, four of its members were in the bottom third for mean deviations and five for standard deviations. It is also interesting to note that the rater who ranked number one according to sum difference (that is, the "highest" rater) was the maintenance engineer of most of the highways in the study. 


\section{RESULTS - CORRELATION OF SERVICEABILITY RATINGS AND ROUGHNESS INDICES}

The inter-relationship between the roughometer roughness values and the serviceability ratings for the three pavement types necessitated correlation and regression analyses. Since there was found to be no significant differences between the three rating panels, the mean of the thirty ratings was assumed to be the present serviceability rating (PSR) of the section.

Scatter-diagrams were plotted with the PSRs as the ordinates and the roughometer roughness values as the abscissas for each pavement type. The scatter-diagrams are shown in Figures 14, 15, and 16 for the rigid, overlay, and flexible sections, respectively.

\section{Linear Analysis}

Correlation coefficients $(r)$ and squared correlation coefficients $\left(r^{2}\right)$ were calculated for the three pavement types. The correlation coefficients and squared correlation coefficients are sumarized in Table 18. Sample calculations for the results herein discussed are presented in Appendix B. 


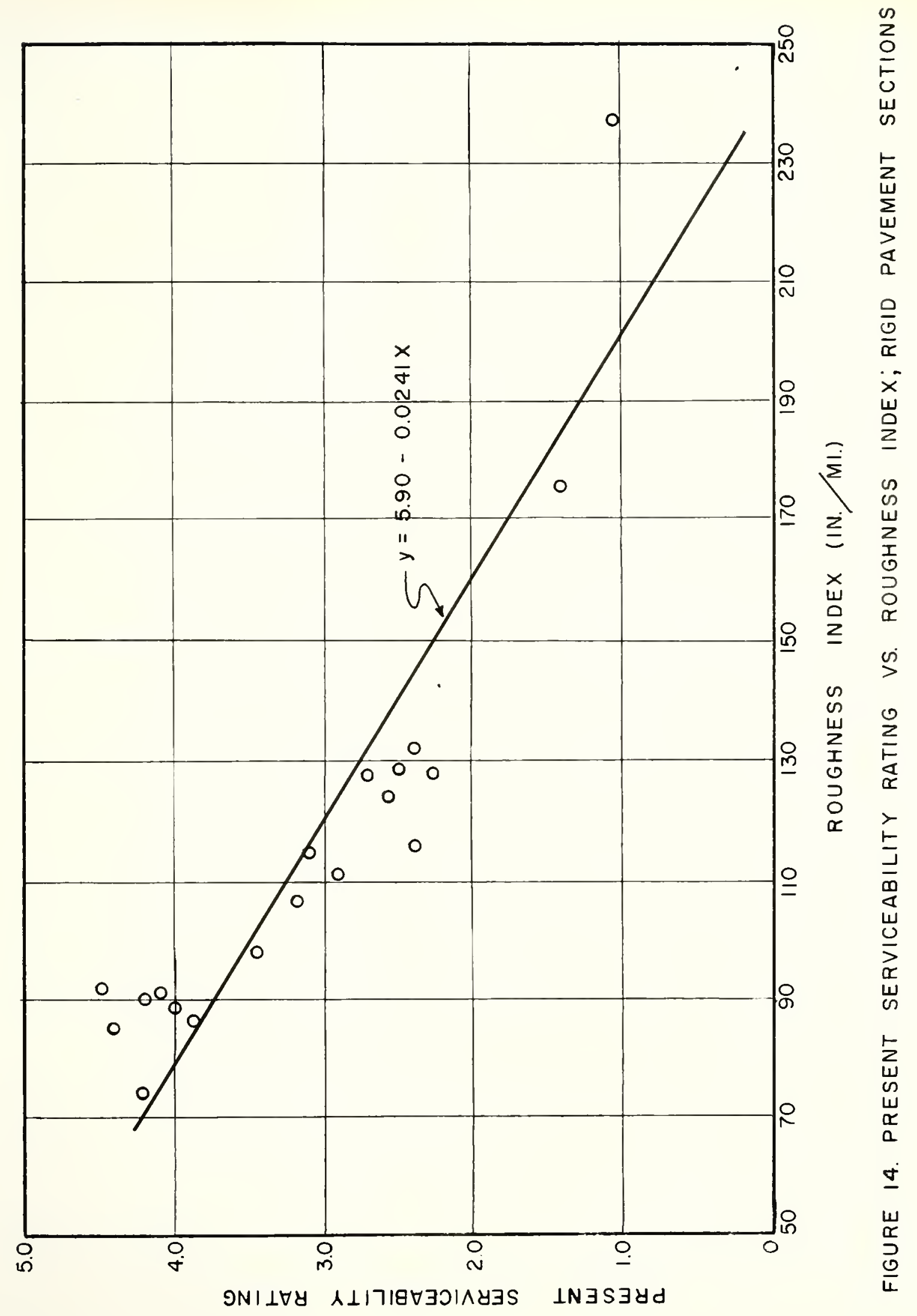




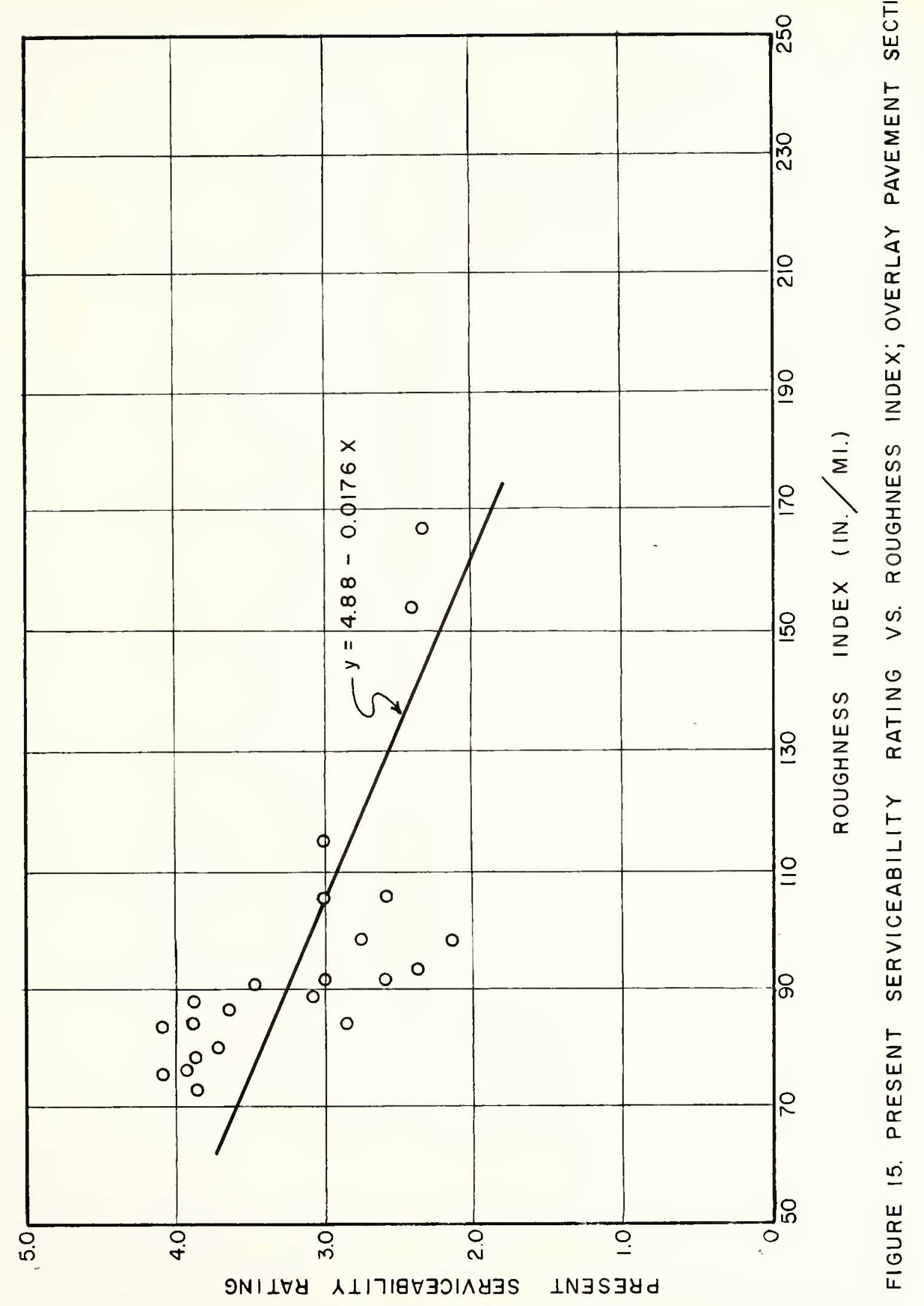




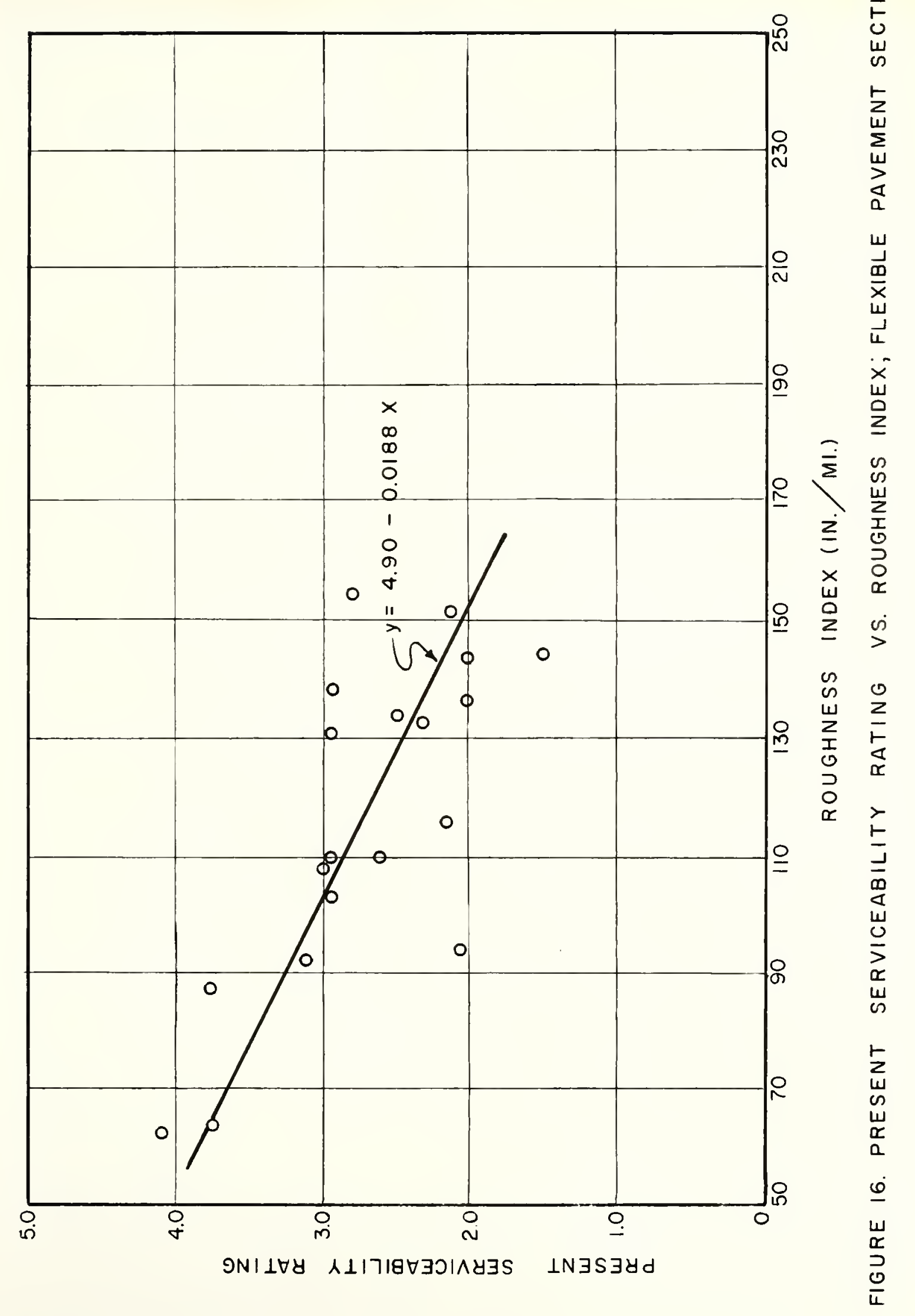




\section{TABLE 18}

CORRELATION COEFFICIENTS AND SQUARED CORRELATION COEFFICIENTS OF PRESENT SERVICEABILITY RATINGS WITH ROUGHNESS INDICES LINEAR AND EXXPONENTIAL CASES RIGID, OVERLAY, AND FLEXIBIE PA VEMENT SECTIONS

\begin{tabular}{ccccc}
\hline Pavement Type & \multicolumn{2}{c}{$r$} & & $r^{2}$ \\
\cline { 2 - 5 } & Linear & Exponential & Linear & Exponential \\
\hline Rigid & -0.90 & -0.98 & 0.82 & 0.96 \\
Overlay & -0.65 & -0.72 & 0.42 & 0.52 \\
Flexible & -0.81 & -0.71 & 0.66 & 0.51
\end{tabular}

The correlation coefficient indicates the amount of relationship between PSRs and roughometer roughness values. The squared correlation coefficient is the amount of the variation of the PSR that can be considered to be explained by the roughometer roughness values. The negative correlation coefficients indicate a negative association of the variables; that is, as the roughometer roughness values increase, the PSR values tend to decrease.

The results indicate the presence of a high negative correlation $(r=-0.90)$ between the PSRs and the roughometer values for the rigid sections. Approximately eighty-two per cent of the variation in the PSR can be explained by a dependence on the roughometer value. There is $a$ fair degree of negative correlation between the PSRs and the roughometer values for the overlay $(r=-0.65)$ and the flexible sections $(r=-0.81)$. Roughometer roughness values account for forty-two per cent and sixtysix per cent of the variation in the PSRs of the overlay and flexible sections, respectively. Therefore, fifty-eight per cent of the variations in the PSRs of the overlay sections and thirty-four per cent of the variation in the PSRs of the flexible sections must be due to other factors. 
These factors may be non-linear forms of the roughometer measurements and/or other physical factors.

\section{Linear Regression Equations}

Linear regression equations were calculated for each pavement type using the roughness measurements as the independent variable $(X)$ and the PSRs as the defendent variable ( $Y$ ). The method of least-squares was used. Sample calculations of results herein discussed are presented in Appendix $B$.

The following least-squares equations resulted:

For rigid pavement sections:

$$
Y=5.90-0.0241 X
$$

For overlay pavement sections:

$$
Y=4.88-0.0176 X
$$

For flexible pavement sections:

$$
Y=4.90-0.0188 X
$$

The least-square regression lines are shown in Figures 14, 15, and 16 for the rigid, overlay, and flexible sections, respectively.

\section{Curvilinear Analysis}

The scatter-diagrams (see Figures 14 and 15) of the rigid and overlay sections indicated an exponential curve of the type: $Y=a X^{b}$, or log $Y=a^{\prime}+b \log X$. Scatter-plots of the roughometer and PSR values on log-log scales (see Figures 17, 18, and 19) showed apparently "straighter" lines for the rigid and overlay sections. Therefore, correlation coefficients and least-square regression equations were calculated for the exponential relationship. Sample calculations of the results herein discussed are presented in Appendix B. 


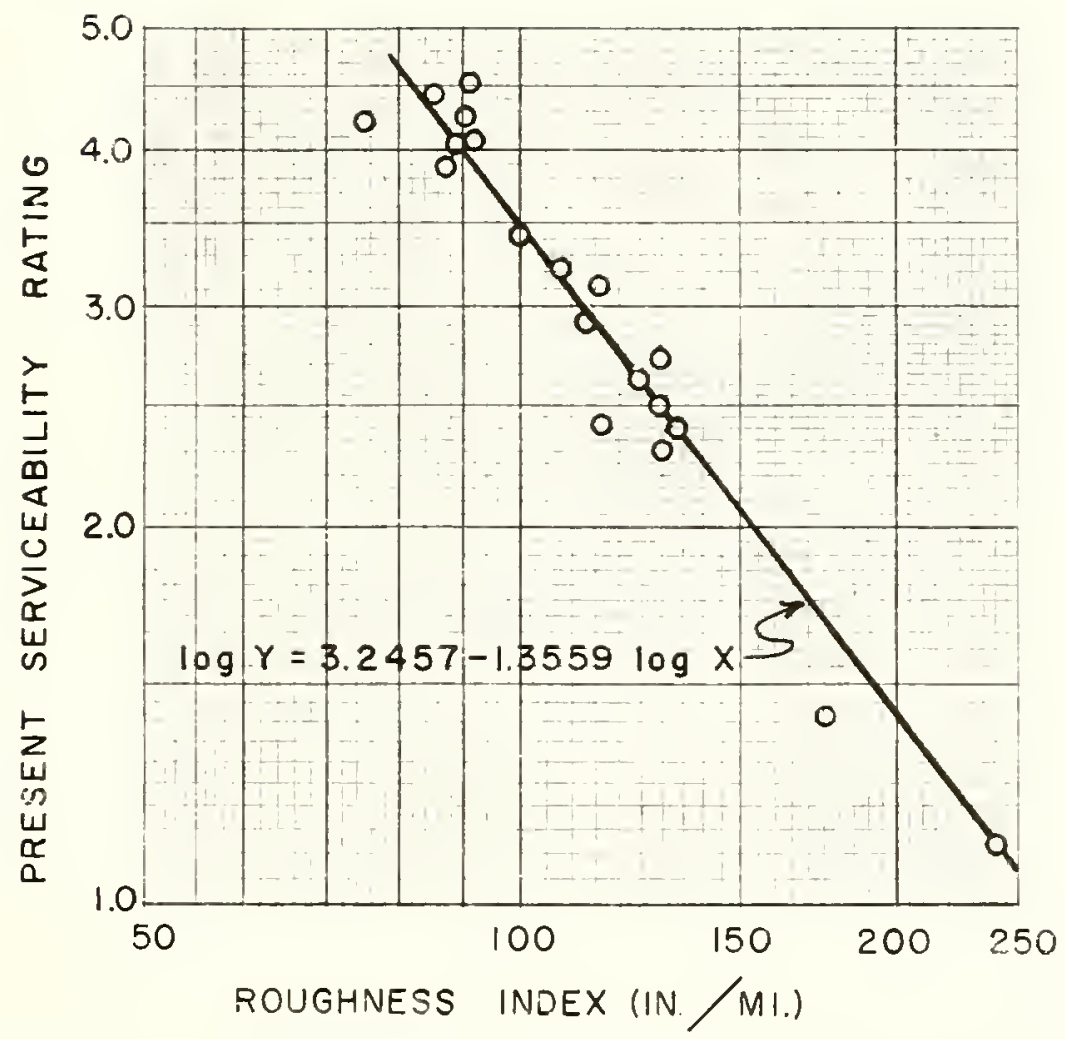

FIGURE 17. PRESENT SERVICEABILITY RATING VS. ROUGHNESS INDEX; LOG-LOG SCALE; RIGID PAVEMENT SECTIONS 


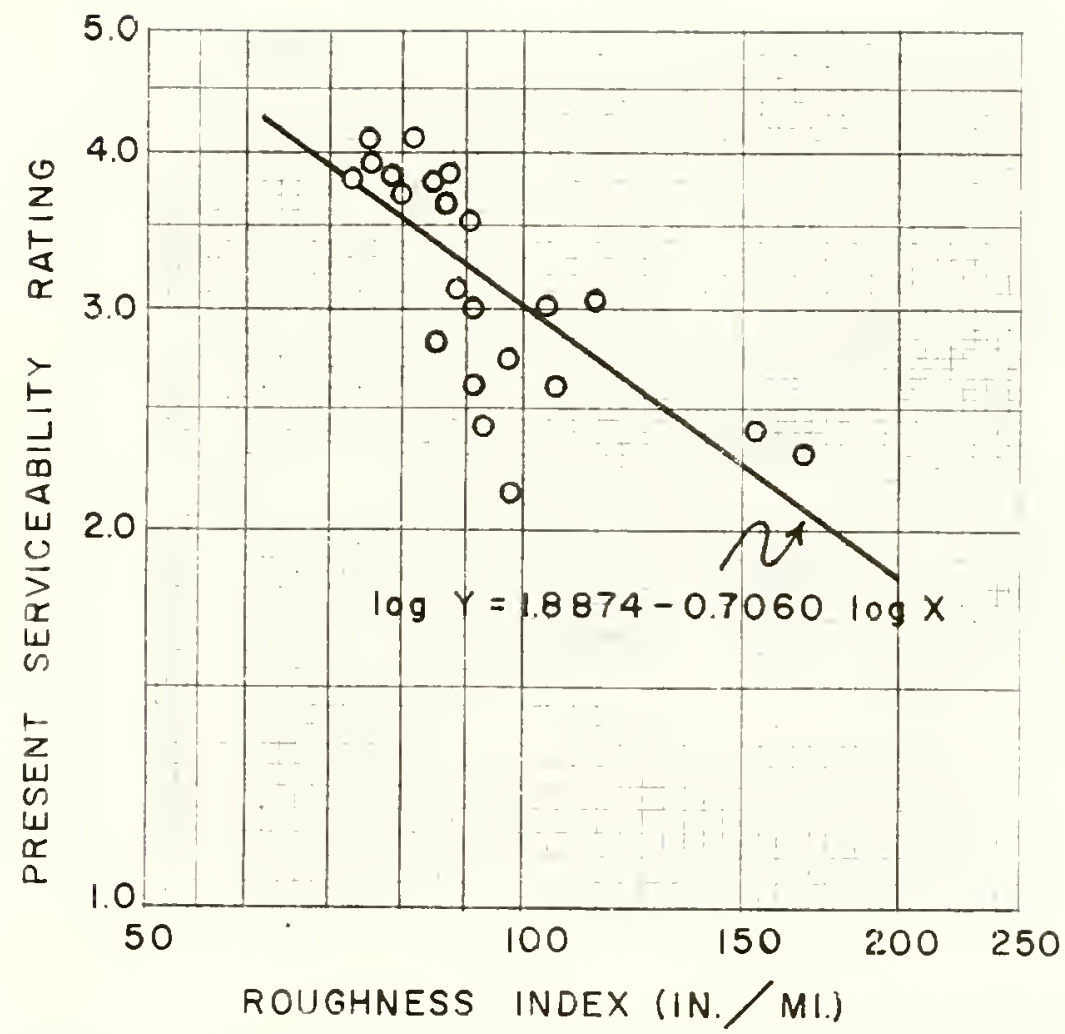

FIGURE 18. PRESENT SERVICEABILITY RATING VS. ROUGHNESS INDEX; LOG-LOG SCALE; OVERLAY PAVEMENT SECTIONS 


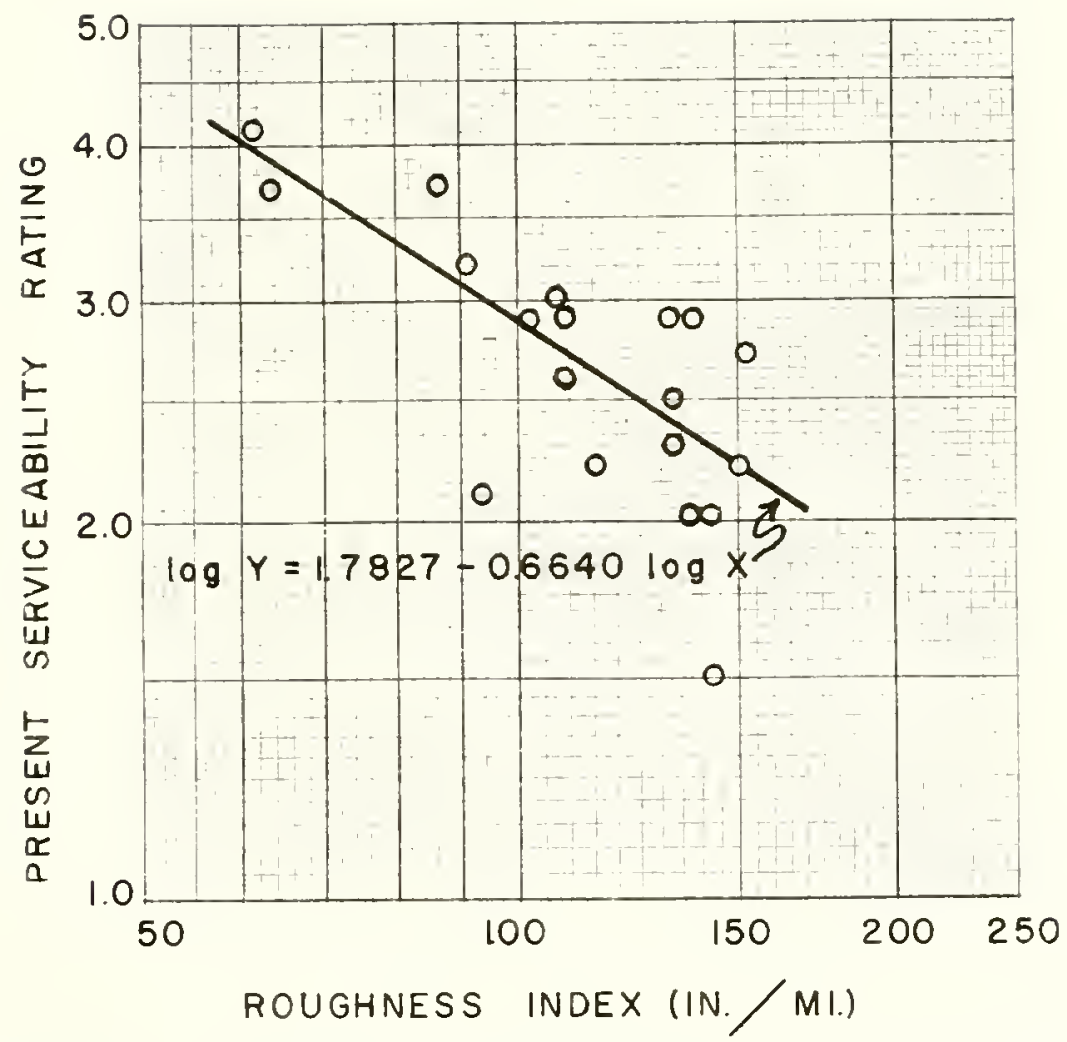

FIGURE 19. PRESENT SERVICEABILITY RATING VS. ROUGHNESS INDEX; LOG-LOG SCALE; FLEXIBLE PAVEMENT SECTIONS 
The correlation coefficients for the exponential relationship are presented in Table 18. The correlation coefficients for the exponential relationship of the rigid and overlay sections are higher than for the Inear relationship. "F" tests were used to see if the variability explained by the exponential function was significantly different from the variability explained by the linear function for each pavement type. The following equation was used:

$$
F=s_{y \cdot x^{2}}{ }^{2}{ }^{2}
$$

where,

$$
\begin{aligned}
& s_{y \cdot x^{2}}=\text { unexplained variability for the linear function } \\
& \left.s_{y \cdot x^{\prime}}\right|^{2}=\text { unexplained variability for the exponential function }
\end{aligned}
$$

The results are sumarized in Table 19. There were found to be no significant differences for the overlay and plexible sections. There was a significant difference at the 0.20 level of probability between the variability explained by the exponential function and the variability explained by the linear function for the rigid sections. The exponential curve presents a better "flt" for the given data than the straight line, and explains 0.14 more of the PSR variance. 


\section{TABLE 19}

"F" TEST COMPARISON OF THE UNEXPLAINED PSR VARIABILITY

FOR THE LINEAR AND EXPONENTIAL FUNCTIONS RIGID, OVERLAY, AND FLEXIBLE PAVEMENT SECTIONS

\begin{tabular}{|c|c|c|c|c|c|c|}
\hline Pavement Type & $\begin{array}{l}\text { D.F. } \\
(N-2)\end{array}$ & $s y \cdot x^{2}$ & $s_{y \cdot x^{12}}$ & $\mathrm{E}$ & $F_{0.10}$ & Conclusion \\
\hline Rigid & 17 & 2.059 & 0.947 & 2.17 & 1.91 & $S$ \\
\hline Overlay & 20 & 2.400 & 1.910 & 1.26 & 1.79 & NS \\
\hline Flexible & 17 & 2.012 & 1.888 & 1.07 & 1.91 & NS \\
\hline
\end{tabular}

Regression Equations

The least-squares method of regression was used and the following equations resulted:

For rigid pavement sections:

$$
\log Y=3.2457-1.3559 \log X
$$

For overlay pavement sections:

$$
\log Y=1.8874-0.7060 \log X
$$

For flexible pavement sections:

$$
\log Y=1.7827-0.6640 \log X
$$

The least-squares exponential regression lines are shown in Figures 17, 18, and 19 for the rigid, overlay, and flexible sections, respectively. Tables 20, 21, and 22 show a comparison of the PSRs with the predicted values of both the linear and exponential equations for the rigid, overlay, and flexible sections, respectively. 
TABLE 20

COMPARISON OF THIRTYMMMBER RATING PANEL PSRS WITH LINEAR AND EXPONENTIAL REGRESSION EQUATION PSRS - RIGID PAVEMENT SECTIONS

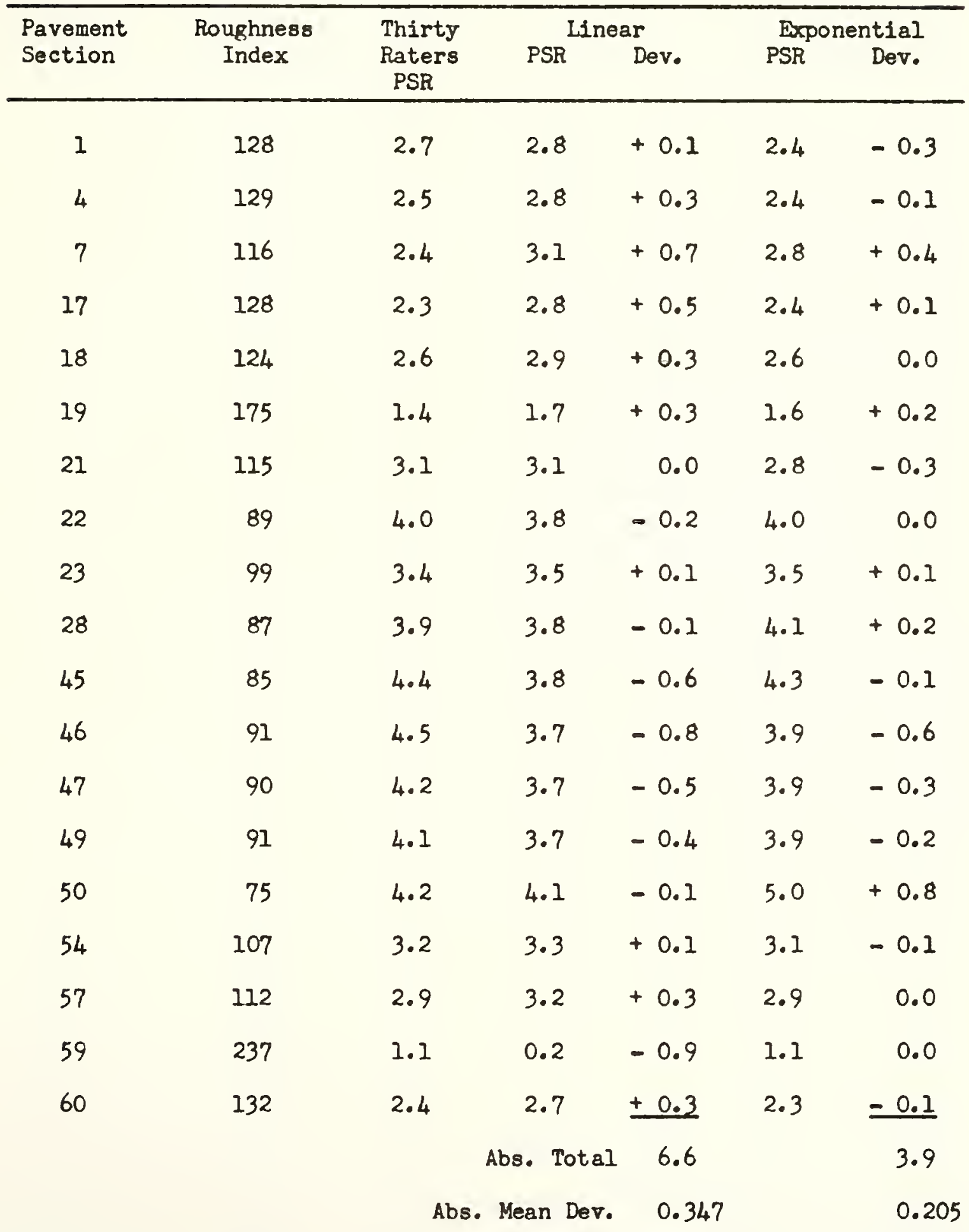


TABLE 21

COMPARISON OF THIRTY-MEMBER RATING PANEL PSRS WITH LINEAR AND EXPONENTIAL REGRESSION EQUATION PSRS - OVERLAY PAVENFNT SECTIONS

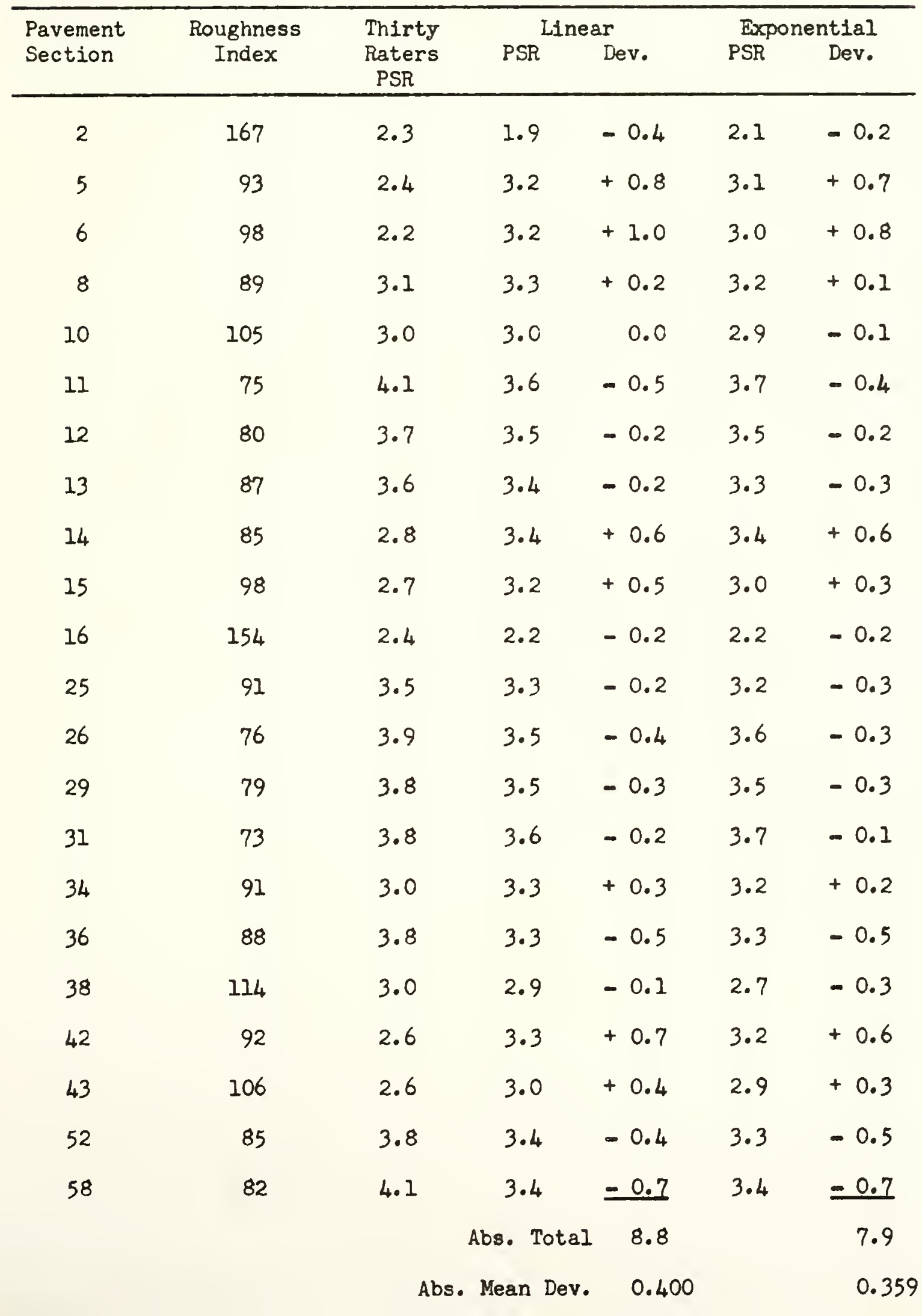


TABLE 22

COMPARISON OF THIRTY-MEMBER RATING PANEL PSRS WITH LINEAR AND EXPONENTIAL REGRESSION EQUATION PSRS - FLEXIBLE PAVEMENT SECTIONS

\begin{tabular}{|c|c|c|c|c|c|c|}
\hline \multirow{2}{*}{$\begin{array}{l}\text { Pavement } \\
\text { Section }\end{array}$} & \multirow{2}{*}{$\begin{array}{l}\text { Roughness } \\
\text { Index }\end{array}$} & \multirow{2}{*}{$\begin{array}{l}\text { Thirty } \\
\text { Raters } \\
\text { PSR }\end{array}$} & \multicolumn{2}{|c|}{ Linear } & \multicolumn{2}{|c|}{ Exponential } \\
\hline & & & PSR & Dev. & PSR & Dev. \\
\hline 3 & 116 & 2.2 & 2.7 & +0.5 & 2.6 & +0.4 \\
\hline 9 & 134 & 2.5 & 2.4 & -0.1 & 2.3 & -0.2 \\
\hline 20 & 139 & 2.9 & 2.3 & -0.6 & 2.3 & -0.6 \\
\hline 24 & 110 & 2.9 & 2.8 & -0.1 & 2.7 & -0.2 \\
\hline 27 & 144 & 1.5 & 2.2 & +0.7 & 2.2 & +0.7 \\
\hline 30 & 155 & 2.7 & 2.0 & -0.7 & 2.1 & -0.6 \\
\hline 32 & 87 & 3.7 & 3.3 & -0.4 & 3.1 & -0.6 \\
\hline 33 & 62 & 4.1 & 3.7 & -0.4 & 3.9 & -0.2 \\
\hline 35 & 103 & 2.9 & 3.0 & +0.1 & 2.8 & -0.1 \\
\hline 37 & 152 & 2.2 & 2.0 & -0.2 & 2.2 & 0.0 \\
\hline 39 & 92 & 3.2 & 3.2 & 0.0 & 3.0 & -0.2 \\
\hline 40 & 110 & 2.6 & 2.8 & +0.2 & 2.7 & +0.1 \\
\hline 41 & 144 & 2.0 & 2.2 & +0.2 & 2.2 & +0.2 \\
\hline 44 & 64 & 3.7 & 3.7 & 0.0 & 3.8 & +0.1 \\
\hline 48 & 94 & 2.1 & 3.1 & +1.0 & 3.0 & +0.9 \\
\hline 51 & 108 & 3.0 & 2.9 & -0.1 & 2.7 & -0.3 \\
\hline 53 & 137 & 2.0 & .2 .3 & +0.3 & 2.3 & +0.3 \\
\hline 55 & 133 & 2.3 & 2.4 & +0.1 & 2.4 & +0.1 \\
\hline \multirow[t]{2}{*}{56} & 131 & 2.9 & 2.4 & $=0.5$ & 2.4 & -0.5 \\
\hline & & & Abs. To & 6.2 & & 6.3 \\
\hline
\end{tabular}




\section{DISCUSSION OF RESULTS}

If one assumes that the present serviceability rating (PSR) is a good measure of the adequacy of a pavement and further assumes that the best judge of the adequacy of a pavement is the judgment of the traveling pubIfc, serviceability ratings obtained by a large panel of motorists would be an excellent measure of the present adequacy of a highway pavement.

Two methods of determining present serviceability ratings have been presented. One method makes use of a rating panel - the number of raters required in the rating panel being dependent on the "accuracy" of the required serviceability ratings. Since there was found to be non-significant panel differences, it is inferred that the amount of rater experience and knowledge in the highway field is not of importance in the selection of raters.

The second method utilizes measurements obtained by a roughometer as the independent varlable in least-squares regression equations to obtain present serviceability ratings. When compared to serviceability ratings obtained by a large rating panel, the ratings obtained by the use of roughness measurements are only fair approximations for overlay and flexible pavement sections but are almost exactly the same for rigid pavements.

Factors apparently not measurable by the roughometer account for approximately fifty per cent of the serviceability rating variation of overlay and flexible pavement sections. Cursory examination of the pavement sections (see Tables 25, 26 and 27, Appendix A) indicatesthat factors 
not completely measured by the roughometer, such as porpoising, sidesway, cracks, patches, and bleeding may account for some of the rating variation of flexible pavements; and factors such as reflection cracks, faulted cracks and joints, blow ups, and widening may account for some of the rating variation of overlay pavements. The least-squares equations derived using roughometer output as the only predictor are not satisfactory for determining the present serviceability ratings for overlay and flexible sections. The results of this study, however, show that roughness measurements are excellent indicators of the serviceability ratings of rigid pavement sections. Fither of the following equations may be employed in predicting PSRs from the roughometer output, but the exponential relationship will provide the more accurate results:

$$
Y=5.90-0.0241 X
$$

or,

$$
\log Y=3.2457-1.3559 \log X
$$

where,

$$
\begin{aligned}
& X=\text { roughometer output }(1 \mathrm{n} . / \mathrm{ml} .) \\
& Y=\text { present serviceability rating (PSR) }
\end{aligned}
$$

Since both the roughometer and the panel rating methods provide excellent serviceability ratings for rigid pavement sections, a cost comparison of the two methods was made using the nineteen rigid povement sections in this study as the pavements to be rated.

The following costs were assumed: 1) all preliminary costs (1.e., costs involved in the determination of homogeneous pavement sections, location of sections, routing of the roughometer and raters, etc.) would be the same for both methods, 2) labor costs would be $\$ 20 /$ day/person for both roughometer crew and rating panel, 3) rating vehicles operational and overhead 
cost would be 7 cents/mile, 4) roughometer and tow truck operational and overhead cost would be 10 cents/mile, and 5) all summarization and analysis costs of the data would be the same (a study of the required work indicates that the costs would be similar).

The measurement of the nineteen rigid pavement sections by the roughometer would require five days. This time was determined from experience with the roughometer on the nineteen sections of the study. For these nineteen sections the roughometer would log approximately 200 miles of pavement. Additional mileage for traveling to and from a central home base and for traveling from one test section to another would require approximately 350 miles. Therefore, a total of 550 miles would be traveled by the roughometer tow vehicle resulting in an operational expense of:

$$
550(\$ 0.10)=\$ 55.00
$$

The roughometer crew consisted of two men: one man to drive and the other to record. Cost of labor was approximately:

$$
2(5)(\$ 20)=\$ 200
$$

Therefore, the total cost of evaluating the nineteen rigid pavement sections by the roughometer would be approximately:

$$
\$ 55+\$ 200=\$ 255
$$

The evaluation of the nineteen rigid pavement sections by a rating panel would require one day. Each member of the rating panel operating from the same central home base would be required to drive approximately 264 miles in order to rate the nineteen sections. Vehicle operating expense would be approximately:

$$
264(\$ 0.07)=\$ 18.50
$$

The total cost for one rater and vehicle for rating the nineteen rigid 
pavement sections would then be:

$$
\$ 18.50+\$ 20.00=\$ 38.50
$$

The number of raters in the rating panel would depend on the accuracy required. The approximate costs for evaluating the nineteen rigid parement sections by a rating panel with from three to eight members is presented In Table 23.

TABLE 23

APPROXIMATE COST FOR EVALUATING NINETEEN RIGID

PAVEMENT SECTIONS - RATING PANEL EVALUATION METHOD

\begin{tabular}{cc}
\hline No. of Raters & Cost \\
\hline 3 & $\$ 115$ \\
4 & 155 \\
5 & 190 \\
6 & 230 \\
7 & 270 \\
8 & 310
\end{tabular}

A seven member rating panel would cost only slightly more than the roughometer. A seven member rating panel would predict mean serviceability ratings that would deviate less than 0.7 from the "true" ratings by chance nineteen out of twenty times, and would predict mean serviceability ratings that would deviate less than 0.6 from the "true" ratings by chance nine out of ten times.

If it is required that the deviations of the predicted serviceability ratings be equal to or greater than 0.6 at the 0.10 level, or equal to or greater than 0.7 at the 0.05 level, the more economical method would be 
the rating panel method, since at most six members will be required, resulting in a maximum cost of approximately $\$ 230$. However, if it is required that the deviations be equal to or less than 0.5 at the 0.10 level, or equal to or less than 0.6 at the 0.05 level, the roughometer would be more economical since an eight member panel would cost approximately $\$ 310$.

The decision of which method to use will depend on the use to be made of the results. If the results are to be used primarily for priority determination in program planning, it should be remembered that even a three member panel (see Section of this report entitled "Evaluation of the Rating Panel Method") produced good results. The method used to determine serviceability ratings for overlay and flexible pavements will also affect the decision as to which method to use for rigid pavements. If the panel method is used for these pavements (and no other good method is known), then it would be efficient to also use it for the rigid pavements. 
CONCLUSIONS

The conclusions made from the data herein analyzed are as follows:

1) The rating panel method of evaluating pavement serviceability is practical; is applicable to rigid, overlay, and flexible pavements; and mintmizes the variations and personal bias involved when pavement maintenance and reconstruction priority programs are determined on the basis of the personal knowledge and judgments of individuals.

2) Although pavement serviceability ratings of individuals vary widely, the mean serviceability ratings of panels of individuals do not and are good estimates of the "true" present serviceability ratings of highway pavement sections.

3) The amount of knowledge and experience in the highway engineering field is not of importance in the selection of members for a rating panel.

4) The roughometer method of evaluating pavement serviceability is objective and simple, but is accurate (i.e., highly correlated with the judgments of the traveling public) onls for rigid pavements.

5) The present serviceability rating (PSR) of a rigid pavement section can be accurately determined from roughometer measurements by the following exponential relationship: 
where,

$$
\begin{aligned}
& X=\text { roughometer output (in./mi.) } \\
& Y=\text { present serviceability rating (PSR) }
\end{aligned}
$$

A slightly less accurate rating can be determined from the following linear relationship:

$$
I=5.90-0.0241 X
$$

6) Roughometer measurements are not good predictors of the present serviceability ratings of overlay and flexible pavements.

7) The panel method of obtaining present serviceability ratings for rigid pavements will be more economical than the method utilizing roughometer measurements if the accuracy required of the panel permits the use of a small panel. Cost calculations should be employed to determine the method which is less costly.

8) Primary highway pavements with PSRs of 2.5 or higher and secondary highway pavements with PSRs of 2.0 or higher are "acceptable" to the traveling public.

9) Primary highway pavements with PSRs of 2.0 or lower and secondary highway pavements with PSRs of 1.5 or lower are "unacceptable" to the traveling public and should be reconstructed. 
BIBLIOGRAPHI 


\section{BIBLIOGRAPHY}

1. Ahlborn, G. and Noyer, R. A., "New Developments in BPR Roughness Indicator and Tests on California Pavements," Bulletin 139, Highway Research Board, pp. 1-28, 1956.

2. Anderson, R. L. and Bancroft, T. A., "Statistical Theory in Research," McGraw-Hill Book Co., Inc., New York, p. 350, 1952.

3. Baerwald, J. E., "Rural Highway Classification and Evaluation Procedures for Indiana Counties," a thesis submitted to the faculty of Purdue University in partial fulfillment of the requirements for the degree of Doctor of Philosophy, January 1956.

4. Buchanan, J. A. and Catudal, A. I., "Standardizable Equipment for Evaluating Road Surface Roughness," Proceedings, Highway Research Board, Vol. 20, pp. 621-638, 1940.

5. Burr, I. W., "Engineering Statistics and Quality Control," McGraw Hill Book Co., Inc., New York, 1953.

6. Carey, Jr., W. N. and Irick, P. E., "The Pavement ServiceabilityPerformance Concept," Bulletin 250, Highway Research Board, pp. 40 58, 1960.

7. Cochran, W. G. and Cox, G. M., "Experimental Designs," John W1ley and Sons, Inc., New York, p. 110, 1950.

8. Duncan, A. J., "Quality Control and Industrial Statistics," R1chard D. Irwin, Inc., Homewood, Ill1no1s, 1959.

9. Holloway, P. M., "Road Roughness Measurements on Indiana Pavements," a thesis submitted to the faculty of Purdue University in partial fulfiliment of the requirements for the degree of Master of Science in Civil Engineering, June 1956.

10. Housel, W. S. and Stokstad, O. L., "Pavement Profile Surveys to Correlate Michigan Design Practice with Service Behavior," Proceedings, Highway Research Board, Vol. 38, pp. 149-177, 1959.

11. Hudson, W. R. and Hain, R. C., "The Calibration and Use of the Bureau of Public Roads Roughometer at the AASHO Road Test," presented at the Annual Meeting of the Highway Research Board, January 1961. 
12. Hveem, F. N., "Types and Causes of Failure in Highway Pavements," Bulletin 187. Highway Research Board, pp. 1-51, 1958.

13. Kipp, 0. L., "Sufficiency Ratings as an Administrative Tool," Bulletin 53. Highway Research Board, pp. 1-2, 1952.

14. Manual of Information Regarding the Operation and Maintenance of the Public Roads Relative Road Roughness Indicator, Bureau of Public Roads, U. S. Dept. of Commerce, 1957.

15. Morgan, A. D., "Correlation of Roughometer and Skid Tests with Pavement Type, Design and Mix," Bulletin 37, Highway Research Board, pp. $38-56,1951$.

16. Morgan, A. D., "Service Record Study of Bituminous Concrete and Sand Asphalt Pavements in North Carolina," Bulletin 154, Highway Research Board, pp. 21-30, 1957.

17. Moyer, R. A., "Motor-Vehicle Operating Costs, Road Roughness and Slipperiness of Various Bituminous and Portland Cement Concrete Surfaces," Proceedings, Highway Research Board, Vol. 22, pp. 13-53, 1942.

18. Moyer, R. A. and Shupe, J. W., "Roughness and Skid Resistance Measurements of Pavements in California," Bulletin 37. Highway Research Board, pp. 1-37, 1951.

19. "Pavement Condition Surveys," Speclal Report No. 30, Highway Research Board, pp. 1-61, 1957.

20. Special Report, AASHO Road Test, Highway Research Board, July 27, 1961.

21. Sufficiency Study Manual, State Highway Department of Indiana, 1960.

22. Yoder, E. J., "Principles of Pavement Design," John Wiley and Sons, Inc., New York, 1959. 
APPENDIX A 
Name

Local Address Phone

Permanent Address

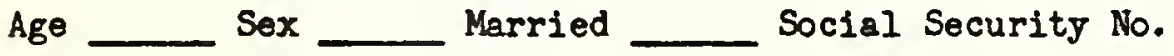

Occupation

Are jou planning to use jour own vehicle? ___ Yes ___ No

If you are not, who is the owner?

Is the vehicle of a type you usually drive? Yes No

Is the vehicle covered by public liability and property damage insurance? If 80 , in what amount?

What type of rehicle is it? Make Year

How many years of driving experience do you have?

How many miles of driving do you average a year?

I understand, if I am selected as one of the raters for the Pavement Serviceability Study, that Purdue University will pay me the sum of one hundred dollars for sixty completed rating forms, which I agree to complete according to instructions. I further understand that all travel expense and responsibilities necessary to complete the sixty forms will be furnished by me at mown expense.

\section{(Signed)}

Applicant Selected and Accepted

Forms and Instructions Delivered Completed Forms Returned 


\section{RATING INSTRUCTIONS}

1. In rating the sections of pavement always keep this question in mind: If I were to ride over a pavement that is just like that represented by this section of pavement every day for the usual purposes, how well would the parement serve me? For secondary highways this service would be primarily for short trips, such as to work or to town, while for primary highways the service would be, in general, for some longer trips.

2. Rate the serviceability of the pavement only. Bxclude all features not part of the pavement itself, such as right of way and median width, grade, alignment, shoulder and ditch conditions, etc.

3. You must not let your opinion as to how the pavement may perform in the future influence your rating of the existing serviceability.

4. You may ride over the parement as you wish. That is, you may ride over the length of pavement you are rating in a car or truck similar to the one in which you normally ride at a high speed and/or at a low speed.

5. Remember you are rating the pavement only. Your car serves as an instrument by which you can compare one pavement with all other pavements on which you have ridden. For example: a truck driver accustomed to driving trucks can readily compare one pavement with another if he is in his truck, whereas a man who normally drives a Cadillac would find a ride in a truck so relatively rough that he would not be able to compare successfully one parement with another. 


\section{RATING INSTRUCTIONS (continued)}

6. You are to travel alone and work independently. You must not discuss your work with, or be influenced by, others.

7. On the rating card there is a scale reading from 0 to 5 with appropriate descriptive adjectives along the side. Mark with a horizontal line the appropriate numerical rating on the scale. Your rating wll be read to two significant figures (e.8., 3.4, 1.8).

8. Fill out every 1tem on the rating card.

9. If you have any questions call Lafayette, 92-2111, or come to Room 215, Civil Engineering Building, Purdue University. 


\section{RATING PROCEDURE}

1. You are to rate the pavement sections in three days. The three days need not be in consecutive order, however, the rating should be completed by - Rating cannot be done during rain or other inclement weather conditions.

2. The map is divided into three parts (i.e., parts A, B, and C). You are to rate part on the first day of rating, part on the second day, and part on the third day.

3. The pavement sections are numerically identified. You are to rate the pavement sections within each part in the order given on the following page. For example: on the first day you are to rate pavement section first, pavement section second, pavement section third, etc.

4. It is very important that you rate the pavement sections in the above mentioned order.

5. The eections are identified by yellow paint markings on the parement (see sketch below). The yellow paint strip indicates the beginning and end of the section; the arrow points in the direction of the pavement section to be rated; and the number identifies the section. 
Rating Order I

(Sample of Ten Rating Orders Used)

\begin{tabular}{|c|c|c|c|}
\hline & First Day & Second Day & Third Day \\
\hline $\begin{array}{l}\text { Part: } \\
\text { Order of Rating }\end{array}$ & $\begin{array}{c}\text { B } \\
\text { Section }\end{array}$ & $\begin{array}{c}c \\
\text { Section }\end{array}$ & $\begin{array}{c}\text { A } \\
\text { Section }\end{array}$ \\
\hline 1 & 59 & 36 & 28 \\
\hline 2 & 60 & 31 & 54 \\
\hline 3 & 41 & 32 & 18 \\
\hline 4 & 50 & 33 & 9 \\
\hline 5 & 43 & 34 & 58 \\
\hline 6 & 21 & 30 & 1 \\
\hline 7 & 45 & 29 & 2 \\
\hline 8 & 46 & 27 & 3 \\
\hline 9 & 47 & 35 & 4 \\
\hline 10 & 48 & 44 & 5 \\
\hline 11 & 49 & 38 & 6 \\
\hline 12 & 51 & 37 & 7 \\
\hline 13 & 52 & 26 & 8 \\
\hline 14 & 42 & 25 & 10 \\
\hline 15 & 53 & 24 & 15 \\
\hline 16 & 55 & & 11 \\
\hline 17 & 56 & & 12 \\
\hline 18 & 57 & & 13 \\
\hline 19 & 40 & & 14 \\
\hline 20 & 39 & & 16 \\
\hline 21 & & & 17 \\
\hline
\end{tabular}




\section{Rating Order I (continued)}

$\begin{array}{lccc} & \text { First Day } & \text { Second Day } & \text { Third Day } \\ \text { Part: } & \text { B } & \text { C } & \text { A } \\ \text { Order of Rating } & \text { Section } & \text { Section } & \text { Section } \\ 22 & & 19 \\ 23 & & 20 \\ 24 & 22 \\ 25 & 23\end{array}$




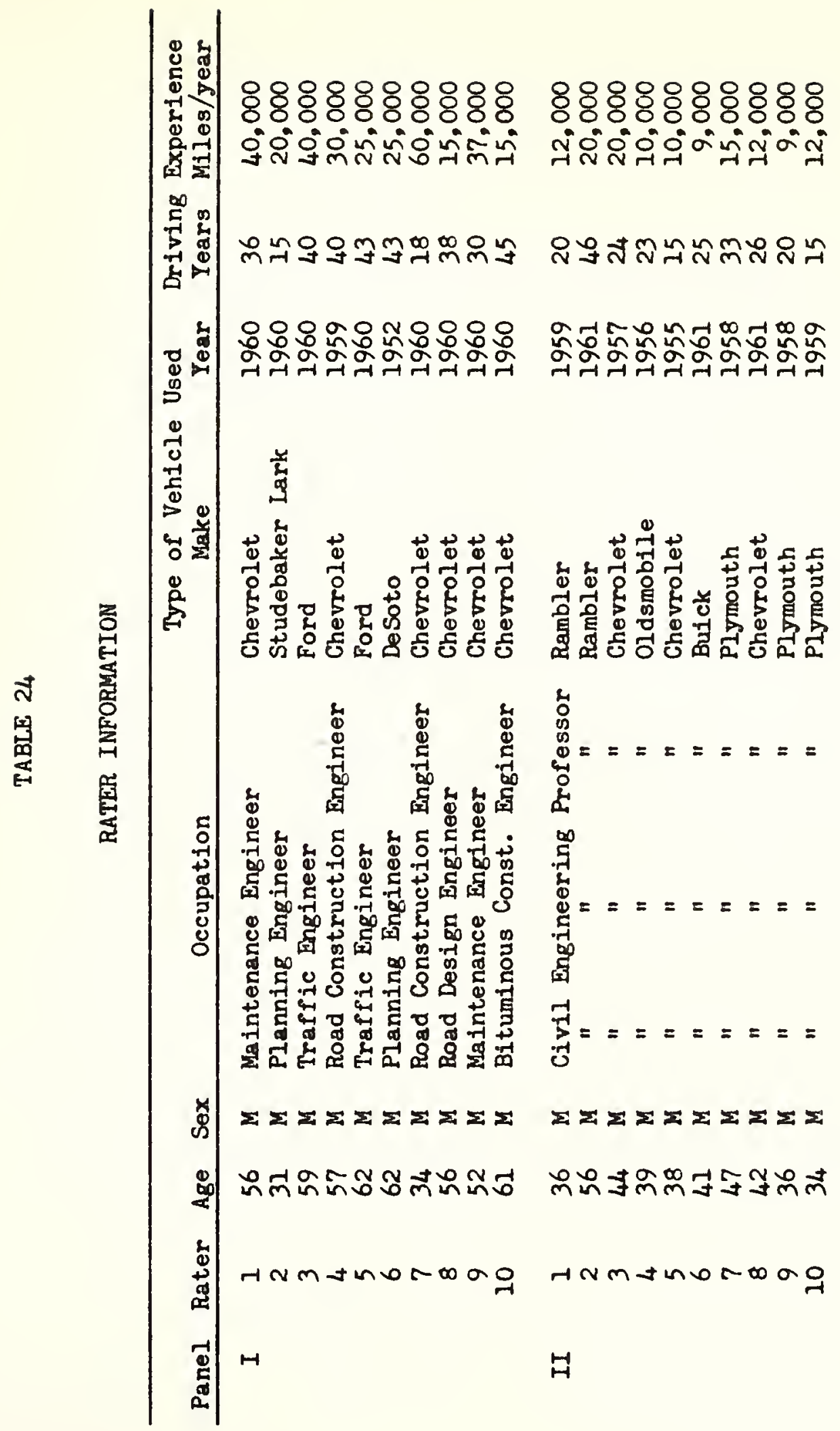




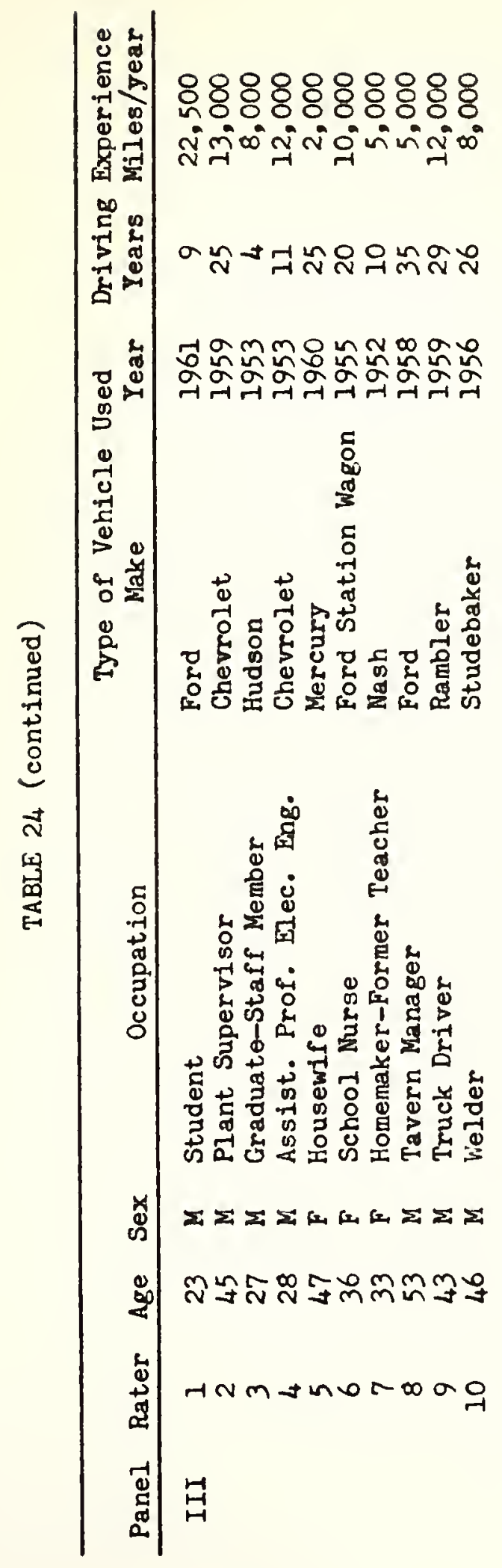


TABLE 25

DESCRIPTION OF RIGID PAVEMENT SECTIONS

\begin{tabular}{|c|c|c|c|c|c|}
\hline Section & PSR & Rank & $\begin{array}{l}\text { Roughness } \\
\text { Index }\end{array}$ & Rank & Description \\
\hline 59 & 1.1 & 1 & 237 & 1 & $\begin{array}{l}\text { Transverse and faulted cracks, } \\
\text { faulted joints, blow ups }\end{array}$ \\
\hline 19 & 2.4 & 2 & 175 & 2 & $\begin{array}{l}\text { Transverse and faulted cracks, } \\
\text { patched cracks, widened }\end{array}$ \\
\hline 17 & 2.3 & 3 & 128 & 5 & $\begin{array}{l}\text { Transverse and faulted cracks, } \\
\text { faulted joints, scaled, widened }\end{array}$ \\
\hline 60 & 2.4 & 4 & 132 & 3 & Faulted short slabs \\
\hline 7 & 2.4 & 4 & 116 & 8 & $\begin{array}{l}\text { Transverse and faulted cracks, } \\
\text { faulted joints, patches }\end{array}$ \\
\hline 4 & 2.5 & 6 & 129 & 4 & Transverse cracks \\
\hline 18 & 2.6 & 7 & 124 & 7 & $\begin{array}{l}\text { Transverse and faulted cracks, } \\
\text { faulted joints, widened }\end{array}$ \\
\hline 1 & 2.7 & 8 & 128 & 5 & $\begin{array}{l}\text { Transverse and faulted cracks, } \\
\text { faulted joints }\end{array}$ \\
\hline 57 & 2.9 & 9 & 112 & 10 & $\begin{array}{l}\text { Transverse cracks, faulted joints, } \\
\text { blow ups, patched joints }\end{array}$ \\
\hline 21 & 3.1 & 10 & 115 & 9 & $\begin{array}{l}\text { Transverse and faulted cracks, } \\
\text { faulted joints, patches, corner } \\
\text { breaks }\end{array}$ \\
\hline 54 & 3.2 & 11 & 107 & 11 & $\begin{array}{l}\text { Transverse and faulted cracks, } \\
\text { faulted joints }\end{array}$ \\
\hline 23 & 3.4 & 12 & 99 & 12 & Cracks, non-homogeneous \\
\hline 28 & 3.9 & 13 & 87 & 17 & Paulted cracks, porpoising \\
\hline 22 & 4.0 & 14 & 89 & 16 & Transverse cracks \\
\hline 49 & 4.1 & 15 & 91 & 13 & \\
\hline 47 & 4.2 & 16 & 90 & 15 & \\
\hline 50 & 4.2 & 16 & 75 & 19 & \\
\hline 45 & 4.4 & 18 & 85 & 18 & \\
\hline 46 & 4.5 & 19 & 92 & 13 & \\
\hline
\end{tabular}


TABLE 26

DESCRIPTION OF OVERLAY PAVEMENT SECTIONS

\begin{tabular}{|c|c|c|c|c|c|}
\hline Section & PSR & Rank & $\begin{array}{l}\text { Roughness } \\
\text { Index }\end{array}$ & Rank & Description \\
\hline 6 & 2.2 & 1 & 98 & 6 & $\begin{array}{l}\text { Transverse and widening reflec- } \\
\text { tion cracks, faulted cracks and } \\
\text { joints, blow ups }\end{array}$ \\
\hline 2 & 2.3 & 2 & 167 & 1 & $\begin{array}{l}\text { Transverse reflection cracks, } \\
\text { faulted cracks, faulted joints, } \\
\text { blow ups, porpoising, non-homo- } \\
\text { geneous }\end{array}$ \\
\hline 16 & 2.4 & 3 & 154 & 2 & $\begin{array}{l}\text { Transverse and widening reflec- } \\
\text { tion cracks, faulted cracks and } \\
\text { joints, rutting, blow ups }\end{array}$ \\
\hline 5 & 2.4 & 3 & 93 & 8 & $\begin{array}{l}\text { Transverse and widening reflec- } \\
\text { tion cracks }\end{array}$ \\
\hline 43 & 2.6 & 5 & 106 & 4 & $\begin{array}{l}\text { Transverse and widening reflec- } \\
\text { tion cracks, faulted cracks and } \\
\text { joints, blow ups, spalled cracks }\end{array}$ \\
\hline 42 & 2.6 & 5 & 92 & 9 & $\begin{array}{l}\text { Transverse and widening reflec- } \\
\text { tion cracks, patches }\end{array}$ \\
\hline 15 & 2.7 & 7 & 98 & 6 & $\begin{array}{l}\text { Transverse and widening reflec- } \\
\text { tion cracks, blow ups, bleeding, } \\
\text { non-homogeneous }\end{array}$ \\
\hline 14 & 2.8 & 8 & 85 & 15 & $\begin{array}{l}\text { Transverse and widening reflec- } \\
\text { tion cracks, faulted cracks and } \\
\text { joints, blow ups, porpolsing, } \\
\text { rutting }\end{array}$ \\
\hline 38 & 3.0 & 9 & 2114 & 3 & $\begin{array}{l}\text { Transverse and widening reflec- } \\
\text { tion cracks, bleeding }\end{array}$ \\
\hline 10 & 3.0 & 9 & 105 & 5 & $\begin{array}{l}\text { Widening reflection cracks, blow } \\
\text { ups }\end{array}$ \\
\hline 34 & 3.0 & 9 & 91 & 10 & $\begin{array}{l}\text { Transverse and widening reflection } \\
\text { cracks, rutting, blow ups }\end{array}$ \\
\hline 8 & 3.1 & 12 & 89 & 12 & Porpoising \\
\hline 25 & 3.5 & 13 & 91 & 10 & $\begin{array}{l}\text { Transverse and widening reflec- } \\
\text { tion cracks, blow ups, bleeding, } \\
\text { non-homogeneous }\end{array}$ \\
\hline
\end{tabular}


TABLE 26 (continued)

\begin{tabular}{cccccc}
\hline Section & PSR & Rank & $\begin{array}{c}\text { Roughness } \\
\text { Index }\end{array}$ & Rank & Description \\
\hline 13 & 3.6 & 14 & 87 & 14 & $\begin{array}{l}\text { Transverse and widening reflec- } \\
\text { tion crscks, porpoising }\end{array}$ \\
12 & 3.7 & 15 & 80 & 18 & $\begin{array}{l}\text { Transverse and widening reflec- } \\
\text { tion cracks, blow ups }\end{array}$ \\
36 & 3.8 & 16 & 88 & 13 & $\begin{array}{l}\text { Slight reflection cracks } \\
52\end{array}$ \\
3.8 & 16 & 85 & 15 & Slight reflection cracks \\
29 & 3.8 & 16 & 79 & 19 & $\begin{array}{l}\text { Slight reflection cracks, non- } \\
\text { homogeneous }\end{array}$ \\
31 & 3.8 & 16 & 73 & 22 & \\
26 & 3.9 & 20 & 76 & 20 & Non-homogeneous \\
58 & 4.1 & 21 & 82 & 16 & \\
11 & 4.1 & 21 & 75 & 21 &
\end{tabular}


TABLE 27

DESCRIPTION OF FLEXIBLE PAVEMENT SECTIONS

\begin{tabular}{|c|c|c|c|c|c|}
\hline Section & PSR & Rank & $\begin{array}{l}\text { Roughness } \\
\text { Index }\end{array}$ & Rank & Description \\
\hline 27 & 1.5 & 1 & 144 & 3 & $\begin{array}{l}\text { Sidesway, porpoising, rutting, } \\
\text { patches, longitudinal and trans- } \\
\text { verse cracking, edge failure in } \\
\text { cuts }\end{array}$ \\
\hline 41 & 2.0 & 2 & 144 & 3 & $\begin{array}{l}\text { Sidesway, porpolsing, rutting, } \\
\text { patches, longitudinal and trans- } \\
\text { verse cracks, edge ravelling, non- } \\
\text { homogeneous }\end{array}$ \\
\hline 53 & 2.0 & 2 & 137 & 6 & $\begin{array}{l}\text { Sidesway, porpoising, rutting, } \\
\text { patches, non-homogeneous }\end{array}$ \\
\hline 48 & 2.1 & 4 & 94 & 15 & Patches \\
\hline 37 & 2.2 & 5 & 152 & 2 & $\begin{array}{l}\text { Sidesway, porpolsing, rutting, } \\
\text { patches, bleeding, non-homogeneous }\end{array}$ \\
\hline 3 & 2.2 & 5 & 126 & 10 & Porpoising \\
\hline 55 & 2.3 & 7 & 133 & 8 & $\begin{array}{l}\text { Sidesway, porpolsing, rutting, } \\
\text { patches, non-homogeneous }\end{array}$ \\
\hline 9 & 2.5 & 8 & 134 & 7 & Sidesway, porpoising, bleeding \\
\hline 40 & 2.6 & 9 & 110 & 11 & Porpolsing, longitudinal cracking \\
\hline 30 & 2.7 & 10 & 155 & 1 & $\begin{array}{l}\text { Sidesway, porpolsing, non-homo- } \\
\text { geneous }\end{array}$ \\
\hline 20 & 2.9 & 11 & 239 & 5 & Bleeding, porpoising, sidesway \\
\hline 56 & 2.9 & 11 & 131 & 9 & Bleeding, porpolsing \\
\hline 24 & 2.9 & 11 & 210 & 11 & Porpolsing, sidesway \\
\hline 35 & 2.9 & 11 & 103 & 14 & Sidesway, porpoising \\
\hline 51 & 3.0 & 15 & 108 & 13 & Porpolsing, bleeding \\
\hline 39 & 3.2 & 16 & 92 & 16 & $\begin{array}{l}\text { Porpolsing, rutting, patches, } \\
\text { non-homogeneous }\end{array}$ \\
\hline 32 & 3.7 & 17 & 87 & 17 & Sidesway, porpoising \\
\hline 44 & 3.7 & 17 & 64 & 18 & Sidesway, porpoising \\
\hline 33 & 4.1 & 19 & 62 & 19 & \\
\hline
\end{tabular}


TABLE 28

LOCATION OF RIGID PAVEMENT SECTIONS

\begin{tabular}{|c|c|c|c|}
\hline $\begin{array}{l}\text { Pavement } \\
\text { Section }\end{array}$ & Highway & From & To \\
\hline 1 & 25 & Logansport north city limit & $1.5 \mathrm{mi}$. north \\
\hline 4 & 35 & $2 \mathrm{mi}$. south of Royal Center & Jct. with hwy. 24 \\
\hline 7 & 421 & Monticello south city limit & $2 \mathrm{ml}$. south \\
\hline 17 & 53 & Jct. with hwy. 18 & $6 \mathrm{ml}$. north \\
\hline 18 & 53 & Jet. with hwy. 18 & Jct. with hwy. 52 \\
\hline 19 & 41 & Jct. with hwy. 18 & $1.25 \mathrm{mi}$. north \\
\hline 22 & 52 & Jct. with hwy. 28 & $5 \mathrm{mi}$. north \\
\hline 22 & 52 & Jct. with hwy. 352 & $2 \mathrm{ml}$. south \\
\hline 23 & 52 & $4 \mathrm{mi}$. south of section 22 & Jct. with 52 By-pass \\
\hline 28 & 25 & $\begin{array}{l}1 \text { mi. north of Jct. with } \\
52 \text { By-pass }\end{array}$ & $1.4 \mathrm{mi}$. north \\
\hline 45 & 65 & Lebanon By-pass & Brownsburg turn-off \\
\hline 46 & 65 & Brownsburg turn-off & Lebanon By-pass \\
\hline 49 & 39 & Jct. with, hwy. 47 & Bridge \\
\hline 50 & 39 & Frankfort south city limit & Jct. with hwy. 38 \\
\hline 54 & 52 & Jct. with 52 By-pass & Jct. with hwy. 53 \\
\hline 57 & 421 & Jct. with hwy. 18 & Delphi south city limit \\
\hline 59 & Union & 26th St. In Lafayette & 52 By-pass \\
\hline 60 & 25 & 18th St. In Lafayette & 52 By-pass \\
\hline
\end{tabular}


TABLE 29

LOCATION OF OVERLAY PAVEMENT SECTIONS

\begin{tabular}{|c|c|c|c|}
\hline $\begin{array}{l}\text { Pavement } \\
\text { Section }\end{array}$ & Highway & From & To \\
\hline 2 & 17 & Logansport north city limit & Jct. with hwy. 16 \\
\hline 5 & 24 & $3 \mathrm{mi}$. west of Logansport & $\begin{array}{l}\text { Burnettsville east city } \\
\text { linit }\end{array}$ \\
\hline 6 & 24 & Monticello east city limit & Idaville west city limit \\
\hline 8 & 421 & $2 \mathrm{mi}$. south of Monticello & Jet. with hwy. 18 \\
\hline 10 & 43 & Jct. with hwy. 18 & Jct. with hwy. 24 \\
\hline 11 & 421 & Jct. with hwy. 16 & Pulaski-White County line \\
\hline 12 & 53 & Rensselaer south city limit & Jct. with hwy. 16 \\
\hline 13 & 53 & Jct. with hwy. 16 & Jet. with hwy. 24 \\
\hline 14 & 24 & Jct. with hwy. 53 & Goodland east city limit \\
\hline 15 & 24 & Jet. with hwy. 53 & Jct. with hwy. 43 \\
\hline 16 & 53 & Jct. with hwy. 24 & $6 \mathrm{mi}$. south \\
\hline 25 & 25 & Jet. with hwy, 43 & Jct. with hwy. 28 \\
\hline 26 & 28 & Jct. with hwy. 25 & Jct. with hwy. 34 I \\
\hline 29 & 136 & Veedersburg west city limit & Covington east city limit \\
\hline 31 & 43 & $\begin{array}{l}\text { Crawfordsville south city } \\
\text { limit }\end{array}$ & Jct. with hwy. 234 \\
\hline 34 & 136 & $\begin{array}{l}\text { Crawfordsville east city } \\
\text { limit }\end{array}$ & New Ross west city limit \\
\hline 36 & 43 & $\begin{array}{l}\text { Crawfordsville north city } \\
\text { limit }\end{array}$ & $\begin{array}{l}\text { Tippecanoe-Montgomery } \\
\text { County line }\end{array}$ \\
\hline 38 & 28 & Jct. with hwy. 52 & $1 \mathrm{ml}$. west \\
\hline 42 & 29 & $\begin{array}{l}\text { Michigantown south city } \\
\text { limit }\end{array}$ & $\begin{array}{l}\text { Clinton Central High } \\
\text { School }\end{array}$ \\
\hline 43 & 28 & Jct. with hwy. 52 & Jefferson west city limit \\
\hline 52 & 29 & Kirklin north city limit & Jct. with hwy. 28 \\
\hline 58 & 25 & Jct. with hwy. 218 & $\begin{array}{l}\text { Rockfield south city } \\
\text { limit }\end{array}$ \\
\hline
\end{tabular}


APPENDIX B 
TABLE 30

LOCATION OF FLEXIBLE PAVEMENT SECTIONS

\begin{tabular}{|c|c|c|c|}
\hline $\begin{array}{l}\text { Pavement } \\
\text { Section }\end{array}$ & Highway & From & To \\
\hline 3 & 16 & Jet. with hwy. 17 & $\begin{array}{l}\text { Royal Center east city } \\
\text { limit }\end{array}$ \\
\hline 9 & 18 & Jct. with hwy. 421 & $2 \mathrm{mi}$. west \\
\hline 20 & 18 & Jct. with hwy. 41 & $4 \mathrm{mi}$. west \\
\hline 24 & 26 & $\mathrm{RR} X$-ing & $4 \mathrm{mi}$. west \\
\hline 27 & 55 & Jet. with hwy. 25 & Jct. w1th hwy. 136 \\
\hline 30 & 32 & Jet. with hwy. 34 I & Jct. with hwy. 25 \\
\hline 32 & 234 & Jct. with hwy. 43 & Ladoga west city limit \\
\hline 33 & 136 & Jamestown west city limit & Bridge \\
\hline 35 & 47 & $\begin{array}{l}\text { Crawfordsville north city } \\
\text { limit }\end{array}$ & Darlington turn-off \\
\hline 37 & 28 & Jct. with hwy. 43 & $R R$ X-ing \\
\hline 39 & 26 & $R R \quad X$-ing & $\begin{array}{l}\text { Edna Mills west city } \\
\text { limit }\end{array}$ \\
\hline 40 & 26 & Edna Mills east city limit & Rossville west city limit \\
\hline 41 & 38 & $\begin{array}{l}\text { Tippecanoe-Clinton County } \\
\text { line }\end{array}$ & Bridge \\
\hline 44 & 32 & Jct. with hwy. 75 & Jct. with Lebanon By-pass \\
\hline 48 & 47 & Jct. with hwy. 39 & Jct. with hwy. 421 \\
\hline 51 & 38 & Jet. with hwy. 39 & Bridge \\
\hline 53 & 26 & $\begin{array}{l}\text { Geetingsville east city } \\
\text { limit }\end{array}$ & Jct. with hwy. 29 \\
\hline 55 & 75 & Jct. with hwy. 26 & Jct. with hwy. 18 \\
\hline 56 & 18 & Jct. with hwy. 75 & Jct. with hwy. 421 \\
\hline
\end{tabular}


The method for randomized block design (7) was utilized to estimate the missing rating. The pavement sections were considered blocks and the raters were treatments. The equation used is as follows:

$$
Y=\text { estimated rating }=\frac{r B+t T-G}{(r-1)(t-1)}
$$

where,

$$
\begin{aligned}
& r=\text { number of pavement sections }=60 \\
& B=\text { total of that section with missing value }=66.4 \\
& t=\text { total number of raters }=30 \\
& T=\text { total of rater's fifty-nine ratings }=194.4 \\
& G=\text { grand total of all ratings for all sections }=5417.1
\end{aligned}
$$

Hence,

$$
\begin{aligned}
Y & =\frac{60(66.4)+30(194.4)-5417.1}{59(29)} \\
& =2.6
\end{aligned}
$$


Sample Calculation:

Least-Squares Regression Equation and Correlation Coefficient for Flexible Pavements

The following equations were employed in the determination of the least-squares regression equations:

$$
\begin{aligned}
& b=\frac{\Sigma X Y-N \overline{X Y}}{\Sigma X^{2}-N(\bar{X})^{2}} \\
& a=\bar{I}-b \bar{X} \\
& I=a+b X
\end{aligned}
$$

Where,

$$
\begin{aligned}
& N=\text { number of pavement sections within pavement type } \\
& Y=\text { dependent variable; present serviceability rating } \\
& X=\text { independent variable; roughness index (in/mt) }
\end{aligned}
$$

The calculation of the least-squares regression equation for the linear relationship of PSR and roughness for flexible pavements is as follows:

$$
\begin{aligned}
N & =19 \\
\bar{Y} & =2.71 \\
\bar{X} & =116.6 \\
\Sigma X Y & =5742.4 \\
\Sigma X^{2} & =272,235
\end{aligned}
$$

Substitution into the above mentioned equations gives:

$$
\begin{aligned}
b & =\frac{5742.4-19(116.6)(2.71)}{272.235-19(116.6)^{2}} \\
& =-\frac{261.334}{13.919 .36}=-0.0188
\end{aligned}
$$


and,

$$
a=2.71+0.0188(116.6)=4.90
$$

Hence, the least-8quares regression equation for the linear PSR-roughness relationship of flexible pavements is:

$$
Y=4.90-0.0188 x
$$

The following equation was employed in the determination of the squared correlation coefficients:

$$
r^{2}=1-\frac{\left(\Sigma Y^{2}-N \bar{Y}^{2}\right)-b(\Sigma X Y-N \overline{X X})}{\Sigma Y^{2}-N^{2}}
$$

for flexible pavements:

$\mathrm{N}, \overline{\mathrm{Y}}, \Sigma X Y, \overline{\mathrm{X}}$, and $\mathrm{b}$ are given above.

$$
\text { s.s. }
$$

$$
\Sigma Y^{2}=147.00
$$

Hence, the squared correlation coefficient for the flexible pavements is:

$$
\begin{aligned}
r^{2} & =1-\frac{147.00-19\left(2.71^{2}\right)+0.0188[5742.4-19(2.71)(116.6)]}{147.00-19\left(2.71^{2}\right)} \\
& =0.658
\end{aligned}
$$

and the correlation coefficient is:

$$
r=\sqrt{0.658}=0.81
$$




\section{Determination of the Variance Ratios}

The variance ratios of the $S, R, P x R$, and $S x G$ sources were determined by dividing their respective mean squares by the $S \times R$ mean square. The variance ratio of the PXG source was determined by dividing the PXG mean square by the PxR mean square, since the SxG interaction was found to be non-significant. The variance ratio of the $G$ source was determined by dividing the $G$ mean square by the $R$ mean square, since the $S x G$ interaction was found to be non-significant.

Since both the $S$ and $P x R$ sources were found to be significant, Satterthwaite approximations were used to determine the variance ratio of the' $P$ source. The following equations were used:

$$
F=\frac{Q_{1}+Q_{4}}{Q_{2}+Q_{3}}
$$

$$
\text { Numerator degrees of freedom }=\frac{\left(Q_{1}+Q_{4}\right)^{2}}{\left(Q_{1}{ }^{2} / d_{0} f_{0}+Q_{4}{ }^{2} / d_{.} f_{0}\right)}
$$

Denominator degrees of freedom $=$

$$
\frac{\left(Q_{2}+Q_{3}\right)^{2}}{\left(Q_{2}^{2} / d_{.} f_{0}+Q_{3}^{2} / d_{.} f_{0}\right)}
$$

where,

$$
\begin{aligned}
& Q_{1}=\text { M.S. }(P) \\
& Q_{2}=\text { M.S. (S) } \\
& Q_{3}=\text { M.S. (PXR) } \\
& Q_{4}=\text { M.S. (SXR) }
\end{aligned}
$$




\section{Determination of the Variance of $\bar{Y}(i) j k$}

The equation used to determine the variance of $\bar{Y}_{(i) j k}$ was as follows:

$$
\text { Var. } \bar{Y}_{(1) j k}=\hat{\sigma}_{S^{2}}+\frac{\hat{\sigma}_{R}{ }^{2}}{10}+\frac{\hat{\sigma}_{\mathrm{PR}^{2}}}{10}+\hat{\sigma}_{\mathrm{SG}^{2}}+\frac{\hat{\sigma}_{\mathrm{SR}}{ }^{2}+\hat{\sigma}_{\mathrm{e}}^{2}}{10}
$$

where,

$$
\begin{aligned}
& \frac{\hat{\sigma}_{\mathrm{SR}^{2}+}+\hat{\sigma}_{\mathrm{e}}^{2}}{10}=\frac{\mathrm{M}_{0} \mathrm{~S} \cdot \mathrm{SR}}{10} \\
& \hat{\sigma}_{\mathrm{SG}}{ }^{2}=\frac{M_{0} S_{\mathrm{SG}}-\mathrm{M}_{\cdot \mathrm{S} \cdot \mathrm{SR}}}{15} \\
& \hat{\sigma}_{P R}{ }^{2}=\frac{M_{0} S_{\cdot P R}-M_{0} S_{S_{S R}}}{(57 / 2)} \\
& \hat{\sigma}_{R^{2}}=\frac{M_{0} S_{R_{R}}-M_{\cdot S \cdot S R}}{57} \\
& \hat{\sigma}_{S}{ }^{2}=\frac{M_{0} S_{S_{S}}-M_{0} S_{0} S R}{30}
\end{aligned}
$$


, 